\title{
Improving Air Travel Comfort \& Experience: Designing for Infection Prevention and Control
}

by

Kayla Daigle

A thesis submitted to the Faculty of Graduate and Postdoctoral Affairs in partial fulfillment of the requirements for the degree of

Master of Design

in the

School of Industrial Design

Carleton University

Ottawa, Ontario

(C) 2021, Kayla Daigle 


\section{Abstract}

The onset of the Coronavirus Disease of 2019 (COVID-19) caused a shift in the air travel industry as safety and precautionary measures were put in place to mitigate some of the risks associated with infection prevention and control. This research documents and reveals a glimpse of the state of current air travel during the pandemic, through the first-hand experiences of passengers. The study consisted of three methods used to collect real-time and recollective reflections from current passengers, while also evaluating the development, implementation, and use of these methods within the context of remote qualitative research. Our findings suggest that passengers' air travel experiences during pandemic conditions are influenced by factors that span layers of user experience, within the larger umbrella of service design. The findings point to new areas of research and design development, that should be explored to support a more positive travel experience during pandemic conditions. 


\title{
Acknowledgements
}

\author{
A special thanks to my co-supervisors - \\ Chantal Trudel from Carleton's School of Industrial Design, thank you for your \\ continuous support, encouragement, and guidance throughout this study. I cannot express \\ my gratitude for all of your help and understanding this past year.
}

Shelley Kelsey from the National Research Council of Canada, thank you for your valuable insight and expertise on air travel and human factors, your patience, and support throughout this study.

To my family and friends -

Thank you for your constant support, patience, and encouragement throughout this past year and throughout my academic career.

A special thank you -

To all the participants who were involved in this study and shared their feelings and experiences for this research. Without your participation and insights, this research would not have been possible. 


\section{Table of Contents}

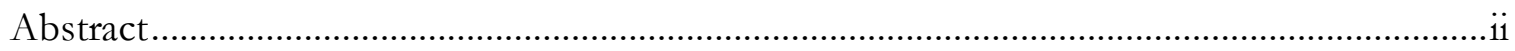

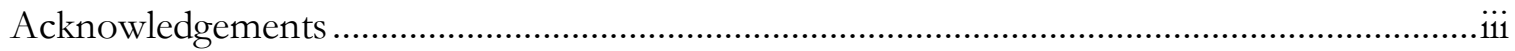

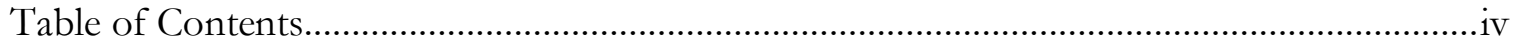

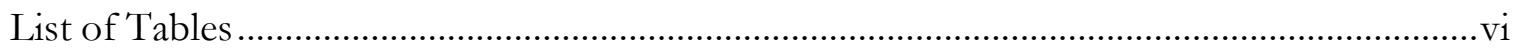

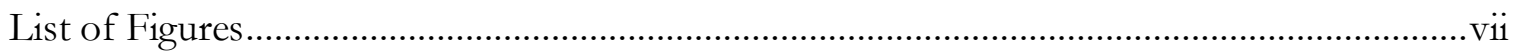

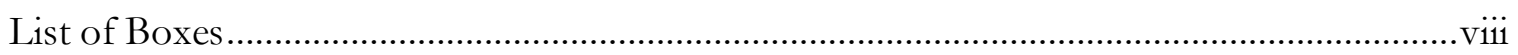

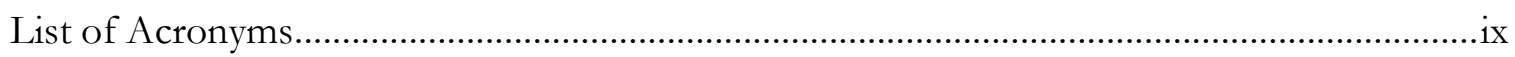

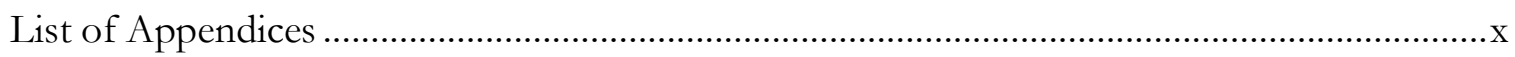

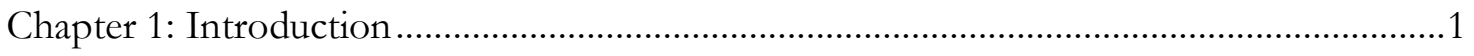

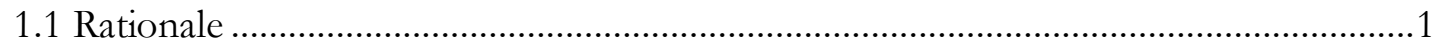

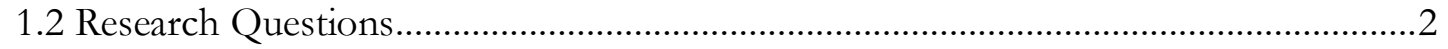

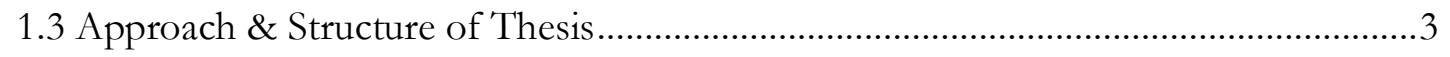

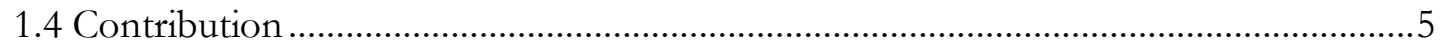

Chapter 2: Literature Review \& Environmental Scan.......................................................6

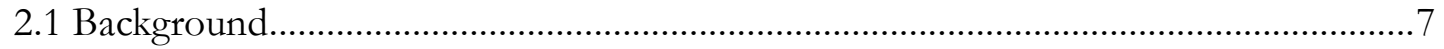

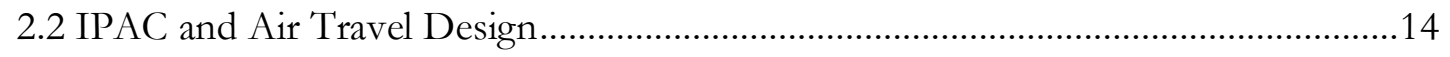

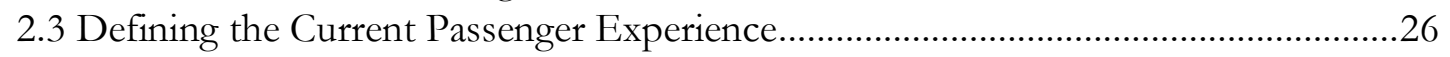

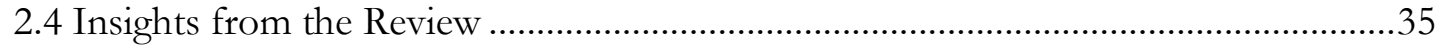

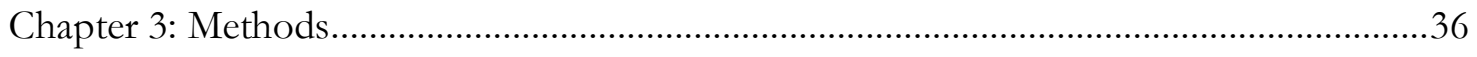

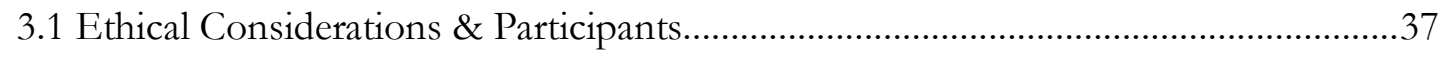

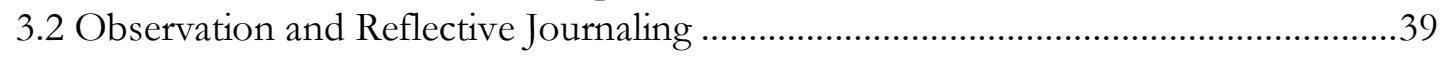

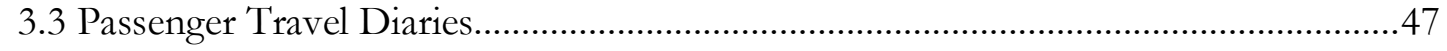

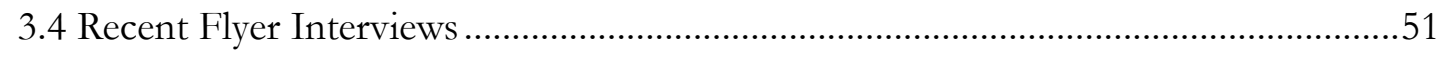

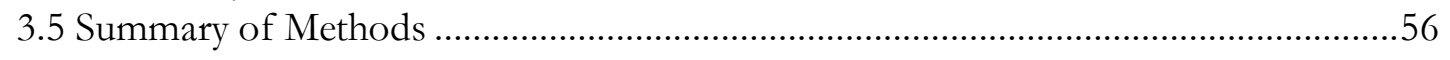

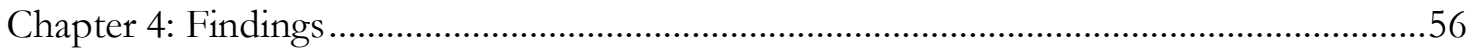

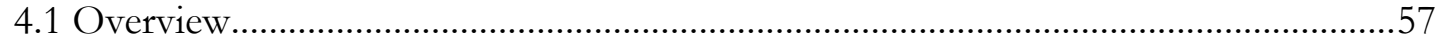

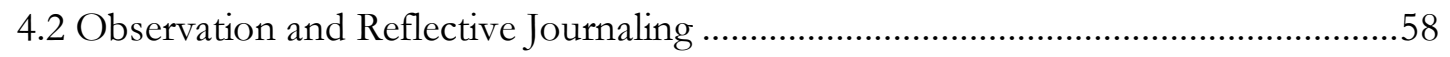

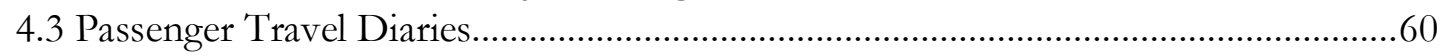

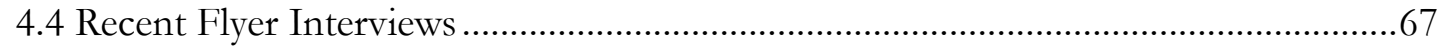




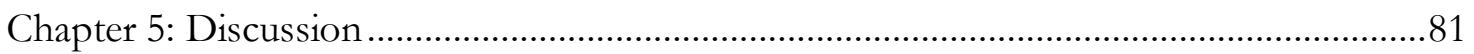

5.1 IPAC Design Considerations in Passenger Air Travel Experience .............................81

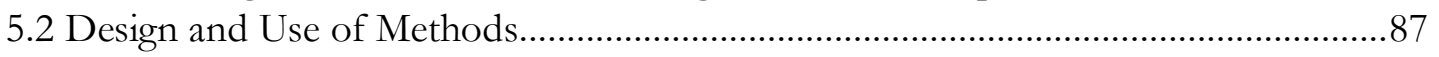

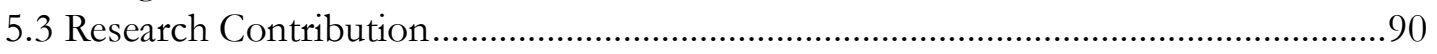

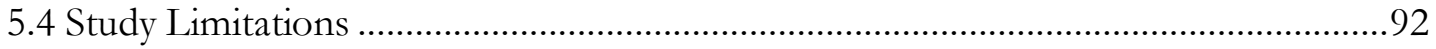

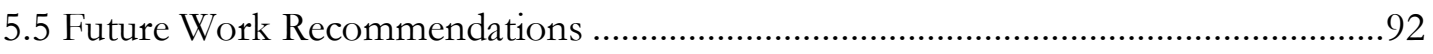

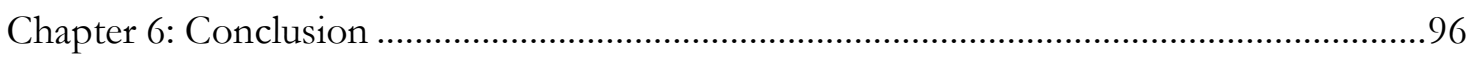

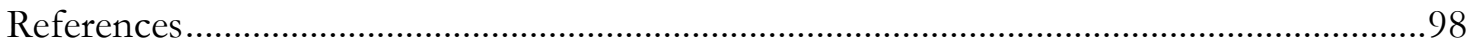

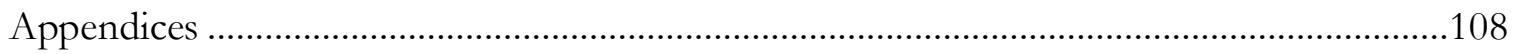

Appendix A Keyword Search Comparing Access to Literature in 2020 and 2021 ................108

Appendix B Detailed Account of Two Passenger Narratives (2020) ....................................109

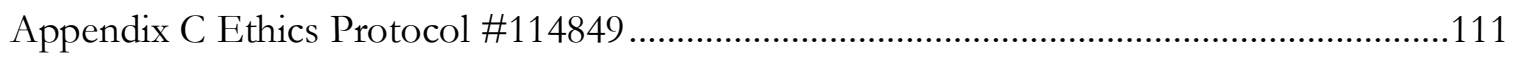

Appendix D Passenger Characteristics and Travel Information (Methods 2 \& 3)................113

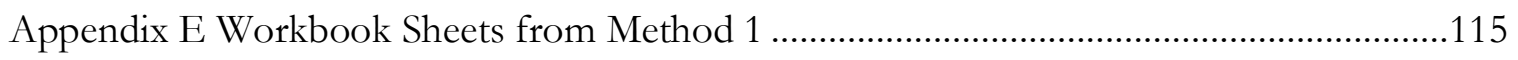

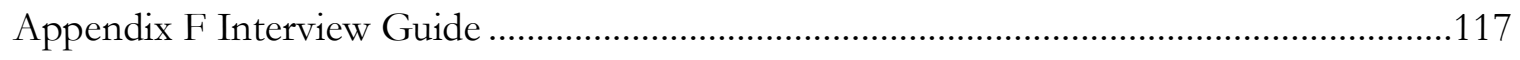

Appendix G Comparison of Airports Visited (July and August 2020).................................118

Appendix H List of Findings and Takeaways from Method 1 .............................................119

Appendix I List of Codes and Related Quotes From Method 2........................................120

Appendix J List of Codes and Related Quotes from Method 3 .........................................123

Appendix K Keyword Instance Count from Method 3 ....................................................136 


\section{List of Tables}

TABLE 1 Examples of Changes Made to Air Travel in Canada...................................................

TABLE 2 Travel Restrictions for British Columbia, Alberta, and Newfoundland and Labrador.......11

TABLE 3 Examples of IPAC Measures Related to the Built Environment and Operations .............24

TABLE 4 Types of Changes Made by Airlines in Response to COVID-19....................................26

TABLE 5 Air Travel IPAC Measures and Proposed Designs for COVID-19 ...............................34

TABLE 6 Categories of Interest - User Experience Considerations (Preece, Sharp \& Rogers, 2015). 55

TABLE 7 Time of Travel Comparison Chart ............................................................................5

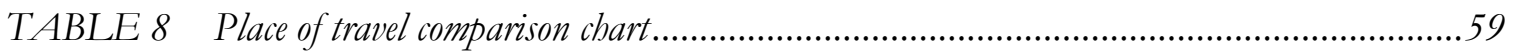

TABLE 9 Pain Points/Potential for Design Opportunity \& Questions from Method 1 ....................60

TABLE 10 UX Category Prevalence from Travel Diaries ........................................................65

TABLE 11 Supportive Quotes from Interview Analysis ...............................................................73

TABLE 12 UX Category Prevalence from Interviews ................................................................ 76

TABLE 13 Layers of Experience Mapped to Passengers' Experiences in Air Travel......................80 


\section{List of Figures}

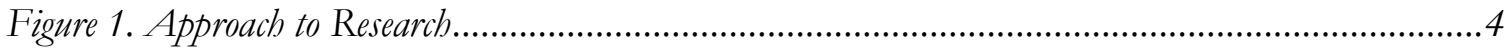

Figure 2. COVID-19 Air Travel Timeline....................................................................................13

Figure 3. Modes of Transmission (HKUMed, 2020).....................................................................15

Figure 4 Transmission Exposure Mapping Based on Passenger Proximity to Direct Infection Source .......18

Figure 5. Direction of Airflow in Cabin (International Air Transport Association, 2021 a) ...................20

Figure 6. Post-Pandemic Air Travel Model, Adapted from Fast Future, 2020 ...................................33

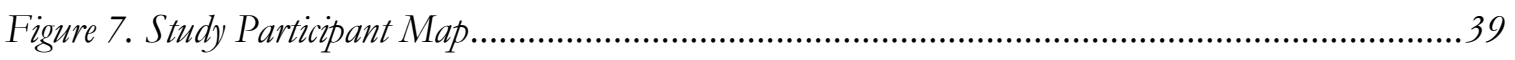

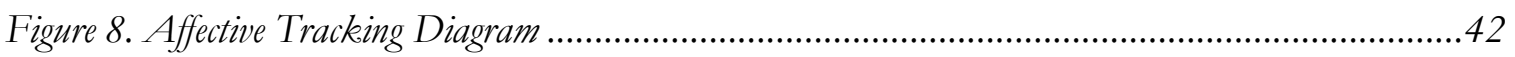

Figure 9. Observation Worksheet 1 - Human Experience (Ottawa Airport in July, 2020) ...................43

Figure 10. Observation Worksheet 2 - Physical Environment ........................................................44

Figure 11. Observation Worksheet 3 - Airport Mapping (Calgary Airport in August 2020)...............45

Figure 12. Observation Worksheet 4 - Cabin Mapping (Montreal Air Canada Flight in July 2020) ....45

Figure 13. Data Analysis - Observational Analysis (Ottawa to Montreal, 2020)...............................46

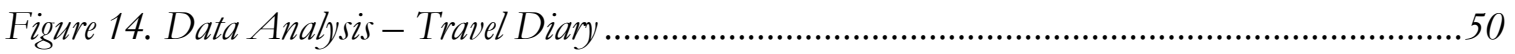

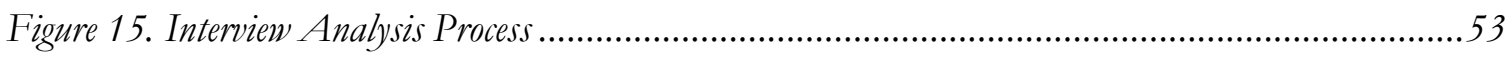

Figure 16. Multi-Method Study Overview ..................................................................................56

Figure 17. Comfort Comparison Chart from Travel Diaries ..........................................................66

Figure 18. User Experience in Air Travel 'Onion Model'................................................................77 


\section{List of Boxes}

BOX 1 Passengers' Overall and ContinuAL PreOccupation With Safety' ......................................61

BOX 2 Passengers' Comfort With Cabin Capacity ....................................................................62

BOX 3 Passengers' Experience With Change In Services and COVID-19 Specific Practices.............62

BOX 4 Importance of Passengers Feeling Prepared ...................................................................63

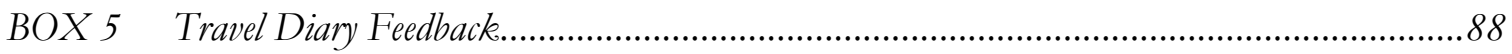




\title{
List of Acronyms
}

\author{
APEX - Airline Passenger Experience Association \\ CATSA - Canadian Air Transport Security Authority \\ COVID-19 - Coronavirus Disease of 2019 \\ ECS - Environmental Control System \\ HEPA - High-Efficiency Particulate Absorbing \\ IATA - the International Air Travel Association \\ IPAC - Infection Prevention and Control \\ PPE - Personal Protective Equipment \\ PX - Passenger Experience \\ SARS - Severe Acute Respiratory Syndrome \\ SARS-CoV or SARS-CoV-1 - Severe Acute Respiratory Syndrome Coronavirus \\ UX - User Experience \\ WHO - World Health Organization
}




\section{List of Appendices}

Appendix A Keyword Search Comparing Access to Literature in 2020 and 2021...............108

Appendix B Detailed Account of Two Passenger Narratives (2020) ....................................109

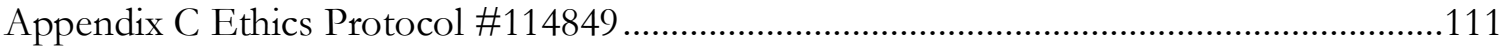

Appendix D Passenger Characteristics and Travel Information (Methods 2 \& 3)................113

Appendix E Workbook Sheets from Method 1 ...................................................................115

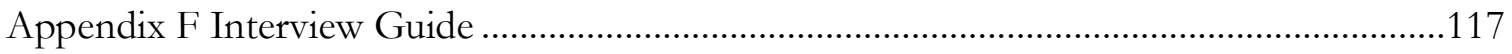

Appendix G Comparison of Airports Visited (July and August 2020).................................118

Appendix H List of Findings and Takeaways from Method 1 ............................................119

Appendix I List of Codes and Related Quotes From Method 2 ..........................................120

Appendix J List of Codes and Related Quotes from Method 3 ............................................123

Appendix K Keyword Instance Count from Method 3 ........................................................136 


\section{Chapter 1: Introduction}

The Coronavirus Disease of 2019 (COVID-19) caused by the SARS-CoV-2 virus has brought unforeseen changes to the passenger experience and the greater context of air travel. This study focuses on using design research methods that gather real-time data from recent flyers to improve our understanding of the passenger experience within the current context of air travel. This study also explores how infection prevention and control (IPAC) measures within air travel might be better supported through design.

\subsection{Rationale}

With the onset of the COVID-19 pandemic, the aviation industry rapidly implemented preventative measures to reduce the risks of infection to its passengers, staff and crew. Airlines implemented safety measures such as: checking the temperature and symptoms of passengers, providing distanced seating, regularly changing high-efficiency particulate air (HEPA) filters in the cabin, disinfecting aircraft surfaces, and maintaining a constant flow of fresh air into the aircraft (Fazel, 2020). Such measures drastically and understandably changed how passenger interactions take place through various points in their air travel journey. This case study describes and illustrates the experience of a group of air passengers that traveled under these measures to provide insight on the impact of these changes. Through this, we identify factors related to design that should be further examined to support passenger experience during pandemic conditions.

The aim of this study was to investigate how changes made in air travel processes and conditions during the pandemic impacted the experience of passengers. The study then considers how the field of design may address pain points and/or challenges that have become 
a part of air travel under such conditions. Within this study, passenger experience (PX) is conceptualized as the entire journey an individual takes part in, from the planning and booking of their travel, up until the disembark at their destination and factors related to this experience (Preece, Sharp, \& Rogers, 2015). The factors we examined include 'people's personal narratives', 'their context', 'their actions or actions of others', 'emotional considerations', 'people's expectations', 'social considerations in the experience', and 'the impact of space and time'. This study also examined how passenger's sense of comfort during pandemic travel contributed to their satisfaction with the experience and desire to travel again under such conditions.

Comfort is a complex phenomenon and has been described as "the pleasant state of physiological, psychological, and physical harmony between human being(s) and (their) environment" (Slater, 1985, p.4). Researchers have identified factors that can support a sense of comfort such as 'peace of mind', 'physical well-being', 'proxemics', 'pleasure', 'satisfaction', 'aesthetics', 'social', and 'association' (Ahmadpour, Lindgaard, Robert, \& Pownall, 2014; Lewis, Patel, D'Cruz, \& Cobb, 2017). These themes were considered in evaluating the perceived level of comfort current passengers experienced in their recent travel. Taken together, factors which affect passenger experience (PX) and comfort may contribute to their overall satisfaction and willingness to re-engage in air travel. Although passenger experience and comfort has been analyzed within the context of 'normal' air travel, these factors have not be studied within the novel circumstances posed by pandemics.

\subsection{Research Questions}

In response to COVID-19, the aviation industry was forced to take immediate action to protect passengers, service and crew members. While this immediate action was necessary, balancing the flight experience of passengers with IPAC measures did not have the luxury of 
time, proper resources and prior research findings. This research documents and reveals a snapshot of the 'current state of air travel during the pandemic' through first-hand experiences of passengers with the intention of providing insight on the following questions:

I. What is it like for passengers to travel by air during the COVID-19 pandemic?

II. How might these experiences be related to the design of elements or factors in air travel?

IV. What recommendations might emerge from this study to belp inform future design studies to support passenger experience and comfort under IP AC measures?

V. How might we design methods to support the documentation of user experience under challenging conditions such as travelling during a pandemic or infectious outbreaks?

The data and analysis from this study is valuable in that it serves to 1) frame the firsthand air travel experiences of passengers during COVID-19; and 2) provide recommendations to support future research that explores factors related passenger experiences during pandemic conditions.

\subsection{Approach \& Structure of Thesis}

This thesis consists of six chapters accompanied by an Appendix which contains supplementary materials that may be helpful in providing a more comprehensive understanding of our research. Figure 1 provides an overview of our research approach. 


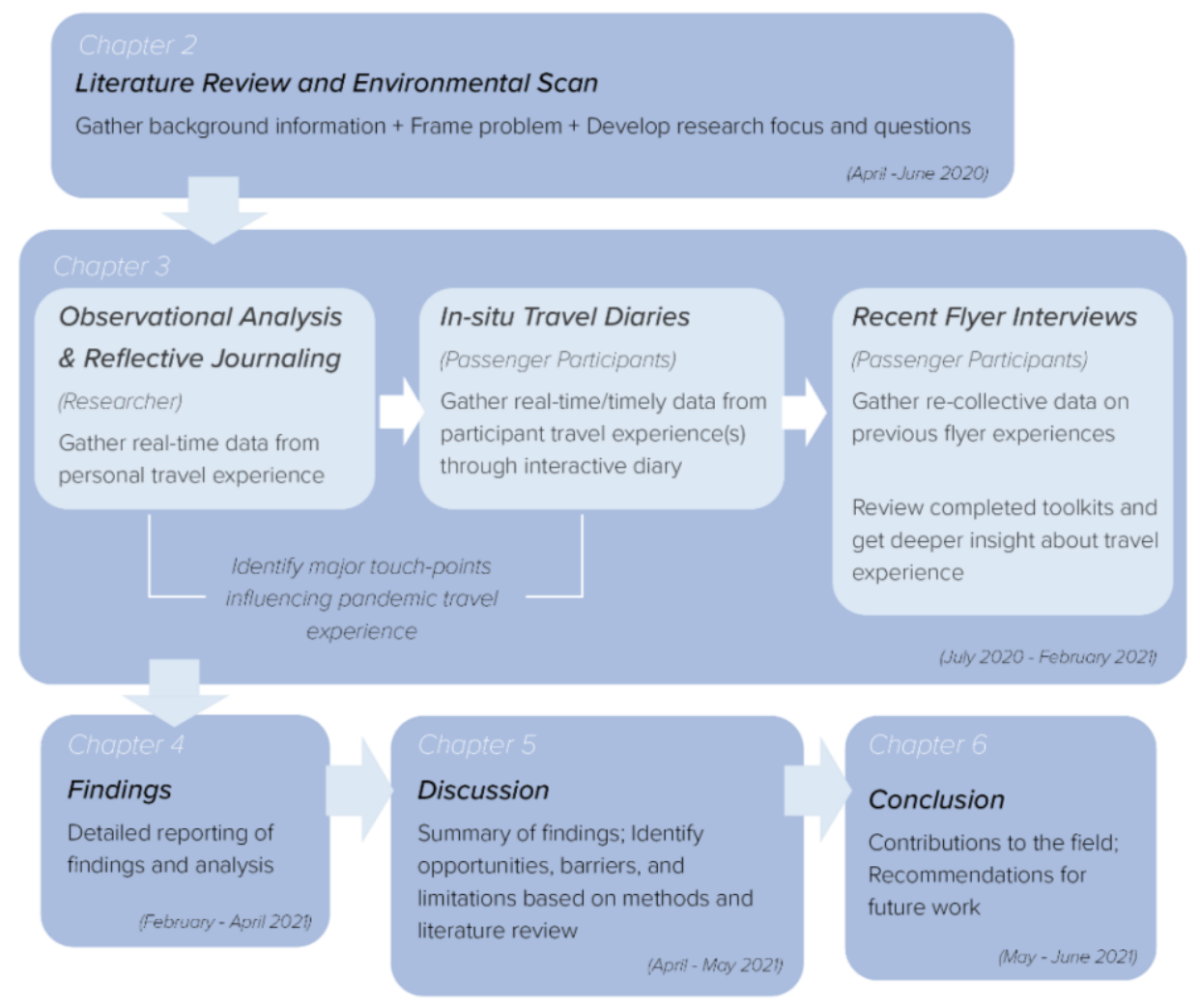

FigURE 1. APPROACH TO RESEARCH

In Chapter 1 - Introduction, we discuss the general subject matter, provide background of the need for this study, outline the research questions to address this need and the proposed methods to answer the research questions.

In Chapter 2 - Literature Review and Environment Scan, we discuss IPAC research within the context of air travel prior to the pandemic, narratives from travellers following the onset of the COVID-19 pandemic, and documentation about COVID-19 responses from public health, aviation authorities, and provincial and federal governments. This establishes the setting for exploring the research questions.

We then discuss the data collection and analysis methods used to explore the research questions in Chapter 3 - Methods. The methods included observation, reflective journaling, 
an in-situ travel diary, and recent flyer interviews to explore passengers' experiences in air travel during pandemic conditions.

Findings emerged during each stage of data collection including information on passenger perceptions of their comfort, safety, and interpretations of new processes and/or changes made to their travel experience. We categorized this information according to factors related to 'user experience' (e.g., personal narratives, their context, etc.). We also mapped the data to specific layers in air travel design (e.g., information design, space, products, services) to examine the potential influence of these elements on passenger experience during pandemic conditions. These results are presented in Chapter 4 - Findings.

In Chapter 5 - Discussion, we summarize the findings from our study by framing the travel experiences of the participants during COVID-19 in relation to systemic layers in air travel design and elaborate on these findings in relation to the literature and environmental scan conducted in Chapter 2. We conclude the study by presenting the opportunities and contributions to the field and recommendations for future work.

\subsection{Contribution}

The primary contribution of our work is the documentation and illustration of people's experiences of air travel during the first year of the pandemic through the first-hand experiences of passengers. Through this work, we offer insight into changes that occurred in air travel during the pandemic, the role design played, and future design opportunities to improve aspects of the experience for travellers. Our study offers insight into specific "pain points' or challenges people experienced during the dynamic conditions posed by the COVID19 pandemic, and the opportunities for design to improve this experience. 
Another contribution of this study is the exploration and use of methods to document passenger experiences during pandemic conditions. Conducting research during pandemics poses significant challenges for both the researcher and participants. This work improves our understanding of how to design and implement methods within such contexts.

\section{Chapter 2: Literature Review \& Environmental}

\section{Scan}

A literature review and environmental scan were conducted to gather current information on air travel experience during the COVID-19 pandemic and background information on IPAC considerations in air travel design. This included information on IPAC and the physical environment of airports and cabin spaces; health and safety guidelines and changes made by airlines and airport authorities during the pandemic; and recent traveler reflections. The emergent nature of the COVID-19 pandemic meant that literature directly related to the virus was sparse. We supplemented this gap by reviewing literature focused on IPAC and aviation which emerged from the onset of the severe acute respiratory syndrome (SARS) caused by the SARS coronavirus (SARS-CoV or SARS-CoV-1) among other literature focused on respiratory viruses in air travel design.

The objective of this stage of the research was threefold. First, we wanted to frame what the current air travel passenger experience might look like according to published accounts. Secondly, we needed to develop an understanding of how IPAC measures during COVID-19 may be influencing the context of air travel. Lastly, we acquired a preliminary understanding of the research that is available about respiratory infectious diseases in air travel 
design. To do this, a keyword search was conducted at the beginning and the end of this research stage, as a way to compare what information about air travel and the pandemic was available. Through this exercise we compared how access to this information changed between March 2020 (the introduction of the pandemic) versus April 2021 (a year following the declaration of the pandemic). This search consisted of looking for keywords, such as "air travel OR airplane" and "coronavirus OR health" to see what information and research was available. Within this search, five publication platforms (Engineering Village, PubMed, Taylor \& Francis, Scopus, ProQuest) were reviewed, based on their relevance to this study (e.g., ergonomics, engineering, design, etc.). In most of the publications, the amount of COVID-19 and air travel related literature nearly doubled by April 2021, compared to the previous year. Appendix A provides the list of keywords searched over these two periods, comparing the journal and/or publication and the number of sources available at each date.

\subsection{Background}

On March 11, 2021, the World Health Organization (WHO) declared the coronavirus disease (COVID-19) had become a global pandemic (World Health Organization, 2020b). The COVID-19 virus is a respiratory infection that spreads primarily through droplets of saliva or discharge when an infected person coughs or sneezes (Government of Canada, 2020a). When the pandemic was declared, countries around the world called to action health and safety recommendations and public restrictions to help slow the effects of transmission. At this point, global numbers continued to climb, and services and industries were forced to change their operations in response. Aviation and tourism, in particular, were greatly affected by the restrictions put in place on domestic and international air travel (International Air Transport Association, 2021b). 


\subsubsection{Health \& Safety Responses}

The health and safety measures from The WHO, as well as national and regional health officials have shaped how individuals act in public environments following the outbreak of COVID-19. The WHO recommends infection prevention and control measures such as: regular hand washing with soap and water or an alcohol-based hand rub; maintaining a physical distance of at least 2 metres between individuals outside of their immediate household; avoiding touching one's face; covering our mouth and nose with a face covering; and avoiding unnecessary travel and group settings (World Health Organization, 2020a). Infection Prevention and Control (IPAC) refers to "evidence-based practices and procedures that, when applied consistently in health care settings, prevents or reduces the risk of transmission of microorganisms" (IPAC Canada, n.d.; Public Health Ontario, 2020).

The Canadian air travel industry implemented changes to their procedures to mitigate risks associated with the COVID-19 virus and transmission to crew and passengers for domestic and international travel (Government of Canada, 2020a). Table 1 outlines examples of the actions taken by Canadian air travel, in terms of recommendations, regulations, protocols, and Government Acts. These changes were made in response to provincial and national health and safety measures from Public Health Ontario and IPAC Canada, as COVID-19 cases and outbreaks continued to increase (IPAC Canada, n.d.; Public Health Ontario, 2020). The changes that have been made to air travel over the past year may have influenced passengers' travel planning and airport and flight experience, as well as their willingness to travel again during pandemic conditions. Understanding the types of changes made to air travel in the past year was important in framing what factors may have impacted passenger comfort and experience under pandemic conditions. 


\begin{tabular}{|l|l|}
\hline Type of change & Example \\
\hline $\begin{array}{l}\text { Regulation: a rule or directive made and maintained } \\
\text { by an authority. }\end{array}$ & $\begin{array}{l}\text { Passengers will be refused if they show COVID-19 } \\
\text { symptoms without a medical certificate or if they } \\
\text { have been refused travel within 14 days due to a } \\
\text { medical reason }\end{array}$ \\
\hline $\begin{array}{l}\text { Recommendation: a suggestion or proposal as to the } \\
\text { best course of action, especially one put forward by } \\
\text { an authoritative body. }\end{array}$ & $\begin{array}{l}\text { Recommended (not mandatory) self-isolation } \\
\text { following domestic air travel in Canada }\end{array}$ \\
\hline $\begin{array}{l}\text { Protocol: the accepted or established code of } \\
\text { procedure or behavior in any group, organization, or } \\
\text { situation. }\end{array}$ & $\begin{array}{l}\text { Face covering requirements for all persons in an } \\
\text { airport or air cabin (staff, crew, and passengers) }\end{array}$ \\
\hline $\begin{array}{l}\text { Act: a written ordinance of Congress, or another } \\
\text { legislative body; a statute }\end{array}$ & Quarantine Act (2005) \\
\hline
\end{tabular}

TABLE 1 EXAMPLES OF CHANGES MADE TO AIR TRAVEL IN CANADA

\subsubsection{Government Response}

In response to the COVID-19 virus, the Canadian federal, provincial, regional, and municipal governments set out various restrictions and recommendations to support the safety and health of the general public. Canadian provinces and territories developed public strategies for mitigation, working with provincial public health authorities and local governments to set policies and recommendations focused on testing and contact tracing services (Detsky \& Bogoch, 2020). Meanwhile, the federal government has been focused on setting policies and restrictions for border closures and the procurement of personal protective equipment (PPE), testing kits, and ventilators (Government of Canada, 2020; Detsky \& Bogoch, 2020).

On March 16, 2020, Canadian international borders were closed for non-essential travel outside of the United States and any international flights into Canada were directed through the primary hubs which included Vancouver, Calgary, Toronto and Montreal (Detsky \& Bogoch, 2020; Jackson, 2020). The United States-Canadian border was closed on March 21, 2020 (Detsky \& Bogoch, 2020). On March 25th, 2020 it was mandatory for travelers to selfquarantine after arriving in Canada by any means of transport following the implementation 
of the Quarantine Act (Quarantine Act, 2005). By April 2, 2020 there were 10,000 confirmed cases of COVID-19 in Canada and more than 1 million confirmed cases globally (Bielecki et al., 2021).

While international borders were closed for non-essential travel during March and April 2020, domestic travel was in the process of a procedural change to support COVID-19 IPAC measures. During this time, national travel was not restricted. However, each Canadian province and territory had set out specific restrictions and recommendations for travelers flying in or through their specific jurisdictions (Government of Canada, 2020d). For example, British Columbia, Alberta, and Newfoundland and Labrador had different compliance restrictions for in-province and international travelers, and in some cases, fines were imposed for non-compliance. Table 2 provides an outline of these travel restrictions and the nuances among the measures. Additionally, the Canadian Government provided a digital list of potential COVID-19 exposure sites, which domestic and international travelers were urged to reference following their flights (Government of Canada, 2020c).

Despite the federal government not mandating specific travel requirements for travelers, there has been cooperation with provincial governments, along with public health organizations, infectious disease specialists, and other related specialists across the country to set out public guidelines and recommendations (Detsky \& Bogoch, 2020). In 2005, the Quarantine Act was established by the Canadian government to allow the federal minister of health to take protective and preventive measures against "communicable diseases" (Quarantine Act, 2005). This act was implemented on March 25th, 2020, requiring everyone who enters the country to self-quarantine for 14 days. At the same time, interprovincial travel was discouraged with some provinces requiring a 14-day quarantine, and Newfoundland 
requiring official permission to enter the province (Detsky \& Bogoch, 2020; Government of

Canada, 2020f).

Travel Restrictions

International Travel

Documentation or

Quarantine Required

British Columbia (Government of British Columbia, 2021)

All non-essential travel should be avoided. This includes travel into and out of B.C. and between regions of the province.
All non-essential travel at the Canada-U.S. border is restricted. Additional screening measures in place at points of entry.

The Canadian border is closed to most international travellers.
Self-quarantine not mandatory for travel within Canadian provinces and territories.

Must follow B.C travel and health public guidelines while in province.

Alberta (Government of Alberta, 2021a, 2021b)

Travellers to other provinces or territories may be subject to additional restrictions and health measures at their final destination.

Some essential service workers are exempt from travel restrictions if they have no symptoms.
The Canada/U.S. border remains closed to non-essential travel.

Recent passengers on domestic and international airlines should monitor Government of Canada list of flights that have confirmed COVID-19 cases.
International travellers must present proof of a negative COVID-19 test result (via either paper or electronic proof of result) to the airline before boarding a flight to Canada.

All travellers entering Alberta from outside Canada must have appropriate plans and the necessary supports in place to quarantine for 14 days. Travellers will be required to submit their quarantine plans through the ArriveCAN mobile app.

Recommended use of ABTraceTogether, a mobile contact tracing app that helps to let you know if you've been exposed to COVID-19or if you've exposed others.

Newfoundland \& Labrador (Government of Newfoundland \& Laborador, 2020)

Travellers are only permitted entry into the province if their purpose of travel meets extenuating circumstances outlined by the Chief Medical Officer of Health.
Travellers entering

Newfoundland and Labrador from international locations and whose travel has been approved by Canada Border Services Agency must also complete the Travel Form.
All residents are required to complete a "Travel Form" within 30 days of expected travel, demonstrate they are a resident of the province, verify their purpose of travel with additional documentation if needed.

All residents of the Atlantic Bubble are required to self-isolate for 14 days upon arrival to Newfoundland and Labrador.

\section{TABLE 2 TRAVEL RESTRICTIONS FOR BRITISH COLUMBIA, ALBERTA, AND NEWFOUNDLAND AND LABRADOR}


Over time, the restrictions made to air travel have been fluid, changing based on COVID-19 outbreaks and case numbers. The actions taken by various governments and officials in Canada demonstrate how air travel has been influenced, but more specifically, dynamically or variably influenced, by the recommendations and restrictions set out to support public health and interest.

\subsubsection{Impacts on Air Travel}

This brief overview of key events that occurred this past year (Figure 2), shows how drastically and dynamically health, travel, and safety shifted in response to the global pandemic. The effects of the COVID-19 virus on the air travel industry introduced extreme IPAC measures, leading to significant changes in the physical environment and service/operations. The following timeline (Figure 2) provides an example of how the context of air travel has changed a number of times through emerging and different recommendations and safety protocols implemented by public health and government officials. As a result, service delivery, and presumably, passenger experience also considerably changed.

The air travel industry was negatively impacted by public health restrictions, and specific measures such as reductions in flight capacity and reduced incentive to travel (Bouwer, Saxon, \& Wittkamp, 2021; United Nations Economic Development, 2021). Between March and April 2020, airlines were recommended to reduce flight capacity and to avoid booking adjacent, or middle seats (Bronca, 2020). At the height of the pandemic, airlines were also urged to cancel or delay flights while waiting for public health guidelines. During this time, WestJet cancelled over 4000 domestic flight routes, removing approximately 18,000 daily flights between May and June 2020 (The Canadian Press, 2020). Comparatively, Air Canada 
halted their flights from May to June 2020, while Air Transat and Sunwing cancelled all trips until the end of May 2020.

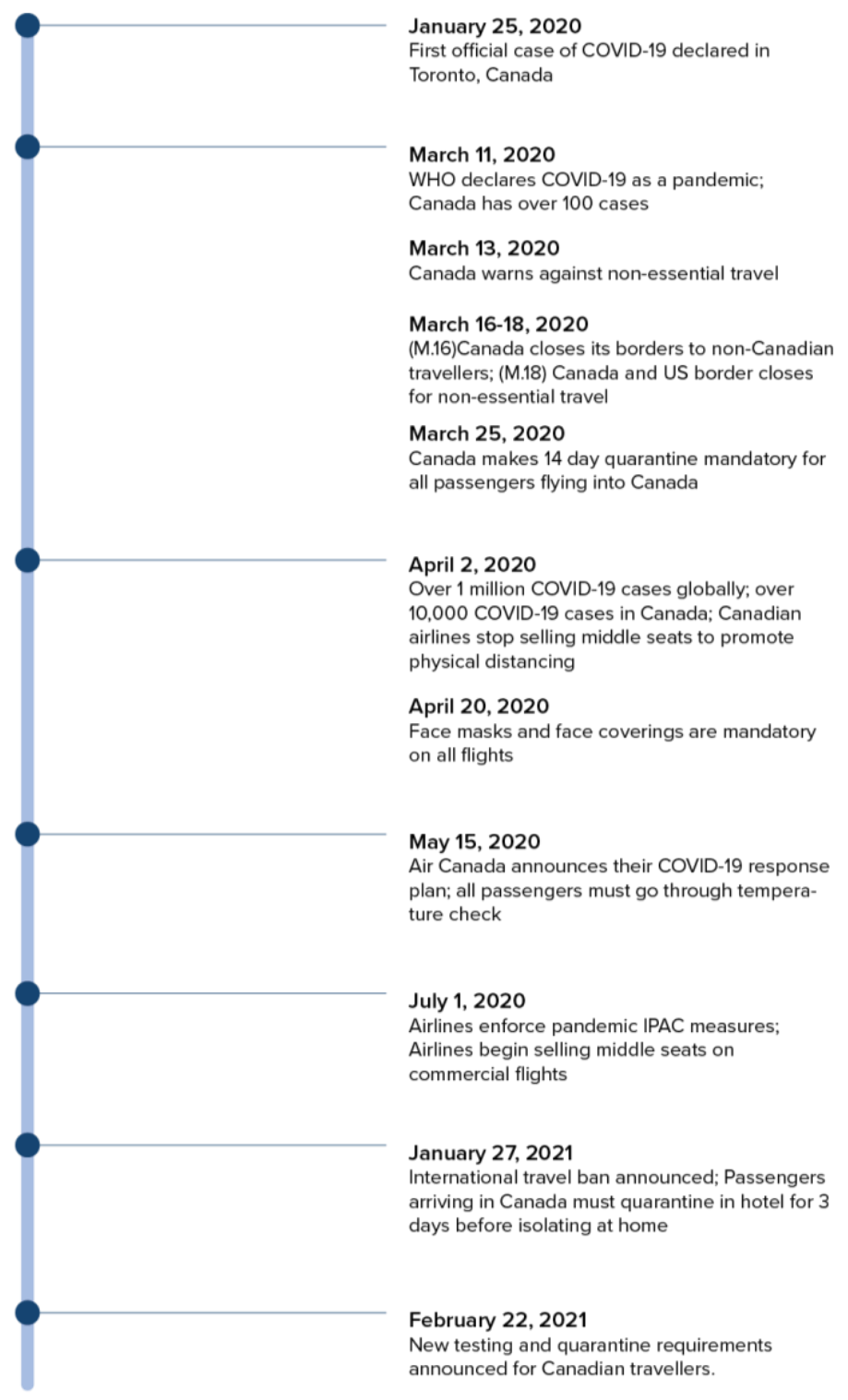

Figure 2. COVID-19 AIR TRAVEL TIMELINE

With reductions in tourism and business travel, flight capacity and routes, and nonessential travel, the air travel industry experienced significant financial losses. According to Proskow (2020), air travel decreased nearly 95\% in the past year and the lack of frequent travel 
resulted in higher fares and reduced competition among airlines. For example, Air Canada suffered financial losses of almost $\$ 1$ billion in their first quarter, with Delta airlines reaching losses of $\$ 60$ million per day (Proskow, 2020). The cuts to air travel tourism resulted in less frequent domestic and international flight availability. In 2020, the International Air Travel Association (IATA) reported its members expected revenue to drop by $\$ 312$ billion for that fiscal period, causing many commercial airlines to remain idle around the world in response to these losses (Fisher, 2020). The significant financial impacts the coronavirus has had on air travel calls into question how air travel industries will adapt to be able to provide a safe and accessible travel experience for their passengers, while also adjusting for the economic losses they have suffered in the past year.

\subsection{IPAC and Air Travel Design}

To date, literature related specifically to the current pandemic, IPAC, and air travel is sparse and therefore, literature we discuss in this section focuses on IPAC studies conducted in aviation research related to SARS and other infectious respiratory diseases prior to COVID19. This section contains selected topics of direct relation to the thesis questions of interest:

- How COVID-19 is transmitted among people

- Pathogen transmission in air cabin environments

- Pathogen transmission in airport environments

- Airline responses to COVID-19

\subsubsection{How COVID-19 is Transmitted Among People}

A major consideration in air travel design within the context of endemic infectious outbreaks, and worse, a global pandemic, is the rapid spread of pathogens across passengers and employees from different local, national and international regions. In 2002, for example, 20 people on an international flight were infected by a single SARS patient, which 
demonstrated how air travel can lead to the rapid spread of infectious diseases and viruses on a global scale (Toon, 2018). Sources of respiratory infection (Figure 3) can be transferred via (1) inhalation of small droplets in the air, (2) inhalation of large droplets within 1 metre of the source, (3) direct transfer of droplets from a surface to an individuals' eyes or nose - each of these falling within the respective labels of airborne, close contact, or fomite transmission in aircraft environments (Lei et al., 2018; Toon, 2012). Understanding the possible pathways of infectious disease transmission in air travel is crucial in identifying risk factors and intervention strategies to help mitigate contamination. There are a number of factors to consider in how the environment plays a role in the spread of infectious diseases, such as confined spaces, limited ventilation, recirculated air, and exposure times, all of which are considered critical in air travel design (Lei et al., 2018). Within air travel specifically, the airport and cabin are enclosed spaces, with the cabin being a potentially worse environment for airborne infection transmission and/or contamination because of its reduced space, high touchpoints, and close proximity to other individuals.

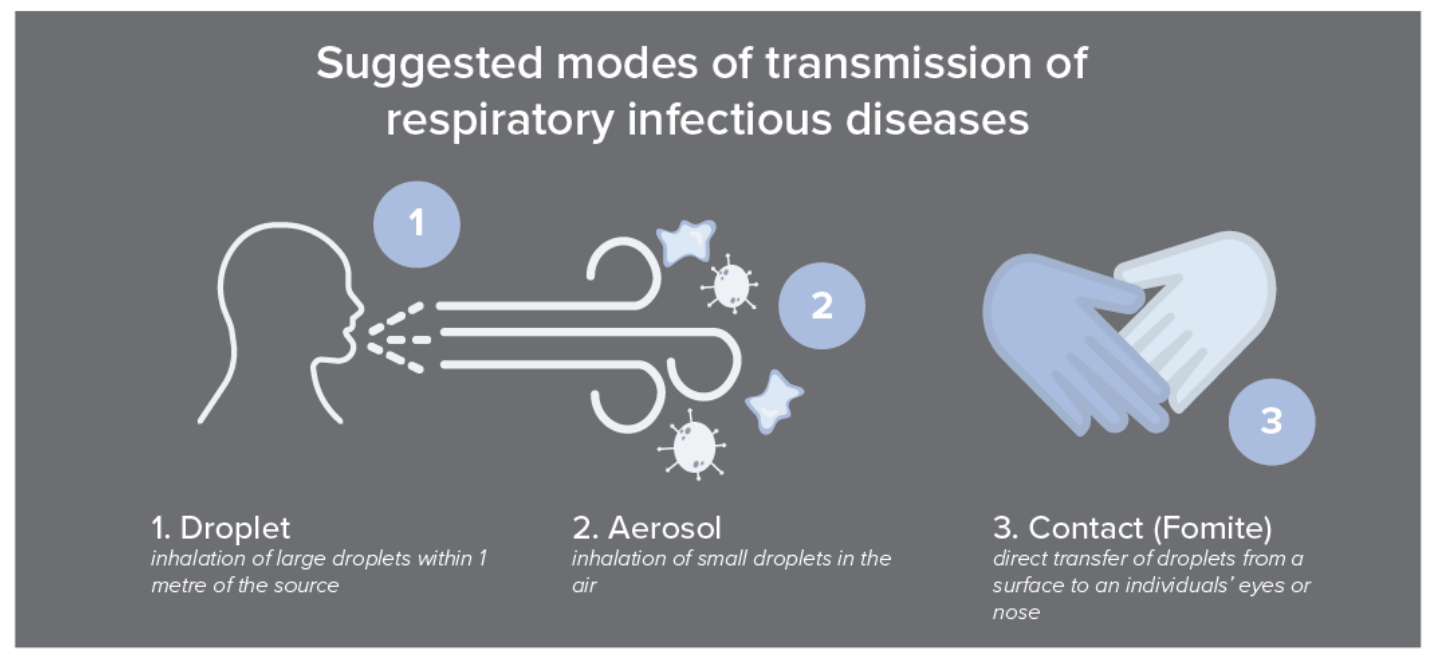

Figure 3. Modes of Transmission (HKUMED, 2020) 
COVID-19, specifically, is spread through respiratory droplets and aerosols that are created when an infected individual coughs, sneezes, sings, shouts, or talks. The droplets can either fall to the ground rapidly near the infected individual or linger in the air (aerosols), depending on their relative size (Government of Canada, 2020b). Infectious droplets and/or aerosols may come into contact with another individual's nose, mouth, or eyes, through inhalation or direct contact with the membranes of the nose, mouth, or eyes. Infectious droplets can also be spread through person-to-person contact with an infectious person or surface contact (fomite transmission) (Luo et al., 2020). Fomite (inanimate surface or object) transmission occurs when an object or surface becomes contaminated by large infectious droplets from an infected individual (Onakpoya et al., 2021). Levels of exposure and contamination because of fomite transmission depend on various factors, such as the time of day, amount of human activity, ambient temperature, and humidity (Menzies, 2005).

There is an ongoing debate about the risk of fomite transmission with COVID-19. There is a growing consensus that airborne transmission is the main route, with some studies showing the risk posed by fomites is low. Goldman (2020) concluded through a review of the literature that fomite risks are present "only in instances where an infected person coughs or sneezes on a surface and someone else touches that surface soon after the cough or sneeze (12h)" (Goldman, 2020, p.893). Other researchers point to fomite concerns in high-risk settings where touch-based behaviours are common and influenced by location, disinfection strategy and surface type (Kraay et al., 2021). Another study (2021) suggests that the risk of fomite transmission decreased with quarantine measures, a reduction in public touchpoints and the promotion of handwashing (CIDRAP, 2021). Despite the low risks of fomite transmission, the phenomenon of 'hygiene theatre' remains prominent in the public domain, with some 
researchers warning that the excessive sanitation of surfaces and touchpoints may distract from more effective ways of preventing and controlling COVID-19 (Thompson, 2021). Researchers are concerned that 'hygiene theatre' may lead to prevention fatigue with people feeling they need to comply to numerous and unmanageable IPAC measures (Goldman, 2020; Thompson, 2020). Specific to air travel, the ongoing debate over fomite transmission and excessive sanitation in public contexts may be tied to how passengers prepare for their travels and perceive their experience based on the health and safety measures in place in the airport and cabin. The dynamic and high-traffic nature of air travel requires an understanding of how pathogen transmission may occur in this context (airport and cabin) in order to mitigate the risks to passengers, staff and crew. For these reasons, we felt it was necessary to look into literature specific to these environments and how pathogen transmission may occur.

Literature specific to COVID-19 and the design of air cabin and airport environments was sparse at the beginning of this study. Although we continued to collect literature on COVID-19 in air travel, most of the literature collected and discussed below focuses on IPAC studies conducted in aviation research related to SARS and other infectious respiratory diseases prior to COVID-19. However, we end this section with a review of information that was available on air industry responses to COVID-19 since this information was being produced and published more rapidly than research specific to cabin and airport design.

\subsubsection{Pathogen Transmission in Air Cabin Environments}

The physical space in a cabin is limited, causing concern with the proximity of passengers and crew over a long duration, relative to the movement of infectious pathogens and the proximity of people to an infected individual. In a 2005 study, Burge suggested that an individual's proximity to an infected passenger and the length of time exposed were critical 
factors for contracting a disease. Cabin mock-up studies have modeled particle transmission based on proximity to an infection source (i.e., an infected or ill passenger). Figure 4 outlines four exposure-based maps, provided by different studies, which demonstrate how infectious particles move within a cabin environment from a source of infection. What this illustrates is that passengers seated within close proximity to an infected passenger (beside and one to two rows in front or behind) are at a higher risk of exposure and infection (e.g., Lei et al., 2018; Toon, 2018; Transportation Research Board, 2010b; Worsnop, 2017). Understanding how infectious diseases move within a cabin's air space is crucial in deciding how passenger proximity and flight capacity may play a role in the spread of respiratory viruses in air travel environments.

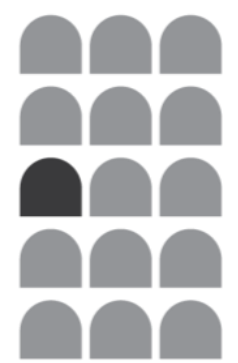

(WHO, 2009)

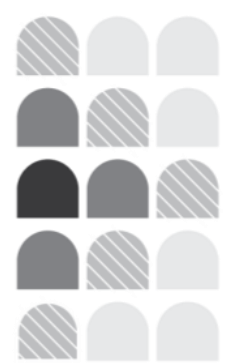

(Transportation Research Board, 2010)

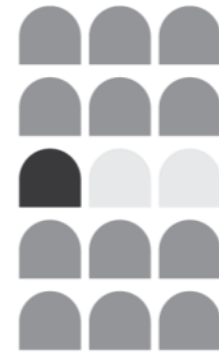

(Lei, et al., 2018)

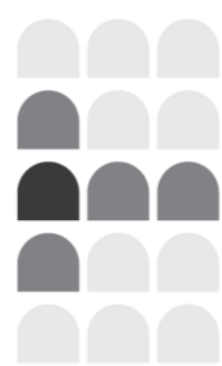

(Toon, 2018)

$\begin{array}{llll}\begin{array}{l}\text { Primary Source } \\ \text { (infectious) }\end{array} & \begin{array}{l}\text { Primary Risk } \\ \text { of Exposure }\end{array} & \begin{array}{l}\text { Secondary Risk } \\ \text { of Exposure }\end{array} & \text { Tertiary Risk } \\ \text { of Exposure }\end{array}$

Figure 4 Transmission Exposure Mapping Based on Passenger Proximity to DiRECT INFECTION SOURCE

The physical environment of the cabin does not provide enough space for adequate distancing on-board, in the case of infection transmission. Due to the confined space, limited ventilation and recirculation of air, coupled with extended exposure times to these conditions 
for crew and passengers, the cabin space poses risks for those on-board (Lei et al., 2018). Understanding airborne transmission of respiratory pathogens in air travel involves examining the size and potential movement of droplets in the air, air flow characteristics within cabin interiors, and how to reduce the risks of airborne transmission based on these conditions. Studying infectious particle movement among passengers within the cabin environment is important to predict the potential for pathogen transmission and design preventative measures to reduce these risk factors. Studies focused on the movement patterns of airborne contaminants through cabin mock-ups and computational fluid dynamics have been used to understand how existing ventilation systems may affect or prevent infection (Hertzberg, Weiss, Elon, Si, \& Norris, 2018; Transportation Research Board, 2010b).

Air flow and ventilation systems in cabin interiors also impact the movement and transmission of pathogens. Aircraft are equipped with environmental control systems (ECS), which provide clean outside air to the cabin (Transportation Research Board, 2010b). Through this system, approximately $50 \%$ of the air is recirculated and passes through a High-Efficiency Particulate Absorbing (HEPA) filter, while the remaining 50\% of air is brought in from outside of the cabin. Within the cabin, air is recirculated every 2-3 minutes, which translates to about 20-30 air changes per hour (Air Canada, 2021; Transportation Research Board, 2010a, 2010b; West Jet, 2021). Researchers have claimed that the use of HEPA filters in conjunction with the ECS in aircraft cabins are comparable to those used in hospital and similar-grade environments (Transportation Research Board, 2010b). While air ventilation measures such as ECS are beneficial in the removal of contaminated air particles, they also facilitate the movement of these contaminants throughout the cabin with air flow fluctuations. In response to this, a 2010 study looked into the direction of air flow out of the air supply and into the 
exhaust slots above passenger seating areas (Transportation Research Board, 2010b). This study found that air moves perpendicular to the aisle, highlighting how airborne pathogens might be controlled within a cabin through particle movement modeling. Similarly, IATA outlines that the risk of transmission in the cabin is low due to passenger seating arrangements, seat backs serving as barriers to air flow contamination, high levels of air filtration and ventilation, and the direction of air flow (International Air Transport Association, 2021a). According to IATA (2021a) air flows in the cabin from top to bottom in the cabin, not along the length of the cabin, which may contribute to reduced risks of transmission on board (Figure 5).

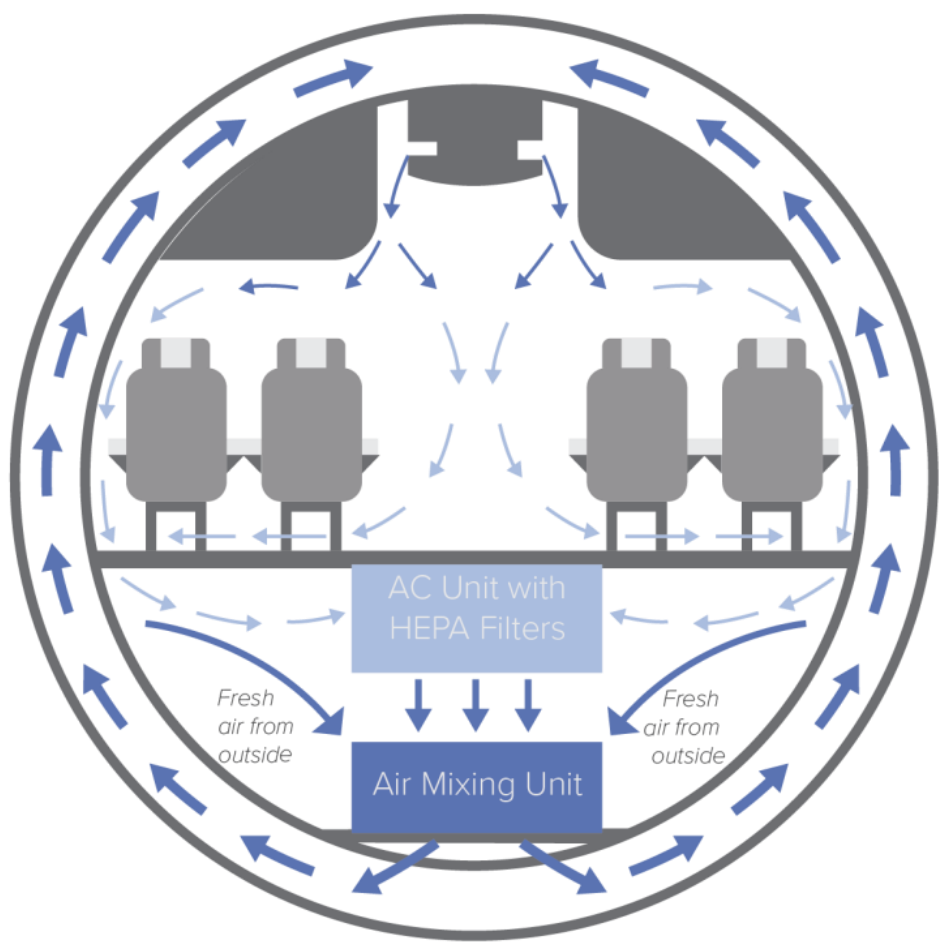

Figure 5. Direction of Airflow in CABin (INTERNATIONAL Air Transport Association, 2021A) 
Additional research has looked into epidemiological and in-depth environmental investigations to provide insight into behavioural risk factors related to respiratory infection transmission within an aircraft (Transportation Research Board, 2010b). Regarding passenger movement or behaviour-related risks, a study conducted by FlyHealthy ${ }^{\mathrm{TM}}$ estimated that nearly $40 \%$ of passengers never leave their seats, $40 \%$ get up at least once during their flight, and $20 \%$ get up at least twice. The authors of the study also found that almost $80 \%$ of aisle seated passengers get up during their flight, while $60 \%$ and $40 \%$ get up from their middle and window seats, respectively (Toon, 2018). Understanding passenger behaviours within the cabin can be used to predict movement patterns, areas of high touchpoints, and to identify more high-risk areas within the cabin that can be used to design specific IPAC measures on-board to reduce the risks of pathogen transmission. Other researchers have examined sterilization, cleaning measures and selection of materials, finishes and equipment to reduce risks of transmission to passengers and crew.

A study by Menzies (2005) examined how airborne microbes in the cabin could be eliminated though sterilization, filtration and dilution. This study claimed that airborne transmission could be reduced with ultraviolet germicidal irradiation or outdoor air ventilation. Current Air Canada and West Jet IPAC measures include similar processes of cleaning between flights and the use of ultraviolet sterilization techniques to prevent the spread of COVID-19 on-board (Air Canada, 2021; West Jet, 2021). Additionally, this study (2005) provided evidence that control the infectious particles could be achieved through the careful selection of equipment, furnishing materials, and with cleaning or replacing filters within the cabin to reduce microbial growth within the cabin (Menzies, 2005). 
Prior research on how infectious particles move within cabin spaces has offered insight into how to mitigate the risks associated with air travel during pandemic conditions. However, because of the dynamic nature of air travel, it is difficult to determine whether infections have spread within cabin environments or at other points in travel (Burge, 2005). It is imperative to also examine the physical environment outside the cabin to identify transmission risks throughout the entirety of passenger travel experience.

\subsubsection{Pathogen Transmission in Airport Environments}

Much of the literature on IPAC research in air travel has focused on air cabin environments with less information available on airport design. Yet, individuals are at risk of exposure from the time of arrival at the airport until the time they disembark and retrieve their baggage at their destination. Airports pose a high risk for the spread of COVID-19 as it can be transferred via surface contact, but more likely, droplet and airborne transmission as discussed. Large droplet transmission can occur in any high traffic area such as the check-in desk, security, pre-flight waiting areas (e.g., food and retail services, gates, washrooms), and the cabin (Transportation Research Board, 2010a). Enhanced protocols for cleaning airports as a response to the pandemic have been put in place, specifically in high-touch areas such as door handles, handrails, elevators, washrooms, and light switches (International Air Transport Association, 2021b). Due to the complex nature of human activity in air travel throughout a variety of environments, it is difficult to confirm where and how contamination occurs.

\subsubsection{Airline Responses to COVID-19}

While the design of the environment plays a crucial role in the spread and/or prevention of infection within air travel, so too do protocols and procedures related to passenger flow through, behaviours and interactions. Recent flyers have experienced extensive 
changes in airline boarding procedures, in-flight experience, and screening and/or testing procedures mandated by new policies. Each new change or addition to the air travel experience has the potential to influence passengers' travel experience.

When looking into how the air travel experience may impact a passenger's experience or comfort, we examined the different procedures and operations Canadian airlines and airport authorities have implemented to reduce the risks of COVID-19 transmission. We are interested in understanding how changes made within these levels of the travel experience may impact a passenger's perception of the current travel experience. In response to the COVID19 pandemic, airlines and airport authorities implemented various IPAC measures to mitigate some of the associated risks for their passengers, staff and crew. Transport Canada worked with Canadian public health officials to develop "Canada's Flight Plan for Navigating COVID19" along with provinces and territories, air operators, and airports to implement IPAC measures (Transport Canada, 2020). Some basic measures included: travel restrictions, enhanced cleaning and disinfection, physical distancing, mandatory health checks, the use of face coverings and temperature checks (see Table 3 for examples of measures related to the built environment as well as operations).

The International Air Transport Association (IATA) website provided additional information, indicating what passengers might expect at different check points within their travel experience (e.g., before you fly, arriving at the airport, onboard the aircraft, and at arrival). Additional information was provided, specific to COVID-19 transmission rates and environmental considerations within the aircraft (International Air Transport Association, 2020a, 2020b). The information provided to passengers prior to their flight, may influence 
their comfort in flying during the pandemic, and help them plan for what to expect during their experience(s).

Examples of IPAC Measures Used by Airlines (Built Environment and Operations)

Airports should encourage physical distancing whenever possible by installing barriers at customer service counters, and clear signage and floor markings throughout the terminal (Transport Canada, 2020).

New cleaning and disinfecting protocols should be put in place in airports, specifically at high-touch surfaces (e.g., kiosks, touch screens) to reduce surface contamination (Transport Canada, 2020).

The Canadian Air Transport Security Authority (CATSA) has adjusted their screening protocols for passengers, and mandated screening officers wear gloves and masks (CATSA, 2020).

All travelers must wear face coverings or non-medical masks, undergo health checks in the airport, and are subject to contactless temperature screening.

Upon arrival in Canada, passengers can use the eDeclaration mobile app for contactless interaction, and passengers can download the ArriveCAN mobile app to submit personal contact and quarantine information in advance (Canada Border Services Agency, 2020; Government of Canada, 2020e).

TABLE 3 EXAMPLES OF IPAC MEASURES RELATED TO THE BUILT ENVIRONMENT AND OPERATIONS

Between April 2020 and July 2020, Canadian airlines (WestJet, Air Canada, Porter Airlines, Air Transat, Sunwing, Flair and Swoop) made changes to their services, travel restrictions, requirements, and protocols for air travel (M.D. Pearl, 2021; Transport Canada, 2020). The most prominent changes to airline and/or airport procedures fell within the following categories - 'proximity to other people', 'flight capacity', 'change in service', 'air ventilation and filtration', and 'testing and screening' (refer to Table 4 which outlines some of the changes made by Canadian airlines).

West Jet and Air Canada implemented physical distancing measures in their cabins in April 2020, acknowledging it is nearly impossible to avoid close proximity to other people inside the cabin space (Air Canada, 2021; Jackson, 2020; West Jet, 2021). Meanwhile, WestJet reduced their services and flight capacity to mitigate the infection risks of person-to-person proximity and touchpoints, only offering food and drink services for flights longer than 90 minutes (International Air Transport Association, 2020a) . WestJet also implemented HEPA 
hospital grade filters on their aircraft to circulate fresh air into the cabin every 2-3 minutes (West Jet, 2021). As of May 2020, passengers boarding Air Canada aircraft were provided with 'customer care kits' which included items such as hand sanitizer, disinfectant wipes, and a disposal bag (Air Canada, 2021; Bowden, 2020). Other Canadian airlines, such as Sunwing and Flare Air, also reduced their flight capacity, suspended international flights, and implemented similar IPAC measures (Evans, 2020; M.D. Pearl, 2021).

At a more systems level of IPAC in air travel, passengers were and continue to be screened with a health questionnaire and temperature check prior to boarding and then provided with a disinfectant wipe upon boarding (International Air Transport Association, 2021b). Air Canada, for example, claims to have "end-to-end health and safety protocols" which includes health screening questionnaires, infrared temperature checks, clean and disinfected service surfaces (e.g., kiosks and counters), mandatory face coverings for passengers and additional PPE for crew as needed (Air Canada, 2021).

\section{Airline Responses to COVID-19 safety measures (types of change)}

Proximity to Other People

Physical distancing measures put in place in the cabin to reduce close proximity to other passengers and crew onboard (Air Canada, 2021; Jackson, 2020; West Jet, 2021).

\section{Flight Capacity Reductions}

West Jet, Sunwing, and Flare Air reduced the capacity of flights to reduce close-proximity and risks of transmission (Evans, 2020; M.D. Pearl, 2021; West Jet, 2021).

Some international flights were suspended to reduce risks of person-to-person transmission (Evans, 2020; M.D. Pearl, 2021).

\section{Change in Service}

In-flight food and drink services were reduced for flights less than 90 minutes (International Air Transport Association, 2020a). 
"Customer care kits" provided to passengers on some flights, containing hand sanitizer, disinfectant wipes, and a disposable bag (Air Canada, 2021).

Passengers are provided with a disinfectant wipe upon boarding (West Jet, 2021).

\section{Air Ventilation and Filtration}

HEPA filters implemented in cabin to circulate fresh air every 2-3 minutes (West Jet, 2021).

\section{Testing \& Screening}

Passengers are screened with a health questionnaire and temperature check prior to boarding and then provided with a disinfectant wipe upon boarding (International Air Transport Association, 2021).

"End-to-end health and safety protocols" which includes health screening questionnaires, infrared temperature checks, clean and disinfected service surfaces (e.g., kiosks and counters), mandatory face coverings for passengers and additional PPE for crew as needed (Air Canada, 2021).

\section{TABLE 4 TYPES OF CHANGES MADE BY AIRLINES IN RESPONSE TO COVID-19}

The changes made to airport and in-flight service, procedures, and operations focus on reducing the risks of transmission through person-to-person contact and surface transmission, while also implementing preventative measures, like testing and screening to avoid the spread of infection as passengers move through each air travel checkpoint (e.g., check-in to boarding). The extensive system-wide changes made to the aviation industry and air travel during COVID-19 understandably created a context of uncertainty. This points to the need to study the impact these changes have had on the services, physical environment, human interactions, and the passenger experience as a whole.

\subsection{Defining the Current Passenger Experience}

The focus of this study is to examine the air travel experiences of passengers during the COVID-19 pandemic. For the purpose of this research, the passenger experience has been defined as the actions and/or interactions a traveler has throughout their entire travel journey, from booking and planning, arriving at the airport, check-in and security, pre-board waiting activities, boarding, in-flight activities, and disembark at their final destination. Within the context of COVID-19, self-isolation 
and mandated quarantine have also been included in framing the experiences of passengers who participated in this study.

\subsubsection{Passenger Narratives during COVID-19}

A review of media sources collected during the COVID-19 pandemic have provided insight into how passengers have been affected by changes made to airline protocols and procedures. Air travelers choosing to fly during the global pandemic were faced with an increased risk of exposure to the virus along with going through heightened public health and safety measures put in place by government and health officials.

A scan of national and international media was done to gather real-time information from recent travelers and journalists covering stories about travelers within the last year. This information demonstrated that passengers around the world shared concerns over: the clarity and transparency of changing protocols implemented by airlines and/or airport authorities; the risk of infection when onboard; concerns with rapid blood tests; and the availability of PPE for employees and passengers (Jackson, 2020; Lei et al., 2018; Ramsay, 2020). The variety of IPAC measures within air travel may have created confusion for passengers, as the responses to the pandemic varied widely among airlines, airports and regions (e.g., provinces, territories, internationally). In an interview for The New York Times magazine, Henry Harteveldt, founder of Atmosphere Research claimed "[t] his uncertainty, combined with unnecessary variation from airport to airport in health screening processes, ends up with confused consumers not being confident enough to take a trip" (Levere, 2020). This sentiment is supported by passengers who shared stories of their traveling following the declaration of the COVID-19 pandemic in March 2020. The information provided to the media by these passengers provides a glimpse into how COVID-19 influenced their travel experience and 
comfort in flying. After reviewing several stories from recent travelers, several reoccurring themes began to emerge, which helped shape our understanding of the current context of air travel (for a more detailed account of two passenger narratives see Appendix B).

An emerging theme that continued to come up in passenger accounts of flying through COVID-19 was the uncertainty about what procedures and/or protocols were in place by different airlines and airports. Many of these reflections related to numerous stations and steps in IPAC processing, extended travel time due to steps under stressful conditions, cleaning and disinfection procedures in high-touch areas, and differences in the types of announcements played in the airport and cabin. In addition, uncertainty in the steps other passengers were doing and the possibility of infecting others on their return flight were of concern. Related to this, there were a number of accounts about passenger expectations of travel. These reflections emphasized passenger expectations that there would be more space in the cabin, or distancing measures in place to make it feel safer. Throughout this scan, we were able to see that some flights differed greatly in their capacity, which could have been a result of specific protocols by the airline to reduce or increase capacity, or the result of mandatory reductions in capacity by airport authorities (i.e., IATA reducing middle seat booking).

Another emerging theme related to the perception of space and time in the airport and cabin. There were many instances where recent passengers made comments about the capacity of the airport or cabin, the duration of time spent in the airport (for screening and testing, or because of delays in flights), and the proximity to other passengers as a result of the physical environment. Lastly, concerns or questions about differences in PPE and protective measures adapted by other passengers and crew continued to come up. According to our scan, there were considerable differences in the type of PPE worn by passengers and crew, as well as the 
number of people following mandatory mask requirements differed by the airport visited and date of travel.

While we cannot generalize such experiences to the many travel experiences of this past year, the stories shared by passengers traveling during the pandemic shed light on the real impact of different IPAC approaches that occurred throughout their journeys. The landscape of air travel has shifted significantly in the past year, in response to the dynamic nature of the COVID-19 virus and our understanding of its impacts. As a result, the passenger experience is changing as new protocols, restrictions, and requirements are put in place by local and federal officials.

\subsubsection{Comfort and Stress}

As changes to air travel continue in response to COVID-19, it is likely important to outline factors that have been identified as supporting passenger experience, by examining specifically concepts related to comfort and stress. Existing research in passenger comfort is important in considering how factors such as the emotional and physical aspects of design can mitigate some of the negative effects of flying within pandemic conditions. Comfort is a subjective term, which can be described as "a pleasant state of physiological, psychological, and physical harmony between a human being and the environment or a sense of subjective wellbeing” (Vink, Bazley, Kamp, \& Blok, 2012, p. 354). Intrinsic factors contributing to a person's experience of comfort (e.g., demographics, anthropometry, physiology, health and well-being, psychology, attitudes or expectations) may affect their perception of comfort and differ among individuals (Lewis et al., 2016). Ahmadpour, Robert and Lindgaard (2014) propose eight themes which can influence one's sense of comfort - peace of mind, our physical well-being, proxemics or how much space we feel we need relative to others, feelings 
of satisfaction, sense of pleasure, social considerations, the aesthetic qualities of design, and lastly, associations we may have with designs or the context in which we find ourselves. These concepts can be used to evaluate passenger comfort in air travel. Within the context of air travel, 'peace of mind', 'physical well-being' and 'proxemics' are particularly important in evaluating passenger comfort (Ahmadpour et al., 2014; Ahmadpour, Robert, \& Lindgaard, 2016). In addition, Vink (2012) suggests that a passenger's perception of their personal space, social factors (other passengers and crew), and perception of hygiene play a major role in their overall perception and experience of comfort and safety in a flight. This suggests that the travel experience should be looked at in terms of a system, which includes the various environmental, contextual, and social considerations that play a role in passenger comfort and experience. Within COVID-19 specifically, these factors are important in addressing passenger comfort with IPAC measures, changes to processes and operations, and interactions with other passengers and crew.

Our environmental scan of media showed that several airlines and/or airport authorities are taking drastic or significant actions to respond to COVID-19, some of which may have posed concerns for the comfort and safety of passengers. Emirates Airlines, for example, were the first airline to conduct on-site rapid COVID-19 blood tests for passengers prior to their boarding as of April 2020, with an estimated 10-minute waiting time for test results (Jackson, 2020). The rapid blood tests were done in response to some countries requiring COVID-19 test certificates upon arrival. Some concerns with the rapid blood tests were that they could produce false positive results and hadn't yet been approved by the Food and Drug Administration prior to their launch (Jackson, 2020). This procedure called into question the effectiveness and ethics of the blood tests, along with privacy and liability 
concerns with unverified methods of testing or collecting health information on passengers. On a similar note, there have been concerns over the privacy and security of personal passenger data being obtained from airports and/or airlines to support contact tracing, testing, and screening. In the spring of 2020, frequent flyer Timothy O’Neil-Dunne, expressed his thoughts on ethics; "Ethics are fine when ethics are all that matters. In this case, it's a pandemic virus. You're not just dealing with individual rights, you're dealing with fellow passengers' basic human rights, and I think that has precedence" as cited in The New York Times (Levere, 2020). It could be argued that this tension around implementing rapid IPAC measures impacts passenger's peace of mind, calling into question whether passengers may need to compromise their individual privacy to protect their own and others' health and safety when flying during such conditions.

Proxemics and physical well-being have also been shown to largely contribute to a passenger's perception of comfort and safety (Ahmadpour et al., 2014; Lewis et al., 2017). With the capacity of flights differing by airline and country of travel, passengers are left 'unknowing', not being able to plan for the capacity of their flight, what kind of distancing measures may be in place in the airport and cabin, as well as their proximity to other passengers throughout their experience. This presents an opportunity to examine the effects of the current state of air travel compared to previous research on the physical contributors to comfort. Uncertainty in flying is at heightened levels, and passengers not knowing where potential risks are and how airlines and airport authorities are taking action to mitigate these risks has presumably impacted passenger comfort and their perception of safety in flying. 


\subsubsection{Expectation for Future Air Travel}

In response to the changes made to the flight experience during the pandemic, there have been a number of studies outlining what the future of air travel will look like, along with suggestions for improved aviation services and products to mitigate some of the health and safety risks in air travel. Proskow (2020) shared his opinion on the current state of air travel, stating " $[\mathrm{b}]$ efore the virus, travel was cheap, plentiful, and pretty easy [...] after COVID-19, everything will be different" and goes on to say "[t]he moment in time we are experiencing now is not unlike $9 / 11$ - a sudden shock to the system that will lead to permanent changes, that will eventually come to feel routine". The current context of air travel is changing and calls for COVID-19 responses and approaches that are thoughtful, consolidated, and coordinated among airlines and airport authorities around the world that respond appropriately to the virus. A research study conducted by Fast Future, Future Travel Experience and APEX identified four potential scenarios for post COVID-19 commercial air travel over the next two years (Taylor, 2020). These researchers suggest air travel will be categorized based on passengers' risk of virus contraction and transmission, and how business class may uphold over economy travel, all within the context of economic recovery and industry collaboration. Figure 6 outlines the 4-scenario matrix that resulted from this study, along with participant predictions of which scenario is most likely to occur post-COVID-19. This exploration about the changing context of air travel post-pandemic demonstrates how researchers in aviation are using real time data to anticipate the landscape of future travel. 


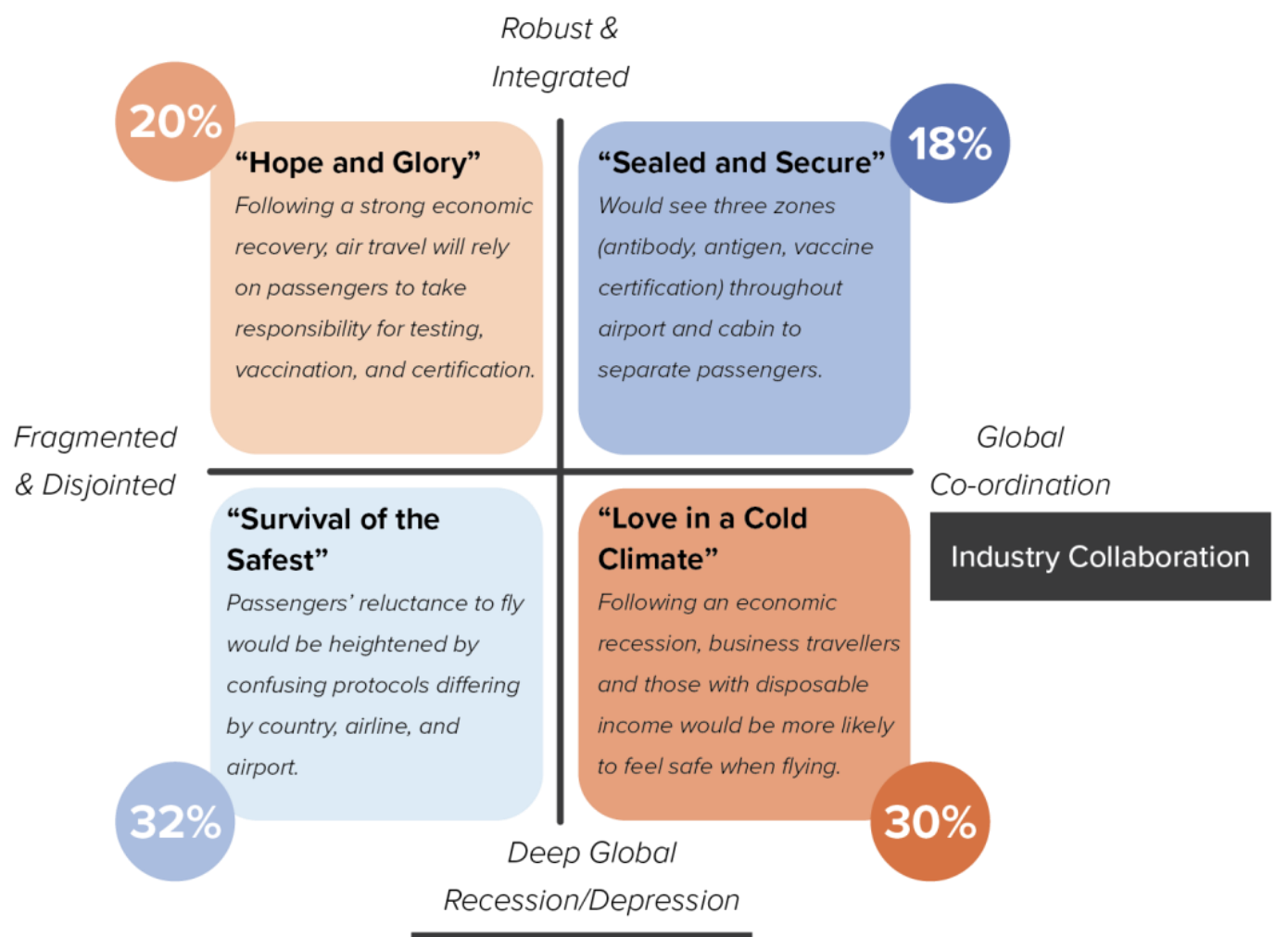

Economic Recovery

Figure 6. Post-Pandemic Air Travel Model, Adapted from Fast Future, 2020

Additionally, several design consultancies and airlines are funding research and design development of physical environments and service in air travel to mitigate the risk of COVID19 transmission and support passenger experience. Some of these proposed designs and solutions have been outlined in Table 5. This scan looked into current or developing designs and what types of design were prominent or centre of focus in air travel. It is interesting to note how most of these proposed designs served as 'quick fixes' to problems, most of which are focused on cabin seating and proximity (e.g., seat partitions, new cabin layouts), and screening processes in the airport (e.g., UV light sterilization, rapid blood tests). There is little work being done that looks into the other areas of travel experience, suggesting that further 
research and design development should consider making improvements to other aspects of the passenger experience. The dynamic nature of COVID-19 calls for rapid changes in the protocols, management and design of air travel for the future. As these proposed solutions continue to emerge, so too does the need to evaluate how the passenger experience has been affected and could be improved to some degree.

\section{Air Travel IPAC Measures and Proposed Designs in Response to COVID-19}

\begin{tabular}{|c|c|c|c|c|}
\hline $\begin{array}{l}\text { Emirates } \\
\text { conducting instant } \\
\text { COVID tests; } \\
\text { conducting blood } \\
\text { tests (Proskow, } \\
2020 \text { ) }\end{array}$ & $\begin{array}{l}\text { China requires } \\
\text { validation that } \\
\text { travellers are } \\
\text { COVID-19 free, } \\
\text { using QR codes } \\
\text { (Sillers, 2020) }\end{array}$ & $\begin{array}{l}\text { Lufthansa, Air } \\
\text { France, and KLM } \\
\text { make masks } \\
\text { compulsory for } \\
\text { passengers and crew } \\
\text { (Sillers, 2020) }\end{array}$ & $\begin{array}{l}\text { Singapore Airlines, Air } \\
\text { Asia, Cathay Pacific } \\
\text { masks compulsory for } \\
\text { passengers and crew } \\
\text { (Sillers, 2020) }\end{array}$ & $\begin{array}{l}\text { Europe's Easyjet } \\
\text { proposed leaving } \\
\text { middle seats } \\
\text { empty (Sillers, } \\
2020 \text { ) }\end{array}$ \\
\hline $\begin{array}{l}\text { Ethiad has } \\
\text { temperature } \\
\text { checks (Proskow, } \\
\text { 2020) }\end{array}$ & $\begin{array}{l}\text { Colorado Frontier } \\
\text { Airlines proposed } \\
\text { making passengers } \\
\text { pay extra to keep } \\
\text { middle seat free } \\
\text { (Sillers, 2020) }\end{array}$ & $\begin{array}{l}\text { Delta, United, } \\
\text { American Airlines, } \\
\text { and JetBlue masks } \\
\text { compulsory for } \\
\text { passengers and crew } \\
\text { (Sillers, } 2020\end{array}$ & $\begin{array}{l}\text { Qatar Airways } \\
\text { introduced PPE suits } \\
\text { for its cabin crew } \\
\text { (Sillers, 2020) }\end{array}$ & $\begin{array}{l}\text { Air Canada was } \\
\text { first airline in the } \\
\text { Americas to } \\
\text { require } \\
\text { temperature } \\
\text { checks in the } \\
\text { airport (Proskow, } \\
2020 \text { ) } \\
\text { Air Canada } \\
\text { mandated masks } \\
\text { since April 20, } \\
2020 \text { (Sillers, } \\
2020 \text { ) }\end{array}$ \\
\hline $\begin{array}{l}\text { Hong Kong } \\
\text { International } \\
\text { Airport (HKIA) } \\
\text { try out Clean } \\
\text { Tech, a full-body } \\
\text { disinfection } \\
\text { facility (Sillers, } \\
2020 \text { ) }\end{array}$ & $\begin{array}{l}\text { HKIA testing } \\
\text { autonomous } \\
\text { Intelligent } \\
\text { Sterilization } \\
\text { Robots with UV } \\
\text { light in airport } \\
\text { (Sillers, 2020) }\end{array}$ & $\begin{array}{l}\text { HKIA use of } \\
\text { invisible } \\
\text { antimicrobial } \\
\text { coatings that destroy } \\
\text { germs, bacteria, and } \\
\text { viruses on high- } \\
\text { touch surfaces in } \\
\text { airport terminal } \\
\text { (Sillers, 2020) }\end{array}$ & $\begin{array}{l}\text { Eye movement } \\
\text { tracking-based user } \\
\text { interfaces for in-flight } \\
\text { entertainment (Sillers, } \\
\text { 2020) }\end{array}$ & $\begin{array}{l}\text { Gesture-based } \\
\text { stowage bin, to } \\
\text { reduce handling } \\
\text { (Sillers, 2020) }\end{array}$ \\
\hline $\begin{array}{l}\text { Rethinking the } \\
\text { layout of the cabin } \\
\text { or zoning cabin } \\
\text { (Taylor, 2020, } \\
\text { Sillers, 2020) }\end{array}$ & $\begin{array}{l}\text { Aviointeriors } \\
\text { "Janus" seating } \\
\text { made of "easy "} \\
\text { cleaning" and "safe } \\
\text { hygienization } \\
\text { materials" } \\
\text { (Hardingham, } \\
2020)\end{array}$ & $\begin{array}{l}\text { Aviointeriors "Janus" } \\
\text { seating configuration } \\
\text { within middle seat } \\
\text { facing opposite } \\
\text { direction to ensure } \\
\text { isolation } \\
\text { (Hardingham, 2020) }\end{array}$ & $\begin{array}{l}\text { Aviointeriors } \\
\text { "Glassafe" shield on } \\
\text { seats to impose safe } \\
\text { barrier between } \\
\text { passengers sitting } \\
\text { close, and to reduce } \\
\text { probability of } \\
\text { contamination } \\
\text { (Hardingham, 2020) }\end{array}$ & $\begin{array}{l}\text { Factory Design } \\
\text { propose a table } \\
\text { insert in middle } \\
\text { seat which adds } \\
\text { shield between } \\
\text { passengers } \\
\text { (Verdon, 2020) }\end{array}$ \\
\hline
\end{tabular}




\subsection{Insights from the Review}

With such rapid changes occurring across the world and air travel being a central conduit of global movement, research on the impact of the pandemic on air travel and the aviation industry has become imperative to support the design and development of elements and overall systems within this new and developing context. Illustrating how government, public health, and the aviation industry responded to the pandemic through a variety of measures offers an opportunity to develop insight into the passenger's experience of such measures. This review of the literature and environmental scan provided an overview of:

1. IPAC research in air travel which occurred prior to the pandemic on cabin environments, and less so, in airport design;

2. IPAC measures that were implemented during the COVID-19 pandemic by authorities, airlines and airports showing differences in approach;

3. key themes that emerged in passengers' flight experiences during the pandemic through an environmental scan of media which include passenger apprehensions about traveling within a pandemic, concerns over PPE and IPAC measures in place;

4. the importance of comfort theory in analyzing passenger experience within the context of pandemics; and

5. speculation on the future of air travel and current design developments in response to COVID-19 which range from screening and cabin-focused designs to post-COVID-19 predictions and views on the future of the industry.

The literature reviewed offers insights into how air travel and passenger experience has changed as a result of COVID-19. The main themes explored point to a need for more transparency and information from airlines about IPAC measures, passenger concerns over shared spaces and proximity to other passengers, and the discrepancy among airline responses 
across domestic and international flights. Additionally, the review highlighted which factors and considerations in the current air travel experience are being focused on (e.g., in-cabin seating and proximity, concerns over PPE worn by passengers and crew, testing and screening processes, and the use of physical space in the airport to support passenger movement and activities). With this in mind, we considered these factors that emerged in our review, while also exploring what other factors may be contributing to passenger experience through the use of our methods. Improving our understanding of passenger experiences during COVID19 through our study can provide insight into how we might better respond to passenger needs and preferences through design.

\section{Chapter 3: Research Methods}

A qualitative and quantitative, mixed-methods approach was used to gain insight on how passenger experience may have been impacted by the COVID-19 pandemic, and the associated changes that were made by airlines and/or airport authorities. The approach consists of three methods that build off one another. The approaches we selected allowed us to respond to both changes in the air travel passenger's experience as well as the dynamic context of researching throughout pandemic conditions. Within each method, we first describe the participant group followed by a combined section focused on Materials and Procedure. 'Materials' and 'Procedure' are combined because the rationale for the design of each method is provided and these concepts are naturally intertwined within the description of the rationale. The rationale for the design is provided as this is also a study in the 'design of methods' used to document experience under pandemic conditions. 
The first method involved observational analysis and reflective journaling by the lead researcher to gather real-time information on her own travel experiences in June and July 2020 to collect preliminary data and plan the subsequent phases of the study. This led to the development of the second method which involved the design and testing of travel diaries with the aim of making it easy for passengers to document real-time information throughout their travel experience or immediate recollections about their experience if they opted to complete the diary upon arrival at their destination. Methods one and two relate more to the field of design in their development and implementation, specifically in the evaluation of their use in real-time data collection and recording user experience in a novel way. The third method involved interviews with participants who completed the travel diaries or recent flyers who could provide recollections about their recent air travel experience during the pandemic. Data was collected from participants who travelled between July 2020 and February 2021. This final method focused on gathering recollective reflections from participants based on their experiences travelling within pandemic conditions.

\subsection{Ethical Considerations \& Participants}

This study received clearance from the Carleton University Research Ethics Board (see Appendix C). Participants were recruited through social media (e.g., Facebook and online forums) and emails sent through personal and professional contacts. This approach was used with the aim of recruiting participants outside the lead researcher's immediate network and to reach a broader demographic of flyers. Participants were selected based on the dates of their most recent travel between July 2020 and February 2021 and their interest in participating in either the travel diary or recent flyer interviews. The selected participants did not receive compensation for their involvement in this study. Participants were briefed on what to expect 
from their participation, the tasks they would be asked to complete and given the accompanying study materials (travel diary and/or interview guide). All participant data was kept anonymous and any identifying information was redacted or removed from the data. Interviews were conducted through a password-protected video conference (Zoom) call and each participant had a unique password for their interview. Prior to the diary study and interviews, participants were sent a consent form to sign, which outlined the use of video in interviews asking if they consented to be recorded. Once participants joined the interview space, they were asked again if for their consent to be recorded verbally through Zoom. Participants were then asked to turn on their microphones and cameras for the interview based on their comfort and signed consent form.

Sixteen participants were recruited, which included individuals planning to travel or who had recently traveled by air within the given timeframe (see Appendix D) for more detail on passenger characteristics and travel information). All participants were Canadian citizens and embarked in domestic or international travel. Any information about specific air couriers and airports visited has been anonymized in the data and our findings. Participant ages ranged between $22-65$ years ( 8 males and 8 females). Of these participants, two completed the travel diaries, eleven were interviewed, and three of these participants took part in both the travel diary and interview (see Figure 7). Participants were recruited until the researcher determined that an acceptable level of saturation had been achieved in terms of identifying key patterns, themes and insights. 


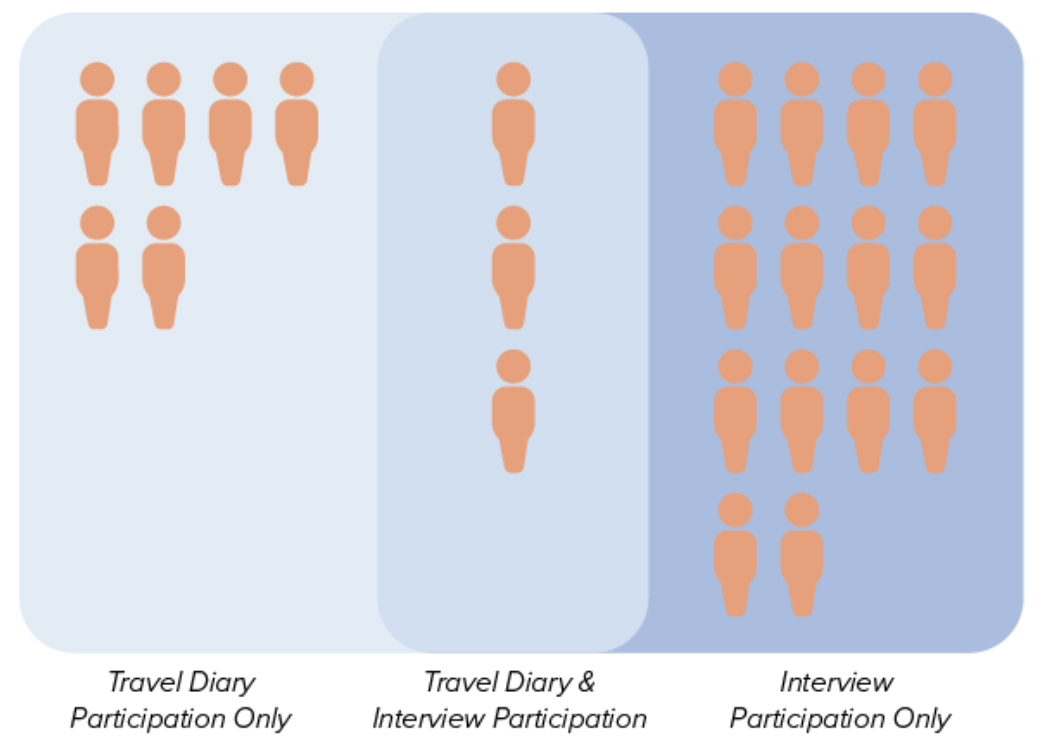

FIGURE 7. STUDY PARTICIPANT MAP

\subsection{Observation and Reflective Journaling}

In the first phase of the study, the lead researcher took three separate flights between July to August 2020 to document her travel experience and any major differences among the flights and airports. Three flights were taken on air courier 1, visiting three Canadian airports in Ontario, Quebec, and Alberta. Three workbooks were designed to document flight experience; interpretations of other passengers' emotions and behaviours; and any observable challenges related to interactions within the airport or cabin environments, as well as with other passengers and crew on the three separate flights.

\subsubsection{Participants}

This first method focused primarily on my travel experience, with a secondary focus on passengers, crew members and airport staff. No identifying information was collected about other passengers or crew, only my interpretation of major or more noticeable emotional states or behaviours. 


\subsubsection{Materials and Procedure}

Observation and reflective journaling were chosen as the initial methods to gather realtime data about the researcher's experience travelling during the pandemic and IPAC measures. Observation is a fundamental method for building study designs since it "...requires attentive looking and systematic recording of phenomena - including people, artifacts, environments, events, behaviours and interactions" (Hanington \& Martin, 2012b, p.120). This experience also presented the opportunity to examine potential differences across airports and provincial responses to COVID-19. As the objective of the first method was to record the researcher's observations about the context which included her experience and observations on fellow passengers, the question of how to document the potential experience of other passengers, including their behaviour but also what they may be feeling was explored. Therefore, a literature review of methods to assist in documenting observable emotions and/or behaviours was conducted to inform the design of the workbooks.

As face coverings were required during travel, it was important to investigate how to perceive emotion based on body language beyond this area of the face. Affective tracking is a tool used to gauge or infer people's emotions, beyond the visual context of facial expressions. A 2019 study by Chen and Whitney looked into tracking the affective states of people with partially concealed faces and found that even when facial features were masked, the visual context of their body language was enough to infer perceived valence and the arousal of the participants. In this sense, an individuals' emotions could be evaluated based on factors, such as tone of voice or contextual information, rather than solely on their body and/or facial expressions. According to Bestelmeyer, Kotz, \& Belin (2017), "[a]rousal (or intensity) is the level of autonomic activation that an event creates, and ranges from calm (or low) to excited (or high). Valence, on the other hand, is the level of pleasantness that an event generates and 
is defined along a continuum from negative to positive." (p.1351). The concept of affective tracking (Figure 8) was integrated into the workbooks to facilitate the documentation of the more 'obvious' or 'observable' emotional or behavioural attributes of other passengers, crew and airport staff.

Another study that was reviewed to design the observational analysis focused on how to recognize or categorize emotional body gestures. The study asserts that "[b]ody language includes different types of nonverbal indicators such as facial expressions, body posture, gestures and eye movements" (Noroozi et al., 2019, p.2). This same study linked six emotions (fear, anger, sadness, surprise, happiness, and disgust) with specific body language. These six emotions were integrated into the workbooks, to track the lead researcher's perceptions of the emotional states of others (e.g. F-: fear, A-: anger, S-: sadness; S+: surprise, H+: happiness, D-: disgust) Additionally, this study offered evidence that human actions and body language can differ based on their dynamics (i.e., periodic or nonperiodic, stationary or transitional), which can be seen in the movement patterns and body language of individuals (Noroozi et al., 2019). Applying this strategy, involved including areas in the workbooks to document the lead researcher's perceptions of other traveler's emotions based on body language as well as identifying body movements where applicable. Based on these previous studies, the workbooks were developed to help map out the physical environment; note key, interesting or striking interactions of passengers, service and crew members; and to describe any tools or systems in place to support IPAC (See Appendix E). 


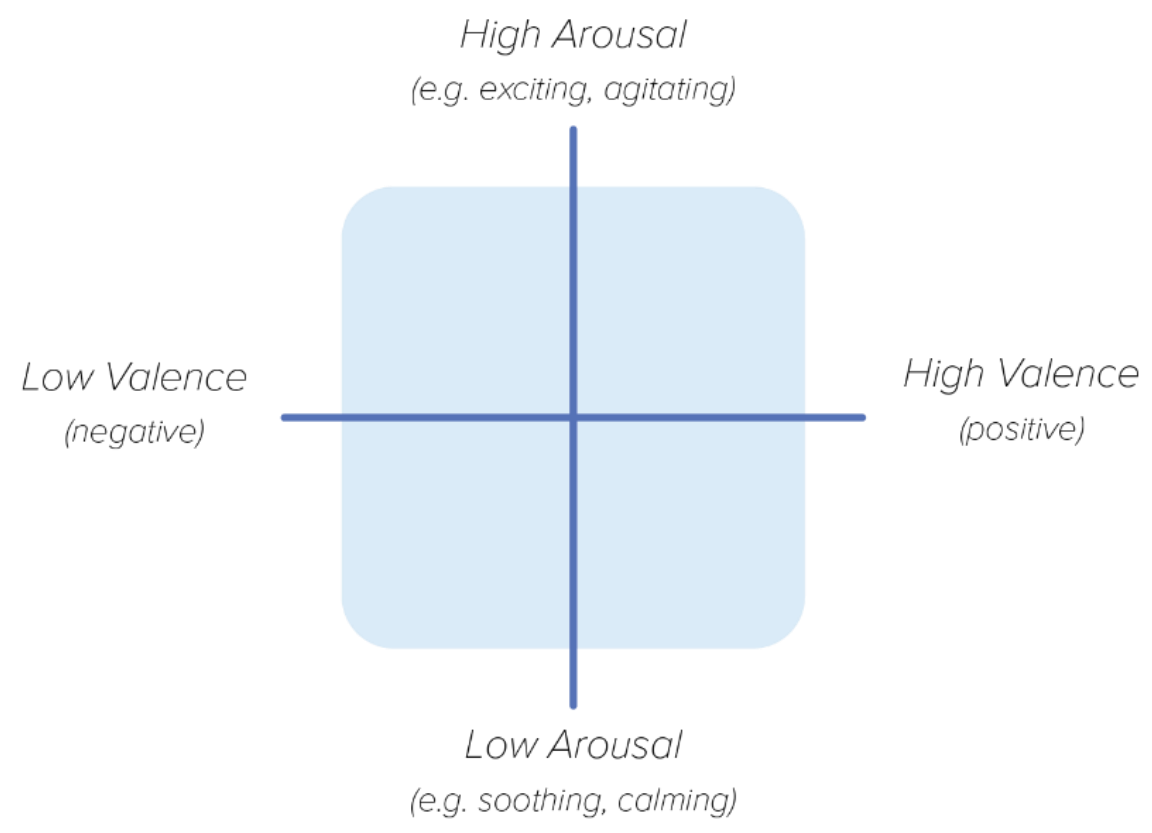

Figure 8. AFFECTIVE TRACKING Diagram

A series of charts were included in the workbooks to document various levels of experience. The first chart was (Figure 9) was used to track key interactions or instances where emotional or behavioural changes were noticed by the lead researcher. 


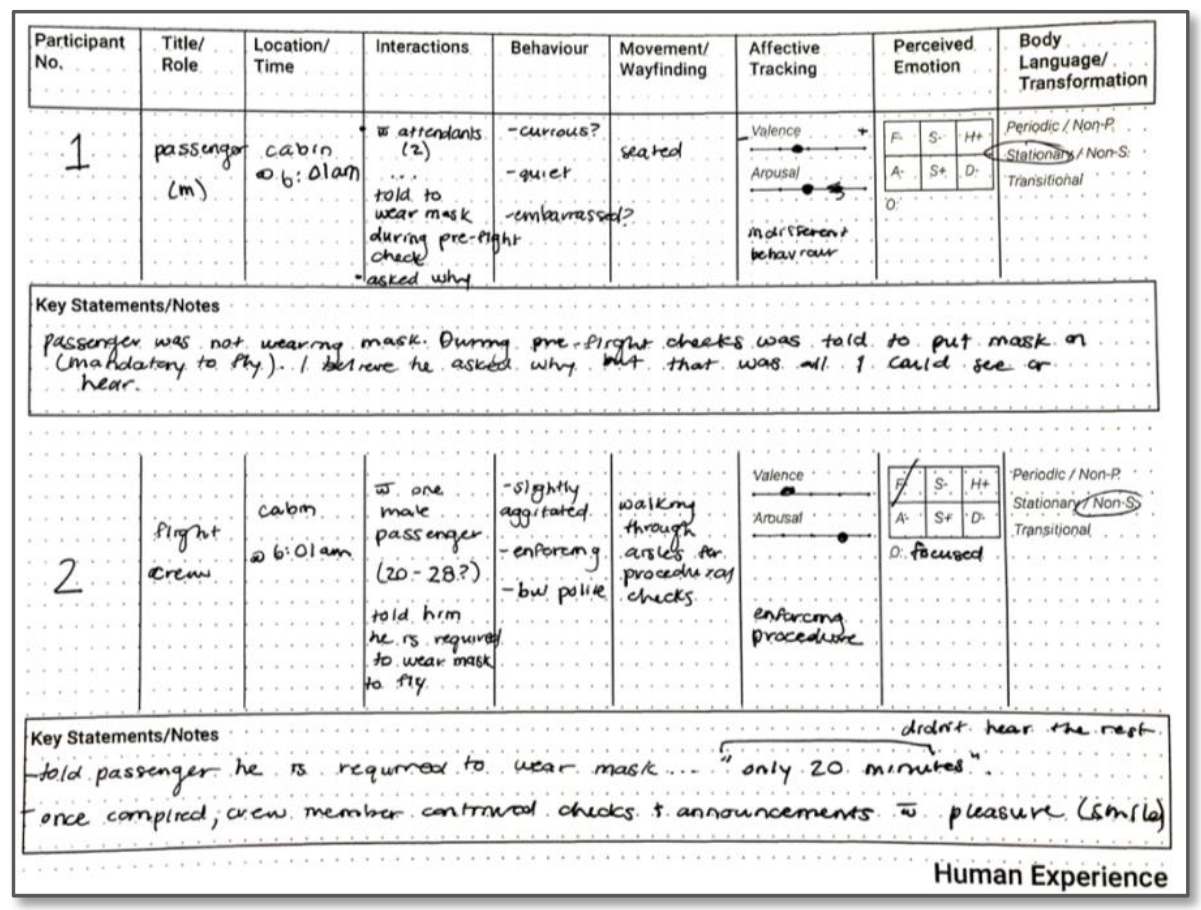

Figure 9. ObSERVATION WorkSHEET 1 - Human EXPERIENCE (CANADIAN AirPORT IN JULY, 2020)

A second chart was designed to record interactions, challenges or 'pain points' in the built environment (airport and cabin), related to COVID-19 IPAC measures. The purpose of this chart was to identify COVID-19 related processes, artefacts or systems in place, the location of measures, as well as key interactions or pain points noticed by the lead researcher. Figure 10 shows how this worksheet was organized to document these interactions. In practice, this chart did not get filled out 'on-site' because of the dynamic nature of the travel experience and difficulty with recording this information on a physical sheet. Instead, voice recordings were used to track her thoughts and experiences on her phone as she made her way through the airports and flights. These were later transcribed and used to fill out this chart after the travel experience. 


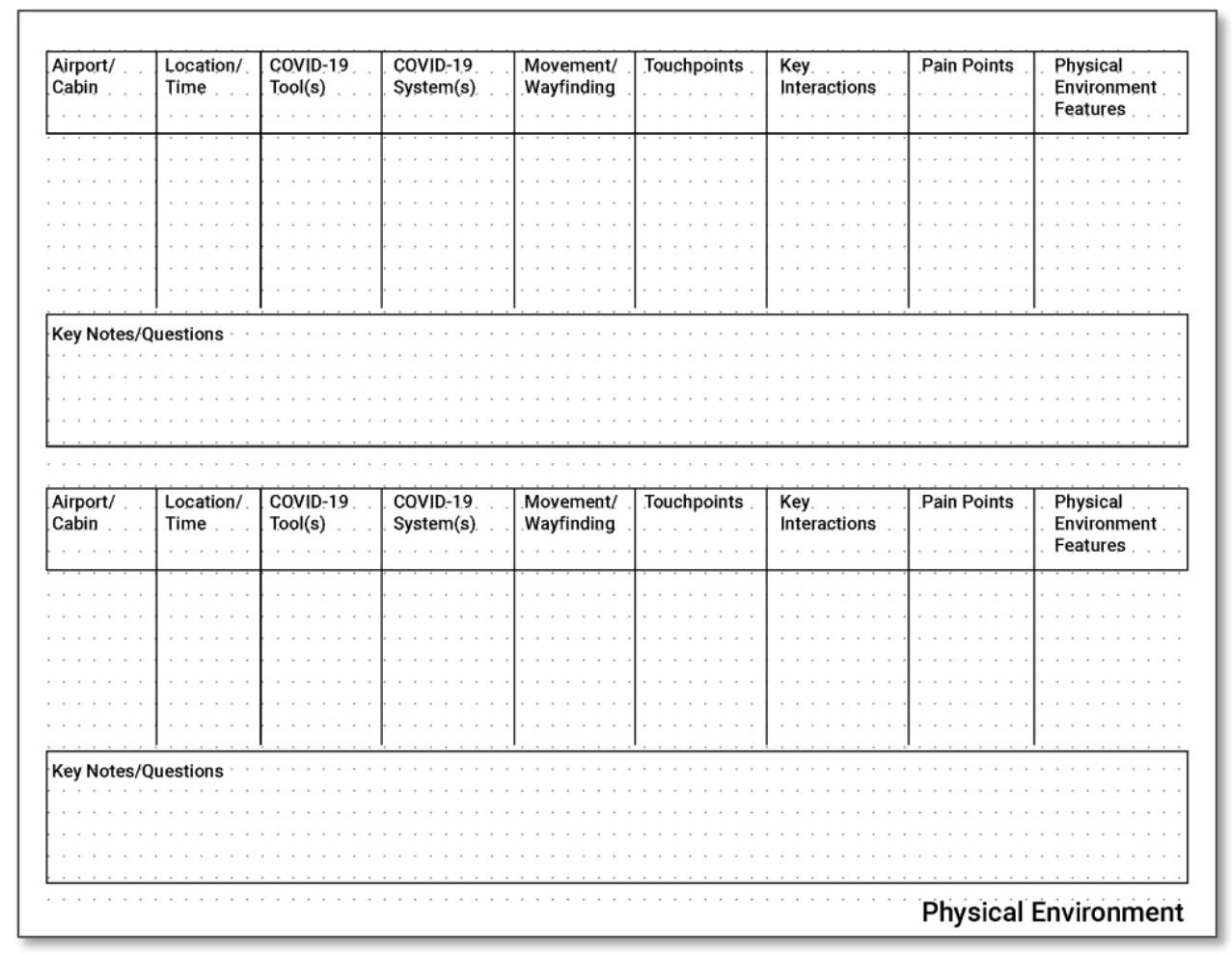

Figure 10. ObSERVATION Worksheet 2 - PhysicAl ENVIRONMENT

The final component of these workbooks were blank floor plans of a generic airport and cabin environment to document IPAC measures, along with key points of interest or pain points encountered through the travel experience. These worksheets provided a way to visually map the travel experience and highlight any key differences between the airport and cabin environments. The floorplans (see Figure 11 and 12) had a point grid to help document key areas in travel experience (check-in, baggage drop, security, gate, cabin). 


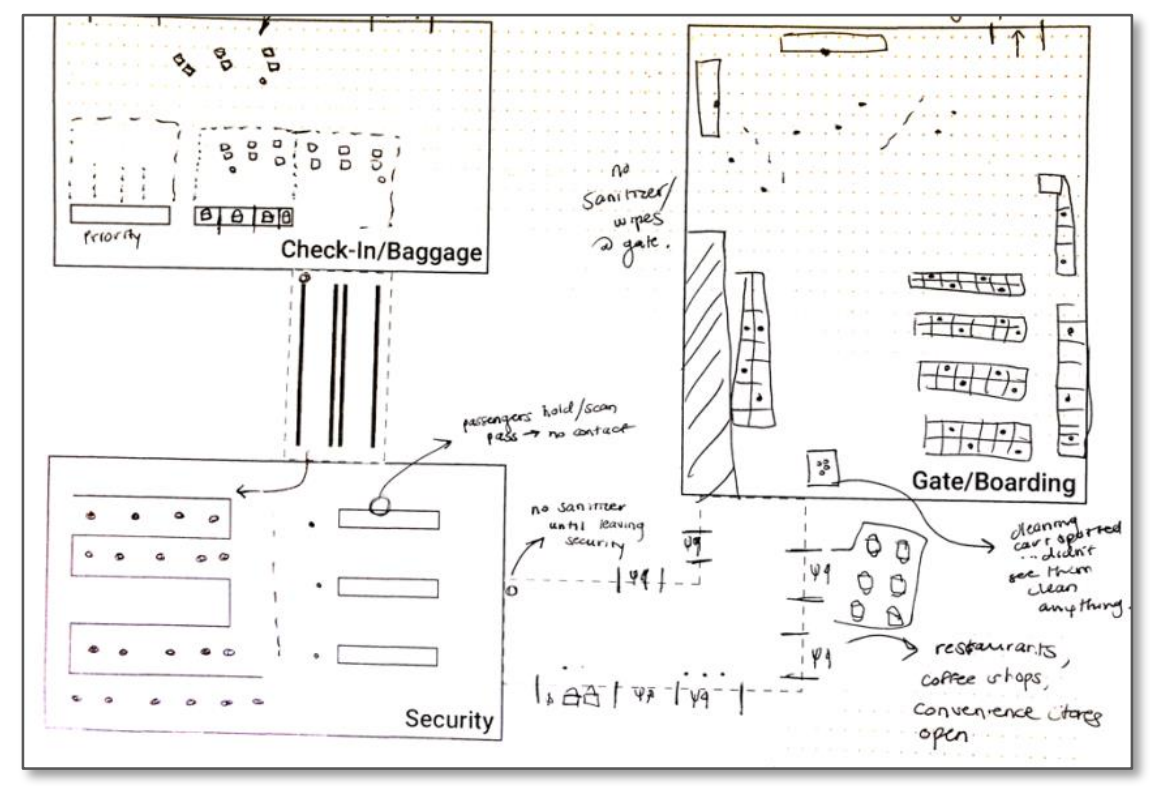

Figure 11. OBSERVATION WORKSHEET 3 - AirPORT MAPPING (CANADIAN AIRPORT IN August 2020)

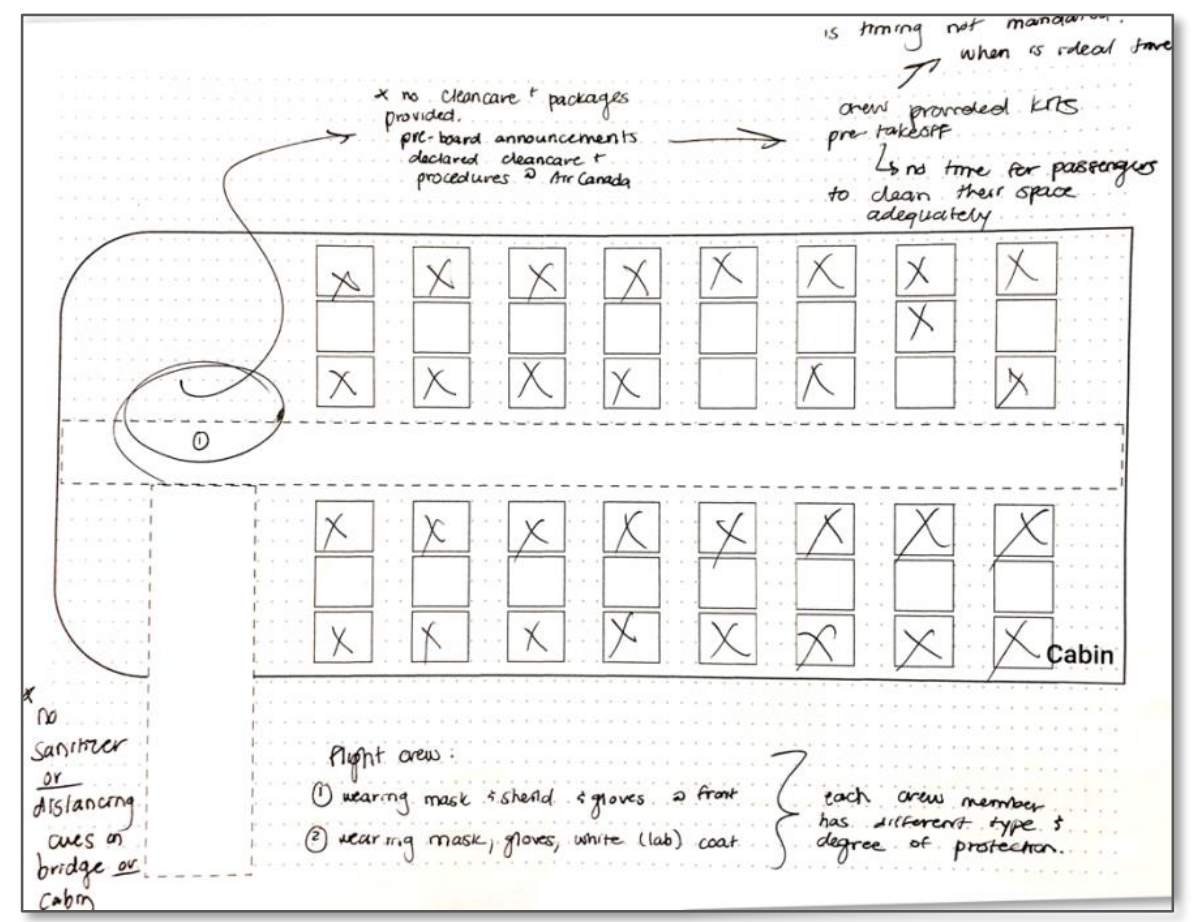

Figure 12. Observation WorksheEt 4 - CABIN MAPping (CANAdian Flight In July 2020) 
Three workbooks were printed and used to collect data about the lead researcher's travel experience and document the context within the 3 airport/airline settings. The workbooks were also used to pilot test the design of a travel diary in anticipation of using a similar tool with future participants during pandemic air travel conditions.

The data gathered from this method was combined into an affinity map to cluster similar elements and differences across the lead researcher's travel experience (Figure 13). The affinity map helped identify key questions, concerns, and areas to study further. The findings from the observational analysis were paired with themes discovered from the first-hand passenger accounts from the environmental scan of recent travelers. This provided a preliminary understanding of the current passenger experience during pandemic conditions and identified areas to explore further. Reflective notes about the use of the workbooks helped inform the design of the travel diary which would be used under potentially stressful circumstances.

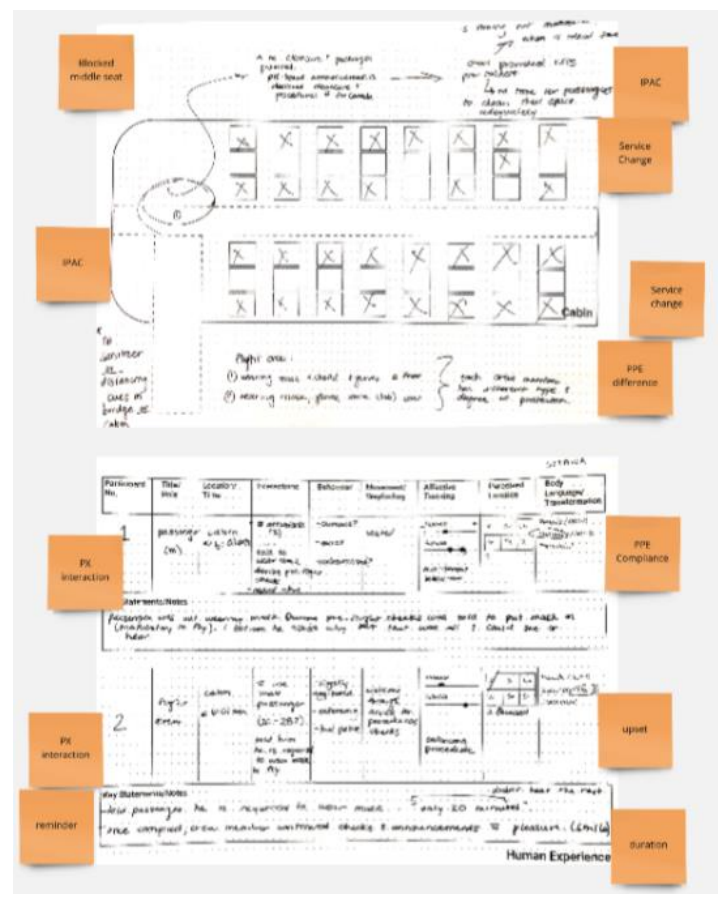

FIguRE 13. DATA ANALYSIS - OBSERVATIONAL ANALYSIS (2020) 


\subsection{Passenger Travel Diaries}

In this second method, a travel diary was designed to collect the reflections, experiences, and attitudes of passengers during or immediately after their travel experience during the pandemic. Because it could be a stressful flight experience, there was consideration around the design and ease of using the tool making use of graphical prompts to guide the participants. If passengers were uncomfortable completing this during the travel experience, they were offered the option to complete it immediately after traveling while the experience was still fresh in their minds.

\subsubsection{Participants}

Participants were included based on their plans to travel within the timeframe of December 2020 and February 2021. These dates were chosen with the hope of recruiting more passengers who may be traveling over the Christmas holidays or winter break in February. Another reason why this time frame was important was that quarantine requirements for travelers returning to Canada had been implemented, another measure potentially influencing travelers' perception of their experiences. Participants 18 and over were recruited through social media (Facebook), a travel agent's blog, along with emails sent through professional and personal contacts to pass on to others (snowballing), with the aim of recruiting a nonhomogeneous sample.

Seven participants were recruited but only five completed the diaries and three of these individuals participated in a follow-up interview. The age of participants involved in this study ranged between 22-59, with most participants falling into 20-29 age range (4 of the 5 participants). Participants for the travel diaries consisted of 1 male and 4 females. 


\subsubsection{Materials and Procedure}

The travel diaries were designed to collect real-time or recollected data about a passenger's entire travel experience during the pandemic. Travel diaries are a common method used to allow participants to self-report their activities, thoughts, feelings and general experiences over a specific period of time (Hanington \& Martin, 2012a; Prelipcean, Susilo, \& Gidófalvi, 2018). This method was chosen because it could be customized to suit participant's preferences in use (e.g., opting for a digital or printed medium, flexibility on when it used in their journey). The tool was intended to be simple and intuitive, leaving space for participants to write notes, sketch, take photos, or use other mediums to reflect on their experience as they saw fit. Participants were given the option of completing a digital (PDF) or printed version of the diary, with all of the participants opting to complete a digital version. The goal of this method was to obtain an in-depth and detailed reflection on traveling during the pandemic from participants to assess any commonalities or differences in the data across participants. Data collection was done until repeated patterns in stories emerged and we felt a level of confidence that the participant information was enough to frame how passenger comfort and experience had been impacted within pandemic travel conditions.

The diary was designed to allow people to document touchpoints and their perceived comfort at these points throughout the travel journey - starting from a planning and booking phase, followed by airport activities (check-in, security, pre-boarding), boarding (waiting to board, entering the bridge, finding one's seat), in-flight activities (overall comfort and experience, lavatory use, food and drink service, interactions with other people), up until their disembark (getting off the aircraft, collecting baggage and leaving the airport). Prompts were included in each section (major checkpoint) to guide participants and a Likert scale at the end of each section asked participants to rate their comfort. 
The diaries were intended to be convenient and easy to complete, especially within the context of the pandemic, where adding another activity or task to a potentially, already stressful experience, may add more stress. A digital travel diary was developed which participants could fill out on their smartphones and/or other devices but a printable option was also provided if preferred. Participants were also given the option of recording how they saw fit (e.g., voice recording, notes, photos, drawing). Participants were also given the choice to opt out of the strategy they chose if they felt uncomfortable and do a retrospective diary instead immediately after flying. According to Janssens, Bos, Rosmalen, Wichers, \& Riese (2018), "Electronic diaries are increasingly used in diverse disciplines to collect momentary data on experienced feelings, cognitions, behavior and social context in real life situations.” (p.1). The use of digital methods have been increasing in user experience studies for its convenience and accessibility for participants and to support the management and collection of data (Prelipcean et al., 2018).

In addition, the toolkit was evaluated on its ease of use during air travel, to help understand how tools such as this may be useful in future aviation studies and, more specifically, documenting experiences in heightened infectious or pandemic conditions. This part of the study asked participants to reflect on why and how they chose to complete the travel diary, the experience of adding another task while flying, and if it may have affected their perception of comfort while flying.

The data gathered from the travel diaries was put into a digital affinity map to highlight key words and themes that emerged from the participant notes, comfort level ratings and other types of input (Figure 14). Each diary was analyzed to identify prevalent themes, pain points and areas of design opportunity within a passenger's experience. For participants who consented to a follow-up interview, questions were developed after reviewing their diaries to 
probe the content more or clarify information. These 30-minute interviews gave participants the opportunity to elaborate or explain things specific to their experience and reflections. This information provided preliminary insight into how the passenger experience may have been influenced by COVID-19 measures throughout instances in their air travel journey.

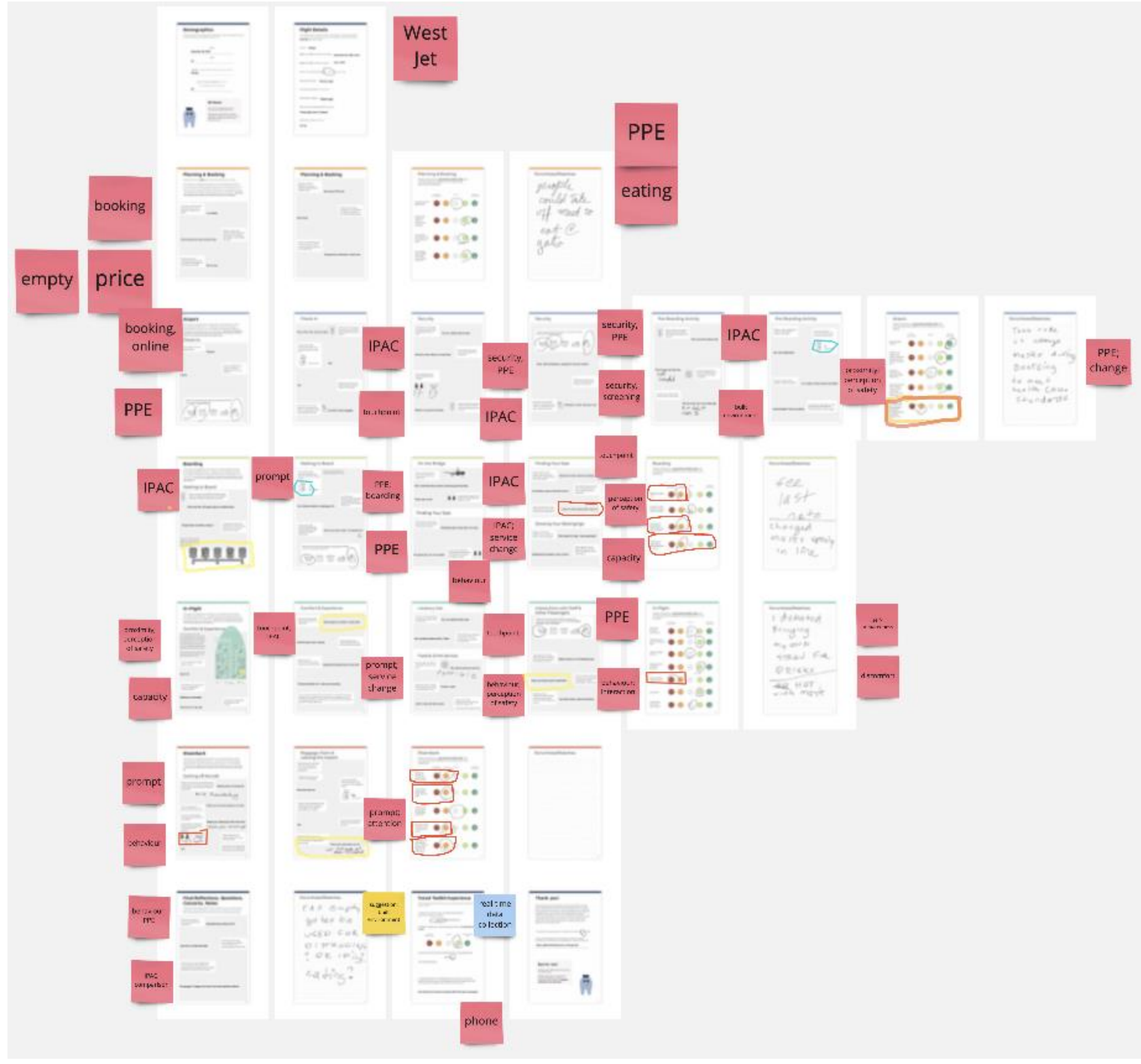

FIgURE 14. DATA ANALYSIS - TRAVEL DiARY 


\subsection{Recent Flyer Interviews}

Interviews were conducted to collect a broader level of information from recent flyers who were interested in discussing their travel diary and passengers that did not participate in the travel diary. The interviews offered insight into passengers that had recently travelled.

\subsubsection{Participants}

For this final method, participants were recruited if they have travelled by air between July 2020 and February 2021 and through the same channels as the Travel Diaries (see section 3.3.1). A total of 14 participants were recruited for this method with 3 of these individuals having completed the travel diary method. Participants consisted of 7 males and 4 females between 22-69, with most participants falling into 20-29 (7 participants), followed by 30-39 age range (4 participants) and finally 40-69 age range (3 participants).

\subsubsection{Materials and Procedure}

Considering the tenuous conditions around COVID-19 and uncertainty about whether people would be flying throughout the testing period, we supported the previous methods used in the study with interviews so that we could capture additional data bearing in mind that changing travel restrictions might affect the ability to collect travel diaries. Indeed, between July 2020 and February 2021, several changes to air travel and tourism restricted or discouraged traveling, which made implementing the travel diary more challenging. The interviews were a way to increase the saturation of the dataset and mitigate the risks to our study due to flight shutdowns.

A main focus of these interviews was to collect reflections from recent flyers were about their experiences related to various elements or factors in the design of systems. Based on the exploratory nature of this study, the semi-structured format of the interviews allowed 
for open conversations with participants and flexible topics to explore (Hanington \& Martin, 2012b). Throughout the interviews, it was important to identify key pain points, interactions, attitudes, and behaviours described by the passengers throughout their entire travel experience, as a way to provide insight on the current context of air travel. Galletta (2013) notes that semi-structured interviews are useful in "eliciting from the participant the meaning he or she gives to the focus of the study and capturing that meaning as accurately as possible". The data from the interviews allowed us to compare each participant's experience what they found positive/negative, their challenges, and finally, opportunities to support air travel during pandemic conditions.

Semi-structured 30-minute interviews were conducted with recent flyers virtually through a video-conferencing platform (Zoom) in January and February 2021. An interview guide (see Appendix F) offered participants the opportunity to explore and prepare for the interview with items they felt may require attention and/or more detail (Clifford, Cope, Gillespie, \& French, 2016). Each session started with asking participants to provide details about the date(s) they travelled, which airline(s) were used, and the destinations. After this, participants were asked to go through their most recent air travel experience, providing details about each major check point (e.g., check-in, security, on-board), while noting anything that stood out to them as it related to COVID-19 or that may have been different compared to flight experience before the pandemic. Throughout the interview, I asked questions to probe specific aspects about the participant's passenger experience to help identify differences in travel processes, the built environment, IPAC measures, social interactions, positive encounters or experiences, and potential pain points or challenges. 
The data from the interviews was analyzed manually through a 'bottom-up' approach (letting codes emerge freely through a review of the data without a codebook or using predefined categories) followed by a 'top-down' manual analysis (e.g., selecting UX categories of interest and mapping the codes to the categories). This process would serve to form both a thematic and content analysis. This involved developing codes that were later mapped to the UX categories of interest (e.g., booking or screening or local requirements may be mapped to the UX category of social) and new codes that emerged from iterative cycles of reviewing the data (e.g., changes to service) which then helped facilitate the development of core themes. The method of descriptive coding was used to help categorize and index the participant data for further analysis. Descriptive coding is used to group codes together to detect patterns of frequency and interrelationship within the participant data (Saldaña, 2011). This strategy was further supported by a content analysis to identify the prevalence of common words and/or codes that emerged from the data. The data underwent a series of stages of coding to identify themes that might best represent how the passenger experience of our participants had been shaped by the pandemic. Figure 15 outlines the analysis process for the interview data.

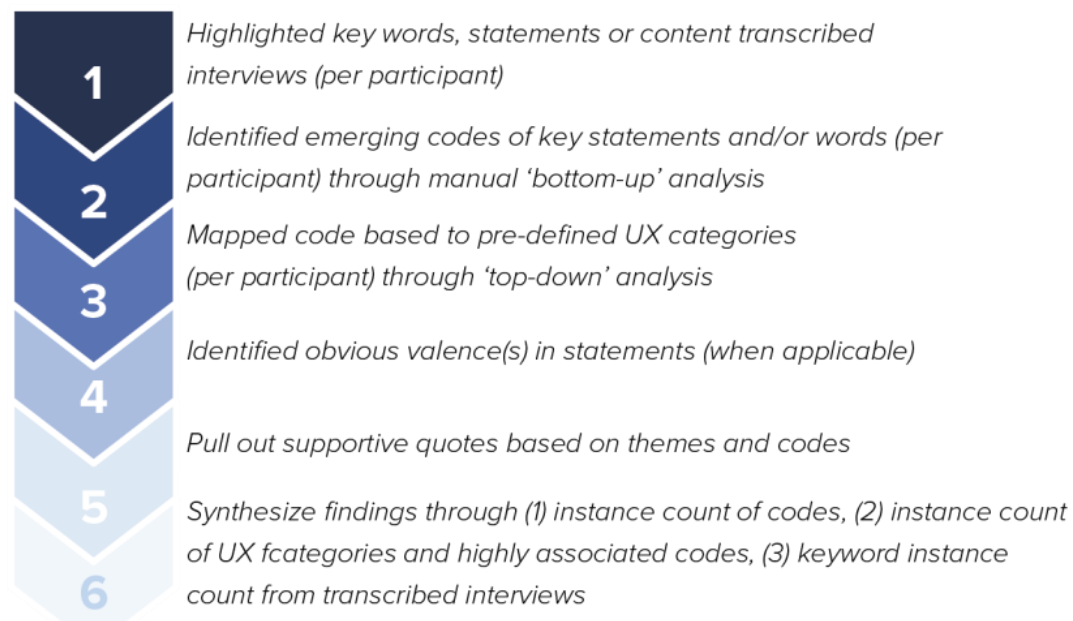

Figure 15. INTERVIEW ANALYSIS PROCESS 
The first step in the analysis involved a first pass of the data - highlighting key statements, words, or content in the transcriptions of each interview. This content was highlighted for further analysis in a second pass to attune to what was said by each participant after reviewing the entire text. The second round of analysis included coding the data according to pre-defined categories of interest based on key statements and content pulled from the transcriptions, based on what we found was emerging (repeating) when reading through each participant's data. As an example, some of these initial codes included the following: booking, interaction, proximity, built environment, and service change. These codes were then mapped to categories that were based on the user experience (UX) framework outlined by Preece, Sharp and Rogers (2015). Specific categories were developed from certain aspects of this framework and were chosen based on their relevance to what appeared to be emerging within the participant data in the second round of analysis. An example of this is the statement "I think there's a lot of people that judge and shun people who choose to travel and I think that is a major contributor to people our age especially (P4)", which was given the codes perception and travel (reasons for and barriers to), which was finally categorized as social according to the UX categories. This example shows the layers of analysis each key statement or piece of content went through within this process.

Within the UX framework, there are eleven total categories to evaluate user experience. The four categories that were not used include functionality, usability, aesthetics, sensual appeal, and sociocultural identity. The categories chosen were content, emotional appeal, social capital, action, people's expectations, narrative, and space and time, as these related more strongly to what we saw emerging in the data and of higher frequency than the others. While there are benefits of including more 
UX categories to evaluate different aspects of the data, we felt the chosen 7 categories could be used to synthesize our findings more comprehensively. Future work could involve mapping our codes to other UX categories. The 7 categories of interest that were applied to the interview content in the next round of data review are outlined below:

Content: relates to a participant's understanding of a particular subject, meaning, or topic.

Emotional Appeal: shows how emotions (e.g., happiness, sadness, frustration, etc.) may be intertwined within a situation or experience.

Social Capital: how social resources can develop and be maintained through social norms and shared values.

Action: related to the process of doing something, typically to achieve an aim or goal.

People's Expectations: includes mental models, interpretations, or a participant's representation of how things work or unfold.

Narrative: the representation or composition of experience, how a situation unfolds.

Space and Time: refers to the space and time which experiences take place and their effect upon those experiences, including the value of public vs. private space and perception of time passing.

TABLE 6 CATEgORIES OF INTEREST - UsER EXPERIENCE CONSIDERATIONS (PREECE, SHARP \& ROGERS, 2015)

Once the codes were mapped to the categories of the UX framework, valence themes (positive or negative) were identified where applicable. These valences helped further characterize the codes whether these instances of experiences were positive or negative, and eventually led to higher order themes. Following this qualitative analysis, the codes were scanned to tabulate an instance count of each code, and to quantify the codes that were most associated with each UX framework category. An instance count of recurring keywords or short phrases from the data was also performed to see if the nature of repetition occurred in the raw data. This resulted in a content analysis of the most prevalent codes and UX categories that also helped identify the major themes or findings from this study. Both the content and 
thematic analysis served to answer the research question 'How bas the passenger experience been shaped by changes made to air travel because of the COVID-19 pandemic??

\subsection{Summary of Methods}

This multi-method study comprised of three methods to answer the following questions. Figure 16 outlines our process of framing the experiences of passengers through each method and its specific focus.

- Method 1: What is it like to travel by air during COVID-19?

- Method 2: How do passengers travelling by air during COVID-19 characterize their experience? How has their comfort in flying been impacted?

- Method 3: How do passengers who have recently travelled by air during COVID-19 characterize their experience? What was important to them in their recollections?

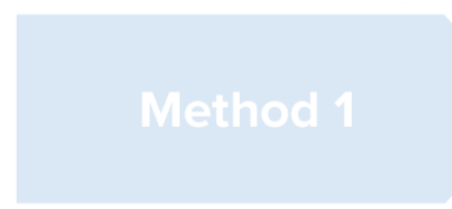

Observational Analysis \& Reflective Journaling

"What is it like to travel by air during COVID-19?"

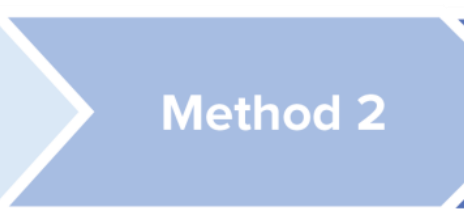

In-SItu Travel Diaries

"How do passengers travelling by air during COVID-19 characterize their experience? How has their comfort in flying been impacted?"

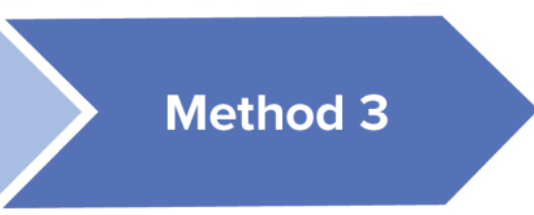

Recent Flyer Interviews

How do passengers who have recently travelled by air during COVID-19 characterize their experience? What was important to them in their recollections?"

Figure 16. Multi-Method Study Overview

\section{Chapter 4: Findings}

The following chapter outlines our results and analysis of each method - observational analysis and reflective journaling, in-situ travel diaries, and recent flyer interviews. The findings from each method were synthesized into themes, helping us better frame our understanding 
of passenger experiences while travelling during the pandemic. We close this chapter by exploring how these themes relate to different levels within the system of air travel design.

\subsection{Overview}

The COVID-19 pandemic forced the aviation industry to take immediate actions to protect travellers, service and crew members within this new context of air travel. The purpose of this study was to document and reveal a snapshot of factors which may be influencing passenger experience during this challenging time. We have helped answer the overall study question 'How has the passenger experience been shaped by changes made to air travel due to the COVID19 pandemic? through:

- an observational analysis and a self-study of travel experience during the pandemic;

- an examination of real-world pandemic air travel data collected from a group of passengers through travel diaries and follow-up interviews;

- discussions with air travel passengers that had recently flown during the pandemic;

- analysing and synthesizing the data through a thematic and content analysis; and

- mapping the themes generated from this analysis to systemic factors or layers of experience which, we suggest, be studied further in future air travel design studies.

The following methods answer the question 'What is it like to travel by air during the COVID-19 pandemic? at three different levels - the researcher's experience, the passengers documenting their experience while travelling, and then passengers' recounting their travel experience. This study revealed considerations to support passenger experience during pandemic travel, considerations that we feel should be examined more closely through the collaborative efforts of designers, human factors specialists and air travel researchers and developers. 


\subsection{Observation and Reflective Journaling}

In this first method, the lead researcher travelled by air, conducting observations and journaling three flights through three Canadian airports between July and August 2020. The process helped us develop further questions about the design of air travel service during pandemic conditions, the documentation of pandemic-related differences across the various flights and destinations, the documentation of potential pain points, and identifying opportunities for more detailed study in the subsequent methods. A major difference that occurred within these three flights was related to the time of travel. Between July and August 2020, flight capacity went from reduced seating and a blocked middle row or adjacent seat (July) to full capacity (August) in the cabin environment. The difference in cabin environment played a role in the service, processes, and the lead researcher's travel experience. Table 7 provides a summary of the key differences and similarities that resulted based on the difference in flight capacity.

\section{Time of Travel Comparison Chart}

\begin{tabular}{|l|cl|}
\hline Differences & Similarities \\
\hline $\begin{array}{l}\text { There was reduced cabin environment at } \\
\text { the beginning of travel versus a full cabin } \\
\text { environment at the end of the trip. }\end{array}$ & $\bullet \begin{array}{l}\text { (Air Courier 1) CleanCare+ kit was given } \\
\text { upon boarding or entering the airplane. } \\
\begin{array}{l}\text { Flight capacity and proximity to other } \\
\text { passengers increased over the travel } \\
\text { period. }\end{array}\end{array}$ & $\begin{array}{l}\text { PPE (face coverings) were worn by crew } \\
\text { and passengers. }\end{array}$ \\
\end{tabular}

\section{TABLE 7 TIME OF TRAVEL COMPARISON CHART}

The researcher also determined differences in the processes and management of COVID19 across different environments within the airports and cabins of each flight taken from different provinces. Some of the key differences and similarities in the airports and flights visited are 
shown in Table 8. A more explicit analysis is provided in Appendix G, which compares reflections taken about the built environment (airport and cabin) at each airport visited.

After reviewing the worksheets and reflections from the journal, different challenges or pain points and potential areas for further design study emerged. These findings were used to direct the development of subsequent methods and further scope the study. A more comprehensive list of findings and takeaways from this stage can be found in Appendix $\mathrm{H}$.

\begin{tabular}{|c|l|}
\hline \multicolumn{2}{|l|}{ Place of Travel Comparison Chart } \\
\hline Differences & Similarities \\
\hline$\bullet \quad \begin{array}{l}\text { There was minimal to no COVID-19 } \\
\text { specific information or hand sanitizers } \\
\text { found at the (Airport B) boarding area or } \\
\text { surrounding airport environment. }\end{array}$ & $\begin{array}{l}\text { Special boarding passengers could not } \\
\text { use kiosks to check-in, creating an } \\
\text { additional touchpoint. }\end{array}$ \\
$\begin{array}{l}\text { There were differences in the type of } \\
\text { PPE worn by crew in the cabin(s). } \\
\text { There were differences in the } \\
\text { announcements played upon arrival at } \\
\text { each province. }\end{array}$ & $\begin{array}{l}\text { Kiosks were not cleaned after each use. } \\
\text { There was COVID-19 signage and IPAC } \\
\text { measures in place in (Airport A) and } \\
\text { (Airport C). Signage and IPAC measures } \\
\text { were less apparent in (Airport B). } \\
\text { No COVID-19 signage seen in the } \\
\text { cabin(s). }\end{array}$ \\
\hline
\end{tabular}

TABLE 8 PLACE OF TRAVEL COMPARISON CHART

This first method outlined a first-hand experience of current air travel, the identification of potential pain points, design opportunities and questions to probe with participants in subsequent methods. Apart from having passengers document or recount their overall experience, the findings (Table 9) pointed to the need to inquire specifically about whether passengers experienced different IPAC measures across airports and cabins, and if so, what they thought about those differences. Looking at potential differences in IPAC measures being used by airports and airlines may help identify how what appears to be 'custom' or 'site-specific' approaches may impact passenger experience, positively or negatively, and provide further insight on where future design studies might focus. 


\section{Pain Points/Potential for Further Design Study \& Questions to Focus Study}

\section{Pain Points/Opportunities}

There are inconsistencies in the type and/or amount of IPAC measures in place at different airports (e.g., signs, distancing cues or partitions, access to hand sanitizers).

Information design could better convey COVID-19 information to passengers via airport and in-flight announcements.

Information about local COVID-19 measures and/or requirements should be made clear upon arrival, and easily accessible prior to an individual's flight.

The physical environment in the airport and cabin could be designed to reduce crowding and the amount of physical touchpoints in a passenger's journey.

\section{Questions}

Why are there inconsistencies in the access to hand sanitizers at different points in the passengers' experience (e.g., check-in vs. security vs. gate area)?

Is there a reason there are differences in the PPE worn by airport employees and cabin crew? Would standardizing this impact a passengers' experience or comfort?

Why are the airline processes and announcements different on each flight, when flying with the same courier?

TABLE 9 PAIN POINTS/POTENTIAL FOR DESIGN OPPORTUNITY \& QUESTIONS FROM METHOD 1

\subsection{Passenger Travel Diaries}

After we collected the 5 travel diaries, the data was analyzed and coded bottom-up, to identify potential patterns and emerging themes of interest. The codes that emerged were then mapped to categories that were based on the UX framework outlined by Preece, Sharp, and Rogers (2015). Twenty-one codes emerged from the analysis of participant comments from the diaries (see Appendix I for the list of codes and related quotes). Based on the frequency of these codes, we developed four preliminary themes related to passenger experience during the pandemic.

The first theme that emerged from the diaries was Passengers' Overall and Continued Preoccupation with Safety as they travelled. Some of the safety factors that preoccupied passengers 
were the use of and consistency of PPE worn by other passengers and crew, the IPAC measures in place, the cleaning and sanitation of high-traffic areas in the airport and cabin, and how other passengers were perceived to be taking their own safety measures (or not). Passengers expressed a higher sense of safety when they saw clear and consistent IPAC measures in place in the airport and cabin (e.g., cleaning of surfaces, clear information on signage), mandatory testing and screening before boarding, and with other passengers following similar measures to themselves (e.g., wearing PPE, cleaning their personal space, keeping distance from other passengers). Passengers expressed not feeling safe mainly due to other passengers removing their masks for an extended time after eating or drinking, and when the physical environment of the airport or cabin did not allow for adequate distancing from other passengers. Box 1 provides a few supportive quotes within this theme.

"No one is acting irrationally that I can tell, not too scared. All are obeying regulations and being safe." (P8)

"I felt safe in the knowledge everyone in the airport had to have a negative test result." (P7)

"I mean, airports are always known as germy places, so I think the main thing was just being EVEN MORE conscious of washing my hands and wiping down hard bags and such." (P8)

BOX 1 PASSENGERS' OVERALL AND CONTINUAL PREOCCUPATION WITH $S A F E T Y$,

The second theme that emerged from the diaries was Passengers' Comfort with Cabin Capacity, which relates to a passenger's proximity to other passengers and/or crew in the cabin, the overall capacity of the cabin, and how the behaviours or actions of other passengers and crew may influence factors related to passenger comfort. The findings suggest that although many participants felt comfortable in what protective measures they personally were doing, they felt discomfort in sitting close to other passengers in an enclosed space (Box 2).

\footnotetext{
"I was comfortable, just trying to keep my distance." (P16)
}

"People are mostly distancing, but kind of like getting on, they're a bit crowded in the aisles. Touchbased: grabbing bags from overhead bins, mostly.” (P8) 


\begin{tabular}{|} 
"When I was sitting next to someone I wasn't as comfortable, so I just tried to lean into the \\
window/face that direction." (P16) \\
"In general, the surprising willingness of people to travel during this time. I also found depending on the \\
city people acted different with regulations. Seemed like the farther West I went the more lax people became." \\
(P16) \\
"People sitting too close." (P15) \\
BOX 2 PASSENGERS'COMFORT WITH CABIN CAPACITY
\end{tabular}

The third theme that emerged from the travel diaries was Passengers' Experiences with Change in Services and COVID-19 Specific Practices. Some of the factors identified within this theme include their experience with and views on screening and testing procedures, the content of the announcements made in the airport and cabin, and the increased cleaning and sanitation measures in place within the cabin (i.e., providing passengers with a disinfectant wipe). Passengers expressed a feeling of uncertainty in knowing whether touchpoints (e.g., security bins) were being cleaned enough or at all. This theme suggests an importance in how service and the management of the organization or operations could be designed to better support passenger experiences. Box 3 below provides examples of participant quotes that support this theme.

$\begin{array}{r}\text { "Flight attendants are very good with COVID compliance orders but are still going about their usual } \\ \text { business." (P8) }\end{array}$
$\begin{array}{r}\text { Staff are all wearing their PPE and maintaining distance where possible (not between each other but } \\ \text { with customers)." (P8) }\end{array}$
They gave us little bags with water, a cookie, and hand sanitizer." (P7)
"Yes, the usual alerts were present, reminding people to avoid flying for non-essential reasons and to
make sure you were adhering to COVID-19 regulations if you had to fly (i.e., mask at all times, separate where
possible)." (P8)
A lot of touching of security bins and I have to wonder how often they actually wash those." (P16)
BOX 3 PASSENGERS'EXPERIENCE WITH CHANGE IN SERVICES AND
COVID-19 SPECIFIC PRACTICES

A fourth theme which emerged from the diaries highlighted the Importance of Passengers' Feeling Prepared which pertains to a passenger's perception of safety or security based on their 
own actions and behaviours. The comfort literature that was reviewed outlined that control is intrinsic to an individual's comfort, suggesting that control over their own actions and behaviours may lead to increased comfort in flying. Factors identified in this theme related to passengers being prepared for different local restrictions across provinces, and cleaning of their personal space in the cabin. Some passengers noted they felt unprepared in knowing local requirements and restrictions resulting from their lack of attention to information or announcements when boarding and taking off. This suggests that information could be better relayed to passengers at different points in their process, to reduce uncertainty. This differs from the first theme discussed, because codes in this theme related to the passenger seeking or finding comfort in their own practices, rather than those influenced by external factors (e.g., other passengers, crew, environment, etc.) (see Box 4 for examples from participants).

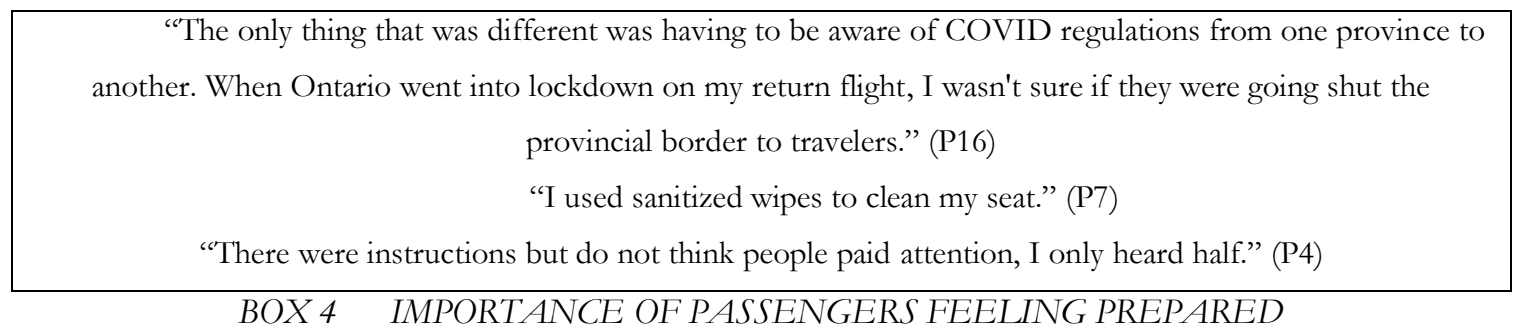

Another level of analysis compared the data, codes and these themes to Roger et al.'s (2015) User Experience framework. This top-down approach involved mapping each code and key statements from participants to be organized within selected UX categories. The UX categories were chosen based on the frequency of codes that began to fall within each key category. The results of this analysis show that Narrative (145), Action (25), Space and Time (21), Content (15), People's Expectations (12), Emotional (9), and Social (7) were the most prominent UX categories related to the participant data. It is worth mentioning that although Narrative had the highest prevalence in the data, this may be a result of the travel diary being constructed 
through a narrative structure, a structure which was intentional to help participants reflect on their experience in real-time. Participant statements under Narrative related to how people interpreted their experiences and the context of their travel process (e.g., going through different check points, recalling interactions with crew), without stating a specific action or experience that could be linked under one of the other categories. A major takeaway from the Action category is passengers' attention to performing specific actions that support them during travel (e.g., filling out a contact tracing app). Within Space and Time passengers focused on the capacity of the physical environment and the value of public versus personal space in the airport and cabin. There were no statements about duration or time passing within the travel diaries. Statements under Content identified some of the underlying situations that may have shaped their experiences (e.g., what local restrictions were in place, the amount of signage and COVID-19 specific information in the airport). Some quotes could be mapped to more than one UX category which we anticipated as they may cross dimensions in user experience. Table 10 shows a summary of the UX categories that emerged frequently in the data from the travel diary supported by participant quotes.

\section{UX Theme Instance Count - Travel Diaries}

Narrative (145)

The representation or composition of an experience, or how it unfolds.

“There were instructions but do not think people paid attention, I only heard half." (P4)

"Yes, the usual alerts were present, reminding people to avoid flying for non-essential reasons and to make sure you were adhering to COVID-19 regulations if you had to fly (i.e., mask at all times, separate where possible)." (P4)

"Flight attendants are very good with COVID compliance orders but are still going about their usual business." (P8)

Action (25)

The process of doing something, typically to achieve an aim or goal.

“[...] had to fill out ArriveCAN app for entry into Canada. Also required to show negative test.” (P7) 
“Touched surface with paper towel." (P4)

"Hand over your passport and boarding pass, then stand back and remove your mask temporarily to show your face for your ID.” (P8)

"I used sanitized wipes to clean my seat." (P7)

\section{Space and Time (21)}

The space and time of which experiences take place and their effect upon those experiences, including the value of public vs. private space and perception of time passing.

"Not at all. Once you're in the airplane everyone is packed in there." (P16)

“No, people aren't really distancing in the aisles as much. A bit, but definitely closer than 6ft apart.” (P8)

"People sitting too close." (P15)

\section{Content (15)}

A participant's understanding of a particular subject, meaning or topic.

"Coming from out-of-country/province, there were reminders to isolate for two weeks." (P9)

"LOTS of signs reminding people to maintain distance and wear a mask at all times...One at every entrance, at check-in and baggage desks." (P8)

People's Expectations (12)

Includes mental models, interpretations, or a participant's representation of how things work or unfold.

"I felt it was safer than I expected." (P7)

"I mean, airports are always known as germy places, so I think the main thing was just being EVEN MORE conscious of washing my hands and wiping down hard bags and such.” (P8)

\section{Emotional (9)}

Shows how emotions may be intertwined within a situation or experience.

"Not very comfortable but comfortable enough to risk flying." (P16)

"When I was sitting next to someone I wasn't as comfortable, so I just tried to lean into the window/face that direction.” (P16)

\section{Social (7)}

How social resources can be developed or maintained through social norms and shared values.

"When I was sitting next to someone I wasn't as comfortable, so I just tried to lean into the window/face that direction.” (P16)

\section{TABLE 10 UX CATEGORY PREVALENCE FROM TRAVEL DIARIES}


The final level of analysis in the travel diary study looked at participants' perceived levels of comfort at each major checkpoint in their travel experience. Figure 17 shows participants felt more comfortable during the planning and booking processes, with higher levels of discomfort in boarding, in-flight, and disembarking processes. The highest levels of discomfort in the boarding process related to waiting in the gate area, and proximity to other passengers while waiting in line to board and proximity within the cabin. Within the cabin, the highest levels of discomfort reported by participants involved using the lavatory, access to food and drink services on board, removing one's face coverings to eat or drink, proximity to other passengers in the cabin, and the cleanliness of a passenger's seating area. With regards to factors influencing comfort upon arriving at the destination, participants reported concerns around access to COVID-19 related information upon arrival, proximity to other passengers when leaving the cabin, access to hand sanitizers and/or disinfectant wipes upon boarding, availability of information about distancing or local requirements for isolation at the destination, and proximity to other passengers at baggage collection.

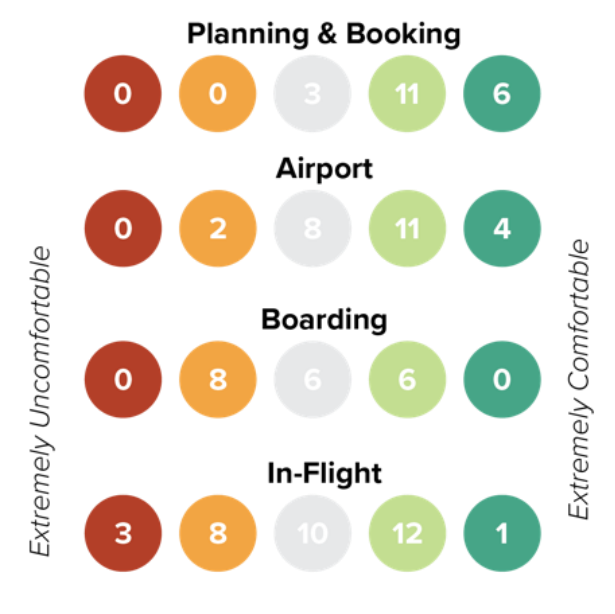

Arrival \& Disembark

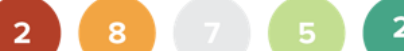

Figure 17. COMFort COMPARISON CHART From Travel Diaries 


\subsection{Recent Flyer Interviews}

After conducting 14 interviews with participants who travelled between July 2020 and February 2021, the data was coded to generate themes followed by mapping the codes to categories of interest from Rogers et al.'s (2015) UX framework. This analysis offered a deeper and broader depth of understanding into what factors may be influencing passenger experience during the COVID-19 pandemic. The first stage of analysis followed a 'bottomup' approach whereby the researcher assigned codes to the data. Forty-one codes were assigned to the interview data. The codes were organized based on their prevalence (instance count), including examples of quotes from participants that support each code. Table 11 provides a summary of this analysis illustrated with participant quotes, but for a more thorough review of these results see Appendix J. The table in Appendix J shows that PPE (124), Perception of Safety (76), Capacity (67), IPAC (63), and Prompt (60) were the top 5 most frequently assigned codes in this first round of coding. The prevalence of these codes demonstrates that a major focus of participants was on their perception of safety based on the PPE being used, the IPAC measures in place, the capacity of the airport and cabin environments, as well as prompts used to increase awareness of COVID-19 specific information. While there were many other codes assigned within this phase of the analysis, these prevalence of specific codes over others suggests there may be a hierarchical structure in passenger experience, regarding factors that dominate their perception of safety and/or comfort in flying within the pandemic.

Further analysis (Table 11, Appendix J) illustrates the valence associated with selected quotes from the participants' data, with predominantly neutral comments, followed by negative associations attributed to the codes PPE (4), Local Requirements (2), Built Environment (2), Booking (2), Testing (2), and Media (1), shown in red text within the table. A total of 20 
negative valences were counted in the participant interview data, most of which related to a general state of uncertainty or not knowing how to prepare for pandemic travel, the local requirements or testing processes, but also how the media had negatively framed traveling during the pandemic. There were a few positive associations, most of which related to the codes perception of safety (2), PPE (2), capacity (1), and proximity (1), shown in green within the table (Appendix J). These positive associations were mostly related to seeing other people wearing PPE, mask relief, and reduced cabin and airport capacity. This analysis revealed factors that may be contributing to a potentially negative air travel experience during the pandemic, some positive qualities, and opportunities to develop a better understanding of these areas to design alternatives.

These codes helped shape our understanding of the different factors and considerations that emerged and that were prominent within participant experiences flying throughout the pandemic, at different points in space and time during their journey, and through different provinces and/or countries. Following the identification of these codes, we grouped them into seven major themes related to passenger experience. These themes are outlined below, with supportive quotes provided for each theme represented in Table 11.

1. Passengers' Overall and Continual Preoccupation with Safety was an overarching theme, which encompasses the broader level of passenger's sense of safety through the services, processes, and operations in place in the airport and cabin. This includes various elements of the travel experience such as the use of PPE, IPAC procedures, cleaning and sanitation of touchpoints, perception of behaviours and actions from other passengers, expectations of the travel experience, and lastly, access to information about the travel process and COVID-19 specific information. Participant statements related to this theme were focused on the overall safety of the system they were experiencing - their own actions and behaviours, interactions with other passengers, 
proximity to others in the cabin and airport, testing and screening processes, and the use of PPE.

2. Passengers' Concerns with PPE Compliance and Consistency was another major theme identified in passengers' narratives, but more specific compared to the first theme. It relates to the use of, and consistency of PPE use such as face coverings, masks, gloves, and other protective gear. The prevalence of codes within this theme related to the PPE worn by the participant, other passengers, and airport staff and flight crew. Codes associated to this theme include IPAC, PPE, and Service. Some of the most prominent concerns within this theme were focused on other passengers removing their masks for relief, rather than for essential purposes like eating or drinking, as well as inconsistencies in the type of PPE worn or expected to be worn by passengers. This suggests a need to evaluate how mask requirements can be clearly outlined to passengers, while also looking into how passengers may be able to find relief from their PPE in a way that does not compromise the perceived safety or comfort of other passengers.

3. Passengers' Comfort with Capacity relates specifically to how the airport and cabin environment played a role in a passenger's perception of safety when near other passengers, airport staff and crew. Most of the statements within this theme relate to the cabin, with a few participants voicing concern over the use of space in the security and gate areas in the airport. These findings suggest that more thought should be put into proxemics in the design of currently crowded or congested areas to reduce health risks and anxiety.

4. Passengers'Awareness of COVID-19 Operations relates to specific practices related to testing and screening procedures, crew and airport staff procedures and actions (e.g., cleaning, providing protective measures), and practices in air travel check-points (e.g., security and check-in). Passengers focused on the process of going through each check-point and their attention to COVID-19 specific procedures and/or operations that influenced their experience. The prevalence of these codes suggests an importance in how the design and continuum of service points and the management of the 
organization or operations at different points and levels in air travel may impact a passenger's perception of their experience.

5. Passengers' Sense of Self-preparedness and Responsibility relates to participants' comfort in their own personal research, preparation, and actions ahead of and during their travel experiences. Key statements within this theme related to booking processes, the use of PPE, cleaning and sanitation, along with feeling a sense of responsibility to do their part to prevent the spread of infection during their travels. Passengers noted how the planning and booking phases were more intensive as they had to prepare for local requirements at their destination and potential changes to these after booking. Passenger statements also focused on having a perceived sense of shared responsibility among the other passengers and crew to practice safety and distancing measures (i.e., using appropriate PPE, cleaning personal spaces, practicing hand hygiene) throughout their experience.

6. Passengers Lack of/Desire to Access Information is a theme which captures participants' concerns with the availability of information, consistency in information, their ability to access information, and ability to recall or retain information related to IPAC measures in the airport and cabin through COVID-19 specific announcements or signage. Participants also expressed a desire for transparency in what protective measures were in place during their air travel experience.

7. Reasons and Barriers to Future Travel within COVID-19 relates to participants' impression of air travel and what would influence them to travel again during pandemic conditions, or not. Key statements in this theme related to social implications (e.g., social stigma from peers for travelling for nonessential purposes), local restrictions, COVID-19 case numbers, and the convenience of air travel versus other means of transport (e.g., automobile or train). Passengers' reasons for travel included its convenience over other means of travel, necessity of travel for work, and overall comfort in travelling in a pandemic. Conversely, barriers to travel were predominately focused on social stigma from peers for non-essential travel, unknown or changes to quarantine 
requirements, and access to the vaccine. In terms of local requirements and restrictions, statements focused on how the local, national, and/or international requirements and restrictions resulting from COVID-19 shape their travel experience and desire to travel again within this context. Understanding how passengers feel about travel in a pandemic can provide insight as to what areas can be improved to promote future travel and support better and safer passenger experience.

We did find outlier codes with a low prevalence in our analysis which stood still be considered within the larger context of air travel in pandemic conditions. Some of these codes included Business Class vs. Economy Service, Accessibility, and Comparisons to Pre-Covid-19 Travel.

\section{Theme 1 - Passengers' Overall and Continual Preoccupation with Safety}

"I don't know how effective this is, but it does make me feel better to wipe down the armrests and seat back." (P1)

"Because we all had to take a test within $72 \mathrm{hr}$ it makes me feel more comfortable that this person has tested negative somewhat recently and the odds are better. It feels a lot better." (P7)

"I was very comfortable with it all because the fact that you weren't allowed into the airport without a negative test within the last 48 hours so immediately that told me that it was safer than most places and then I felt that everyone was all covered up." (P14)

Theme 2 - Passengers' Concerns with PPE Compliance and Consistency

"People in front of me had their masks pulled under their nose and that was annoying. So when the flight attendants walked by, they must have seen them as well and they made an announcement and the people put their masks back on." (P7)

"While we were boarding was the airline itself did not like a few of our masks, so we had to switch out our masks and we actually did that at the gate and it felt weird just because there wasn't an area to switch out the masks they pretty much told us to take them off in front of everyone and put on a different mask, which I thought was weird and felt like verification of our ID. Everyone had to take of their mask as well which I thought was interesting." (P4)

“The only time I felt uncomfortable was when people took off their masks to eat on the plane.” (P11)

"We didn't want to eat on the plane, so we ate beforehand. So in the airport the only time you could take your mask off was when you had something to eat so we kind of separated ourselves to eat and I noticed not everyone did that and I know that's something I spaced myself away from was when someone else was eating and they lowered their mask." (P4)

"I did notice a decent amount of people had the same idea and some people were definitely slower eaters just because it gives you a chance to have your mask off for longer." (P2)

Theme 3 - Passengers' Comfort with Capacity

"The more empty, the more safe it was at this point." (P1) 
"The most comforting part at the airport was empty, whip through 30 minutes super quick, not many lineups not many taking off masks at that point. I felt pretty safe." (P11)

"I feel like even when you're two chairs away from someone you're still rather close -- so I'd rather have some sort of barrier, but you have to keep in mind families wouldn't want to be scattered. So maybe having some with one person, some with two, some with four [seats together]." (P6)

"When they were lining up to board the plane to scan their passports, they were cognizant but once they got onto the plane no one really was $6 \mathrm{ft}$ apart it was bunched up and when getting off the plane, everyone was trying to get off." (P11)

\section{Theme 4 - Passengers' Awareness of COVID-19 Operations}

"Announcements were played over the intercom in the airports telling you keep social distanced, wear masks, a lot of hand sanitizer stations were put in place where you could sanitize your hands." (P12)

"I didn't pay attention to the screening they do for covid -- the bottom line is that people can lie but they can't lie about temperature and they're doing that, and I think that's a really good thing." (P3)

"Increased automation of the airport experience... was something I found that I appreciated." (P1)

Theme 5 - Passengers' Sense of Self-Preparedness and Responsibility

"I feel comfortable in the way I'm approaching this scenario so it doesn't really matter to me what they're doing because I know I'm being as safe as I can.” (P7)

"I brought my own of everything (Hand Sanitizer and I knew I'd have to have it for the trip) and I had to buy masks because I haven't been wearing masks in AUS and the numbers were very low, but I did buy masks before I left and I bought the disposable ones, because I knew I'd have to change them and use multiple ones on the journey." (P5)

"I carried hand sanitizer on myself, which I never would have done before and two of the other guys I travelled with did as well. We wore masks throughout airport.” (P10)

"I would have to say the most challenging part was getting the ticket, booking more than once, was a real hassle. Also figuring out what Canada was mandating at the time because they were changing two-week quarantine and fly directly to Calgary connecting flights and was kind of hard to figure out." (P11)

\section{Theme 6 - Passengers Lack of / Desire to Access Information}

"Something that was pretty consistent was the socially distancing signage. I think that was the most consistent and predominant throughout all of these airports, not so much about sanitizing or washing your hands." (P7)

"If there's a different time, they could let you know about different protocols to expect when you land would be." (P4)

"I think just knowing what to expect at different points of the process and knowing that they are doing something is a good first step for sure." (P4)

Theme 7 - Reasons and Barriers to Future Travel within COVID-19

"I would wait until numbers chill out a bit. I don't think I'd travel unless it was a necessity." (P6)

"Beside the quarantine, it wouldn't stop me from flying again. I did cancel my February trip because of the 14 day minimum quarantine, not because of wearing the mask or all of security or inconveniences.” (P10)

"I think there's a lot of people that judge and shun people who choose to travel, and I think that is a major contributor to people our age especially." (P4)

"Physical comfort-wise I'd be comfortable to travel again if I had to but that mentality and social stuff. I wouldn't do it unless it was less frowned upon." (P8) 
"You know what the impediment is -- it's the rules when you come back. This whole idea of having to quarantine for a certain amount of days when you get back... Not for the reason of risk, but for the consequences of when I come back that I become more isolated for 10 or 14 days or whatever it is supposed to be. That is a pain." (P3)

"When it comes to our decision to travel, we would like to and will but it will determine what restrictions that are.” (P12)

\section{TABLE 11 SUPPORTIVE QUOTES FROM INTERVIEW ANALYSIS}

A second level of analysis compared the data and the codes that were generated to the categories from Roger et al.'s (2015) UX framework. This top-down approach to the analysis allowed each code and key statements to be organized within the chosen UX categories. The results of this analysis show that Narrative (387), Space and Time (114), Content (102), and Action (87), People's Expectations (87), Social (46), and Emotional (21) are prominent within the participant data. As mentioned with the travel diaries, Narrative has the highest prevalence in the data which may be a result of the interview guides being developed to follow a narrative of the participant as they walked through and reflected on their recent travel experience(s).

This level of analysis revealed that the physical and digital spaces of the airport and cabin played a large role in the passenger's travel experience during the pandemic, as well as their interactions with both digital and physical touchpoints within each environment. The use of physical spaces in the airport and cabin, along with the capacity of and proximity to other passengers were major considerations in how people discussed their travels. The data also suggests that people choose to act or behave in particular ways in response to PPE and IPAC measures (e.g., taking off their mask for sense of relief or trying to reduce personal instances of contact or touchpoints in the cabin and airport). This provides an insight into how processes and operations, as well as the environment play a role in how passengers go through their respective and shared travel journeys. 
The UX analysis also highlighted a low valence in both the Social (46) and Emotional (21) categories. Social considerations revealed challenges related to the social stigma of traveling during the pandemic, negative experiences in person-to-person interactions, and the frustration of PPE reducing ease of communication (i.e., an older passenger had difficulties hearing announcements and crew in the cabin because of the masks and environmental noise). A summary of the interview results is shown in Table 12.

\section{UX Theme Instance Count - Travel Diaries}

\section{Narrative (387)}

The representation or composition of experience, how a situation unfolds.

"I honestly don't usually listen to the entire safety instructions anymore so I was already out of focus. So I didn't pay attention to the full audio but I do remember at the beginning hearing them say a few things about keeping masks on ...the whole flight crew kept their masks on for the entire flight." (P2)

"If everybody went when they are supposed to they wouldn't have to do that but to be honest with you if you want to avoid that, you load the plan the opposite direction. You have the people on the back go on first and then fill it up going the other way." (P3)

"It was not the ideal situation and it felt like a relief when I was able to get home. I wasn't sure if they would cancel the flights so I was glad I was able to come back, even though there wasn't a lot of choice where I could go through.” (P5)

\section{Space and Time (114)}

The space and time which experiences take place and their effect upon those experiences, including the value of public versus private space and perception of time passing.

"Airports are always a bit eerie because they're emptier"(P1)

"Something that's unique about this travel... the biggest thing that's unique is how few people were in the airport, how it's like a ghost town.” (P3)

"I tried to be strategic and take seats at the back to avoid sitting near people." (P5)

“They put two flights, one to Montreal one to Toronto, two lines together, not exactly socially distanced at the airport, everyone was cramped together.” (P14)

"We booked it so that I always took the window seat and she always took the aisle seat. And we were lucky we booked that way because nobody was sitting between us and I think because of COVID nobody was sitting between us too. But we were lucky that we had that row to ourselves." (P6)

\section{Content (102)}

A participant's understanding of a particular subject, meaning, or topic. 
"Basically anywhere you have to touch something, I would love to see wipes and/or hand sanitizing stations." (P1)

"I feel like the flight crew had their assigned section of the cabin, which is common for most flights, So I only actually remember seeing 2-3 flight attendants for the majority of the flight -- you see the 1 or 2 at the front of the cabin when you get on and off the plane but for the actual flight, the person who came and asked [food, tea, coffee, etc.] was the same person and they had a mask on the entire time." (P2)

\section{Action (87)}

The process of doing something, typically to achieve an aim or goal

"I think a lot of people were waiting for their flights and it gave them a chance to take a break from wearing the mask in the terminal safely.” (P2)

"I literally tried to sleep and not move or touch anything. Just sit there and wait it out." (P7)

"Try to board people as fast as you can even if you have to board early. I'd rather sit in my chair on the plan than sit in the gate with another flight so close to me." (P7)

"One of the greatest things was walking on the plane and getting the sanitizing wipe from the steward and wiping the seat down, seatbelt headrest, arm rests, tray, $\mathrm{tv}$ and all of that before I even sat in it. That was nice to get priority and get on and get that done before you were inundated with people." (P9)

\section{People's Expectations (85)}

The mental models, interpretations, or a participant's representation of how things work or unfold.

"We were watching them already start to sanitize the plane and I was disappointed because here, I would have assumed they'd have special people come in there and that's all they do. They're hand sanitizing experts, and they go in there with special equipment and do a bang-up job but really all it was the flight attendants taking whatever and wiping this and that down." (P3)

"I don't know if they can do much more than what they are doing. All of the hard surfaces, cleaning of the plane, touch points, running down the aisle wearing masks, trying to minimize contact with service getting in and out of plane with as few interpersonal contacts that are unnecessary is just fine with me." (P13)

"I think safety-wise, I think airplanes have done a good job of staying on top of things." (P8)

\section{Social (46)}

How social resources can develop and be maintained through social norms and shared values.

"I was actually quite impressed by the lack of shenanigans amongst other passengers." (P1)

"The biggest thing that stood out to me was not my concern, but the other guy's concern when I was standing beside him when my bag was stuck. That was the biggest thing that resonated with me." (P3)

"I think there's a lot of people that judge and shun people who choose to travel and I think that is a major contributor to people our age especially." (P4)

“No, everyone was doing it so I didn't question it and they made us take off our masks for that." (P11)

"On the way back, it was a bit more strict, no one was allowed to be in the airport who wasn't flying. You weren't allowed any family members seeing people off or anything else like that. They were very strict on that. All airport staff were wearing face shields.” (P14)

Emotional (21) 
Shows how emotions may be intertwined within a situation or experience.

"Always kind of unimpressed with how the airline handles loading and unloading the plane." (P1)

"I guess I was surprised to see how much was done. I am more comfortable flying now than I probably ever was." (P9)

\section{TABLE 12 UX CATEGORY PREVALENCE FROM INTERVIEWS}

The final analysis of the interview data involved an instance count of keywords or short phrases that emerged in the original transcripts. This list, found in Appendix K, has these keywords organized based on their prevalence, and offers more granular insight into specific factors that were discussed by recent flyers.

This instance count showed an emphasis on words such as flight, mask or face covering, food or eat, airport, and crew or employee or flight attendant. Within these top words, the context of current air travel can be framed in terms of what recent flyers continue to bring up about their reflections and experiences. These words are most associated with processes and operations, person-to-person interactions, environment design, and service design, pointing to areas of future considerations in air travel design.

\subsection{Synthesis of Findings - Layers in Design that May Influence Experience}

In the travel diary and interview methods, participants were asked to reflect on their most recent travel experience, specifically noting any differences in their experience related to COVID-19, but also to reflect on the measures taken (or not) by local airlines and/or airport authorities. We have documented these experiences from each method to answer the question 'How might these experiences be related to the design of elements or factors in air travel?'. The results of these methods illustrate the relative dominance of certain UX considerations in these 
experiences which have been thematically outlined above. However, we felt it was also important to map their narratives to different systemic layers of 'design considerations' within the context of air travel (Figure 18). The framework of analysis developed for this study was adapted from Wilson and Sharples' (2014), 'Onion Model' and was used as a tool to map, organize, and interpret interacting layers or levels of factors that may be shaping passenger experience while travelling under pandemic conditions.

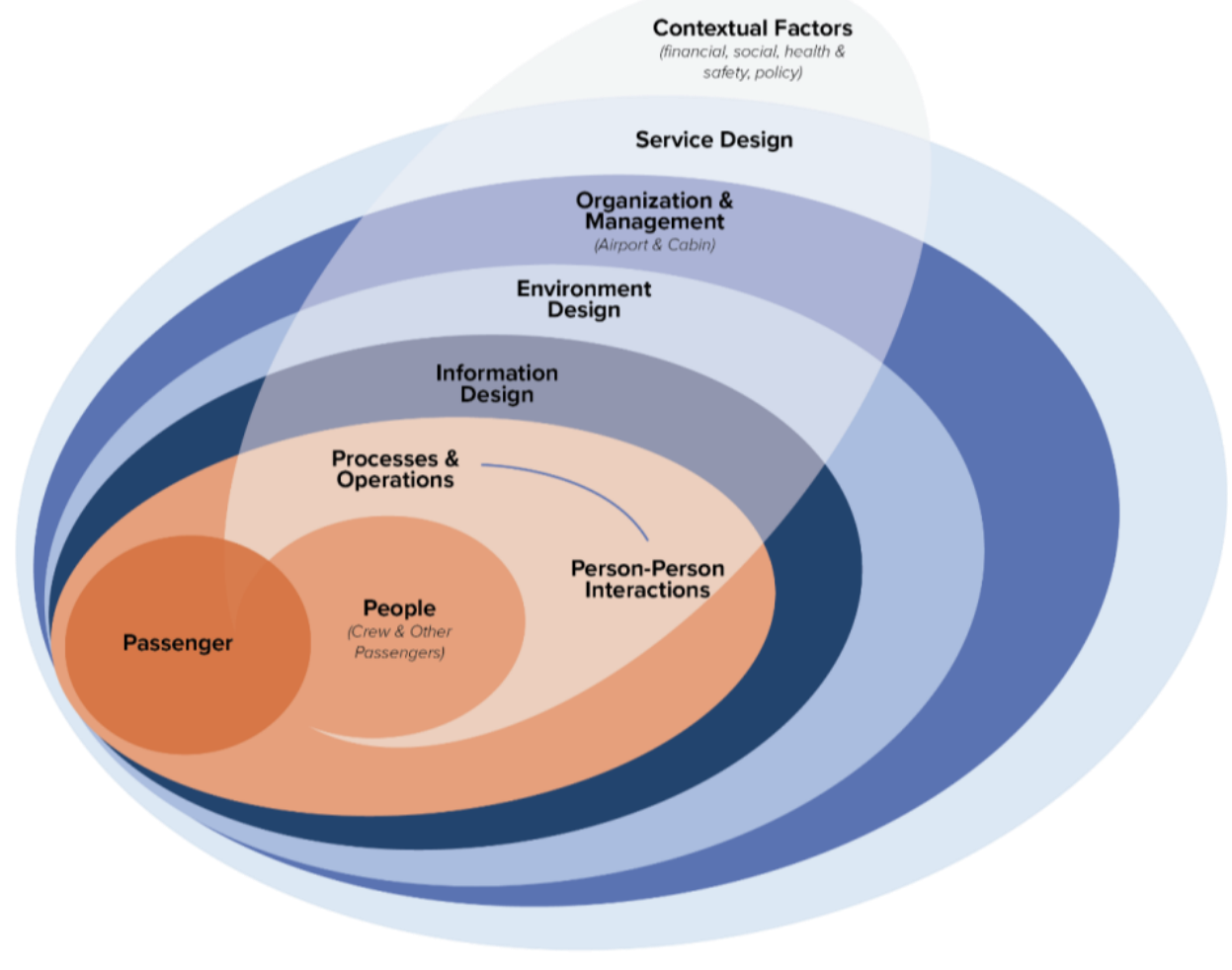

Figure 18. User ExPERIENCE IN AIR Travel 'ONION MODEL'

Within this framework, each layer represents a factor that contributes and impacts the current passenger experience to some capacity. The core of this study is focused on the Passenger, their relationship to People and perspective on other factors, layers or elements of experience that may be influencing their overall travel experience. The first layer of this model 
focuses on Processes and Operations and Person-to-Person Interactions that may influence passenger experience. This layer captures the passenger's personal interactions and processes that involve crew, other passengers, airport, and operational staff experienced in the journey. The second layer of this model, Information Design, relates to any communications touchpoint that a passenger interacts with to obtain information that was designed without involving direct interaction with any other individual. The Environment Design layer captures touchpoints within the physical or digital/virtual environment that a passenger interacts with, that may not involve staff or personal interactions (e.g., the design of interiors, specific aspects of check-point environments such as kiosks, to even more specific products used in travel such as headsets or movie selection interfaces). Organization and Management relates to administrative planning, policies, standards or controls specific to operators such as airlines and/or airport authorities spanning the airport and cabin. A modification that has been made to the Onion Model is adding Service Design, which includes all aspects of the air travel envelope that may inform the design of the service - considerations that directly form the service model such as regulations, standards, and guidelines; the overall environment and its touchpoints; information design; processes or operations; and person-to-person interactions. This service layer links a comprehensive span of factors that may contribute to a person's experience in air travel. Contextual Factors such as personal or social factors, financial barriers and health and safety regulations, also influence each layer but may be beyond the service provider's control.

This model was used to map our findings from the 3 methods to a wholistic scale of design, looking at air travel design as a layer of elements and factors in a system which may contribute to passenger experiences. Table 13 shows which layers of experience were prominent in passenger experience during COVID-19 air travel. Our findings from each 
method were organized in this table based on which level of experience passengers focused on the most in their narratives (with key themes shown in italics) or had the highest levels of comfort (or discomfort). What this illustrates is that factors that were important to passengers occurred at all levels of air travel - Processes and Operations, Person-to Person Interactions, Information Design, the design of the Environment (airport and cabin), Operations and Management, Service Design, and Contextual Factors. However, some layers had a higher concentration of themes and discomfort ratings associated with them relative to others (e.g., Layer 1), indicating that these specific layers should perhaps be examined more closely in consideration a more strategic approach to air travel Service design during pandemic or infectious outbreak conditions.

\begin{tabular}{|c|c|c|c|}
\hline $\begin{array}{l}\text { Layers in Service } \\
\text { Design }\end{array}$ & $\begin{array}{l}\text { Key Takeaways from } \\
\text { Method } 1\end{array}$ & Method 2 Findings & Method 3 Findings \\
\hline $\begin{array}{l}\text { 1. Processes \& } \\
\text { Operations }\end{array}$ & $\begin{array}{l}\text { Differences in PPE worn by } \\
\text { other passengers and crew left } \\
\text { researcher questioning } \\
\text { inconsistency. } \\
\text { Differences in IP AC measures } \\
\text { used between provinces left } \\
\text { researcher questioning } \\
\text { inconsistency. } \\
\text { Reduced services available in } \\
\text { airport (e.g., food and dining), } \\
\text { which led to spot crowding. }\end{array}$ & $\begin{array}{l}\text { Passenger comfort in } \\
\text { boarding processes and } \\
\text { screening measures. } \\
\text { Passengers' Overall and } \\
\text { Continued Preoccupation with } \\
\text { Safety }\end{array}$ & $\begin{array}{l}\text { Passengers' Overall and } \\
\text { Continued Preoccupation with } \\
\text { Safety } \\
\text { Passengers' Concerns with } \\
\text { PPE Compliance and } \\
\text { Consistency } \\
\text { Reasons and Barriers to } \\
\text { Future Travel within } \\
\text { COVID-19 }\end{array}$ \\
\hline $\begin{array}{l}\text { 1. Person-to- } \\
\text { Person } \\
\text { Interactions }\end{array}$ & & $\begin{array}{l}\text { Passenger discomfort in } \\
\text { cabin capacity and } \\
\text { proximity to other } \\
\text { passengers. } \\
\text { Passengers' Comfort with Cabin } \\
\text { Capacity } \\
\text { Passengers' Overall and } \\
\text { Continued Preocupation with } \\
\text { Safety }\end{array}$ & $\begin{array}{l}\text { Passengers' Overall and } \\
\text { Continued Preoccupation with } \\
\text { Safety } \\
\text { Passengers' Comfort with } \\
\text { Capacity }\end{array}$ \\
\hline $\begin{array}{l}\text { 2. Information } \\
\text { Design }\end{array}$ & $\begin{array}{l}\text { Differences in COVID-19 } \\
\text { signage between provinces left } \\
\text { researcher questioning } \\
\text { inconsistency. } \\
\text { Announcements in airport and } \\
\text { cabin varied between provinces } \\
\text { left researcher unsure of clarity }\end{array}$ & $\begin{array}{l}\text { Passenger comfort in health } \\
\text { and safety information } \\
\text { when booking. } \\
\text { Passenger discomfort and } \\
\text { uncertainty in local } \\
\text { requirements or restrictions }\end{array}$ & $\begin{array}{l}\text { Passengers' Overall and } \\
\text { Continued Preoccupation with } \\
\text { Safety } \\
\text { Passengers' Awareness of } \\
\text { COVID-19 Operations }\end{array}$ \\
\hline
\end{tabular}




\begin{tabular}{|c|c|c|c|}
\hline & $\begin{array}{l}\text { and consistency of provided } \\
\text { information. }\end{array}$ & $\begin{array}{l}\text { from arrival } \\
\text { announcements. } \\
\text { Importance of Passengers' } \\
\text { Feeling Prepared }\end{array}$ & $\begin{array}{l}\text { Passengers' Sense of Self- } \\
\text { Preparedness and } \\
\text { Responsibility } \\
\text { Passengers' Lack of / Desire } \\
\text { to Access Information }\end{array}$ \\
\hline $\begin{array}{l}\text { 3. Environment } \\
\text { Design }\end{array}$ & $\begin{array}{l}\text { Inconsistencies in access to } \\
\text { hand sanitizers in airport and } \\
\text { cabin left researcher looking for } \\
\text { IPAC measures. } \\
\text { Capacity of cabin was different } \\
\text { based on time of travel, which } \\
\text { challenged distancing efforts. }\end{array}$ & $\begin{array}{l}\text { Passenger comfort in IPAC } \\
\text { measures in place in airport. } \\
\text { Passenger discomfort in } \\
\text { boarding location and } \\
\text { capacity. } \\
\text { Passenger discomfort in } \\
\text { cabin capacity and } \\
\text { proximity to other } \\
\text { passengers. } \\
\text { Passengers' Comfort with Cabin } \\
\text { Capacity }\end{array}$ & $\begin{array}{l}\text { Passengers' Comfort with } \\
\text { Capacity } \\
\text { Reasons and Barriers to } \\
\text { Future Travel within } \\
\text { COVID-19 }\end{array}$ \\
\hline $\begin{array}{l}\text { 4. Organization } \\
\text { \& Management }\end{array}$ & & $\begin{array}{l}\text { Passengers' Experiences with } \\
\text { Change in Service and } \\
\text { COVID-19 Specific Practices }\end{array}$ & $\begin{array}{l}\text { Passengers' Concerns with } \\
\text { PPE Compliance and } \\
\text { Consistency } \\
\text { Passengers' Awareness of } \\
\text { COVID-19 Operations }\end{array}$ \\
\hline 5. Service Design & Comprises themes above. & $\begin{array}{l}\text { Passengers' Experiences with } \\
\text { Change in Service and } \\
\text { COVID-19 Specific Practices } \\
\text { Comprises themes above. }\end{array}$ & Comprises themes above. \\
\hline $\begin{array}{l}\text { 6. Contextual } \\
\text { Factors }\end{array}$ & & $\begin{array}{l}\text { Importance of Passengers' } \\
\text { Feeling Prepared }\end{array}$ & $\begin{array}{l}\text { Passengers' Awareness of } \\
\text { COVID-19 Operations } \\
\text { Passengers' Sense of Self- } \\
\text { Preparedness and } \\
\text { Responsibility } \\
\text { Passengers' Lack of / Desire } \\
\text { to Access Information } \\
\text { Reasons and Barriers to } \\
\text { Future Travel within } \\
\text { COVID-19 }\end{array}$ \\
\hline
\end{tabular}




\section{Chapter 5: Discussion}

This section discusses our findings relative to the study's research questions and the information found in the literature review and environmental scan. Our study focused on documenting passenger experience in air travel during COVID-19 to develop a better understanding of systemic elements or factors in design that are of importance to passengers and may help inform future areas of focus in design. Four main questions were explored through three methods. In this chapter we also discuss passengers' feedback on the design of these methods to provide insight on conducting research under pandemic conditions in potentially stressful contexts. We conclude this chapter with our study contributions and limitations.

\subsection{IPAC Design Considerations in Passenger Air Travel Experience}

In this section, we discuss aspects of the literature review and environmental scan compared to our documentation of factors of importance in passenger experience, with the intention of answering 'What recommendations might emerge from this study to help inform future design studies to support passenger experience and comfort under IP AC measures?'.

\subsubsection{User Experience Considerations}

Through data collection and analysis, several themes emerged and our adaptation of Roger et al.’s (2015) UX framework helped identify where passenger experiences were focused. In methods two and three, we saw a prominent focus on the categories of Action, Space and Time, and People's Expectations from participant documentation (travel diaries and follow-up interviews) and travel recollections (interviews). These findings demonstrated that passengers 
were focused on: the design of the airport and cabin environment; the impact of their own actions and processes within air travel to support safety; and how IPAC measures and contextual factors outside the service (i.e., the role of media) shape their interpretation and expectations of travel. The UX categories Social and Emotion came up frequently in passenger experience, illustrating some of the key considerations directly connected to their comfort levels in travelling. The most prominent considerations within these categories related mostly to person-to-person interactions with other passengers, or contextual factors such as worries about social stigma and/or judgement for non-essential travel.

Compared to the literature review and environmental scan, the UX categories that passengers focused on were factors that went beyond what our review revealed. The literature we collected was very cabin-centric, with an emphasis on the built environment (e.g., seat layout and capacity) and airflow/ventilation. Although passengers discussed cabin capacity in both methods, other prominent UX considerations from our analysis revealed that passengers were also concerned with the design of the airport (service and environment), processes and operations within the airport and cabin procedures, as well as a high focus on social factors as a barrier for future travel. This suggests that research should consider these layers within the larger umbrella of service design, to support a better user experience for passengers.

\subsubsection{Layers of Experience within Passenger Air Travel Experience}

Our findings from each method were mapped to the different layers of experience through our adaptation of the 'Onion Model' (see section 4.5 - Synthesis of Findings). This helped identify what aspects of the travel experience passengers were focused on, which were predominately within the service design of processes and operations, information design, and the design of environments, within the airport and cabin. 
The Service Design level of this system is defined by the planning and organization of people, infrastructure, and means of communication between passengers, crew and airport staff. Many of our findings demonstrate the need to outline specific responsibilities done at a service and systems level, specifically consistently designing, implementing and managing: the extra roles and tasks service members have had to take on as a result of the pandemic; and heightened IPAC measures and protocols. In terms of service design, our literature review and environmental scan did not reveal studies that focused on the responsibilities of airport staff and crew or the organization of people in the airport and cabin. Based on its relevance in all three methods and at each layer of our analysis, we see a need for more research focused on the service level of user experience in air travel.

Within the layer of Processes and Operations, our findings suggest that clarity in what measures are being done at the information and service levels are important in passengers finding reassurance in any new measures in place. Some of these measures include 1) making sure all information given to passengers about COVID-19 specific measures in the airport should be made clear and transparent, and 2) making sure screening measures in airports are consistent and reliable, preferably at the beginning of the airport process (e.g., at check-in) to avoid spreading infection throughout the airport. The literature we reviewed touched on what local requirements were in place in Canada at various points within the last year (Detsky \& Bogoch, 2020; Government of Canada, 2020a, 2020d, 2020f), and emergent designs focused on rapid testing measures in the airport (Jackson, 2020; Proskow, 2020). Despite this, and to the best of our knowledge, there was no research that focused on how these processes have influenced passenger experience or how the passenger was made aware of changes to processes, procedures, or operations in the airport and cabin. 
Within the layer of Information Design, our findings suggest that the availability, clarity, and transparency of information offered to passengers throughout their entire air travel experience is important in providing details about how their air travel journey or service may have changed, the IPAC measures in place, processes and operations in place at each airport and airline, and communication regarding COVID-19 specific information in general. Other insights that emerged include 1) the need for consistent language and visual tools in signage 2) the need to provide education and transparency about following COVID-19 measures and what airlines and airport authorities are doing in terms of service and IPAC measures. Additionally, some passengers noted they tune out of announcements in the airport and cabin, so finding a way to provide the same information in a more accessible and impactful way would be useful. In our review of the literature and environmental scan, there was no literature available at the time of our searches that focused on how information is provided to passengers at each level of their experience. Finding ways to increase access to relevant and consistent information for passengers within each touchpoint of their experience could mitigate some of the uncertainty passengers discussed.

The Environment Design layer occurred frequently in our findings with discussions centering around both the airport and cabin design. We also found this layer studied to a greater degree in the literature review than other layers of experience. Within the design of the cabin, we found that most of the literature focused on capacity and adjacency. The amount of literature focused on the design of the cabin environment is consistent with what passengers described as important in their travel experience. However, most of the literature and grey material we reviewed placed emphasis on the cabin experience (Burge, 2005; Hertzberg et al., 2018; Lei et al., 2018; Menzies, 2005; Toon, 2018; Transportation Research Board, 2010b; 
Worsnop, 2017) with little research focused specifically on the airport (International Air Transport Association, 2021b; Transportation Research Board, 2010a). Comparatively, passengers in this study placed an emphasis on the design of the airport, in terms of its use of space for screening and testing, shared eating spaces, or adequate spaces to accommodate physical distancing. Within the airport, the capacity of shared spaces impacted passengers' comfort levels, specifically when there was crowding during waiting and boarding procedures, calling to question the impact that capacity and proximity have on passenger comfort. Increased cleaning and sanitization measures for high-touch areas (e.g., kiosks and interactive screens) and increased access to hand sanitizers in the airport and cabin were also a focus of passengers. We found very little literature focused on IPAC design in airports (International Air Transport Association, 2021b; Proskow, 2020; Sillers, 2020) suggesting a need to conduct research on the air travel experience within airports and its influence on passenger experience during infectious outbreaks.

A major theme that came up from passengers related to their Overall and Continual Preoccupation with Safety. Participants were focused on the entire air travel experience and we found that concerns over safety came up at each point in their stories (e.g., check-in through to disembark), not at a specific part or process. This suggests that passengers were constantly preoccupied with safety measures throughout their entire travel experience. Our literature review and environmental scan did not reveal studies in IPAC air travel that focused passenger perceptions around safety. Some of the articles we collected with passengers' narratives (Bowden, 2020; Brooklyn, 2020; Chor, 2020; McGregor, 2020; Ramsay, 2020) mentioned concern over uncertainty in flying, but not specific to their safety or the safety measures in place within the airport and cabin. Because of its relevance to the participants, we feel that 
research looking into factors that could increase a passenger's feeling of comfort and/or safety within the airport and cabin should be further explored.

Another finding from this study related to passengers' Concerns with PPE Compliance and Consistency. Most of the literature and passenger narratives we reviewed in our environmental scan focused on the physical aspects of the cabin (and less so airport) as potential sources for concerns or discomfort (e.g., high-touch areas, crowding). However, this theme showed that passengers are concerned about PPE worn by other passengers, airport staff and crew, and the procedures around these IPAC measures. This focus emphasizes the importance of consistency in IPAC measures, such as PPE, and passenger comfort related to other people complying with consistent PPE resources and measures.

The theme related to Passengers' Sense of Self-preparedness and Responsibility focused on the individual actions and IPAC measures taken by the passenger themselves, their comfort in the actions and behaviours of other passengers and crew, as well as what testing and/or screening measures were in place at their time of travel to manage their experience. Our literature review on comfort found that people find intrinsic comfort in having control over a situation and their experiences (Lewis et al., 2016) but beyond this, there was no specific literature related to a passengers' sense of feeling prepared about travelling within pandemic conditions. Another focus of passengers was their Reasons and Barriers to Future Travel within COVID-19. Most participants mentioned that the social stigma surrounding non-essential travel, uncertainty in local requirements, and necessity for travel during COVID-19 were main contributors to their lack of desire to travel within the pandemic. The most prominent factors of these themes were in the processes and operations, person-to-person interactions, information design, and contextual factors. This compares to the Fast Future study (2020), 
which predicted that post-pandemic travel would most likely result in passengers' reluctance to fly because of confusion in the protocols in place by different countries, airlines and airports. This demonstrates that each level of experience within service design may influence a passengers' comfort in travel, as well as their desire to travel again under these same conditions.

After mapping our findings to our adapted 'Onion Model' framework, User Experience framework, and the literature review and environmental scan, we were able to develop a better understanding of what factors have changed and/or influence a passenger's travel experience within the context of the COVID-19 pandemic.

\subsection{Design and Use of Methods}

The dynamic and novel nature of pandemic conditions offered an opportunity to explore several design research methods that could be used for remote qualitative data collection. The use of the travel diary and recent flyer interviews provided a better understanding into what aspects of these methods were useful, and what challenges arose because of COVID-19. The ultimate goal of using both methods was to collect real-time documentation, recollections and current feedback from participants about the context of air travel in pandemic conditions, to answer the following question, 'How might we design methods to support the documentation of user experience under challenging conditions such as travelling during a pandemic of infectious outbreaks?'.

\subsubsection{Use of Travel Diaries during Pandemic Conditions}

A final layer of analysis was conducted with participants on the actual use of the methods in this study. The travel diary was developed so that participants would, ideally, be easy to integrate the documentation into their journey, without creating any added stress or 
concern as they traveled during the pandemic. Recent flyer interviews were added to allow people to participate if implementing the travel diaries provided challenging due to the changing restrictions on flying. Since the goals of this study focused on obtaining real-time reflections about the current travel experience, the travel diaries and recent flyer interviews were developed to prompt participants about their pandemic passenger experiences, recalling anything that may have stood out or influenced their travel.

After collecting feedback, mainly from the travel diary participants, the diary was described as "easy - to extremely easy to use". Most participants were able to complete their travel diaries at each major checkpoint in the travel experience, while on board their flight, or soon after travelling. Quotes from these participants can be found in Box 5.

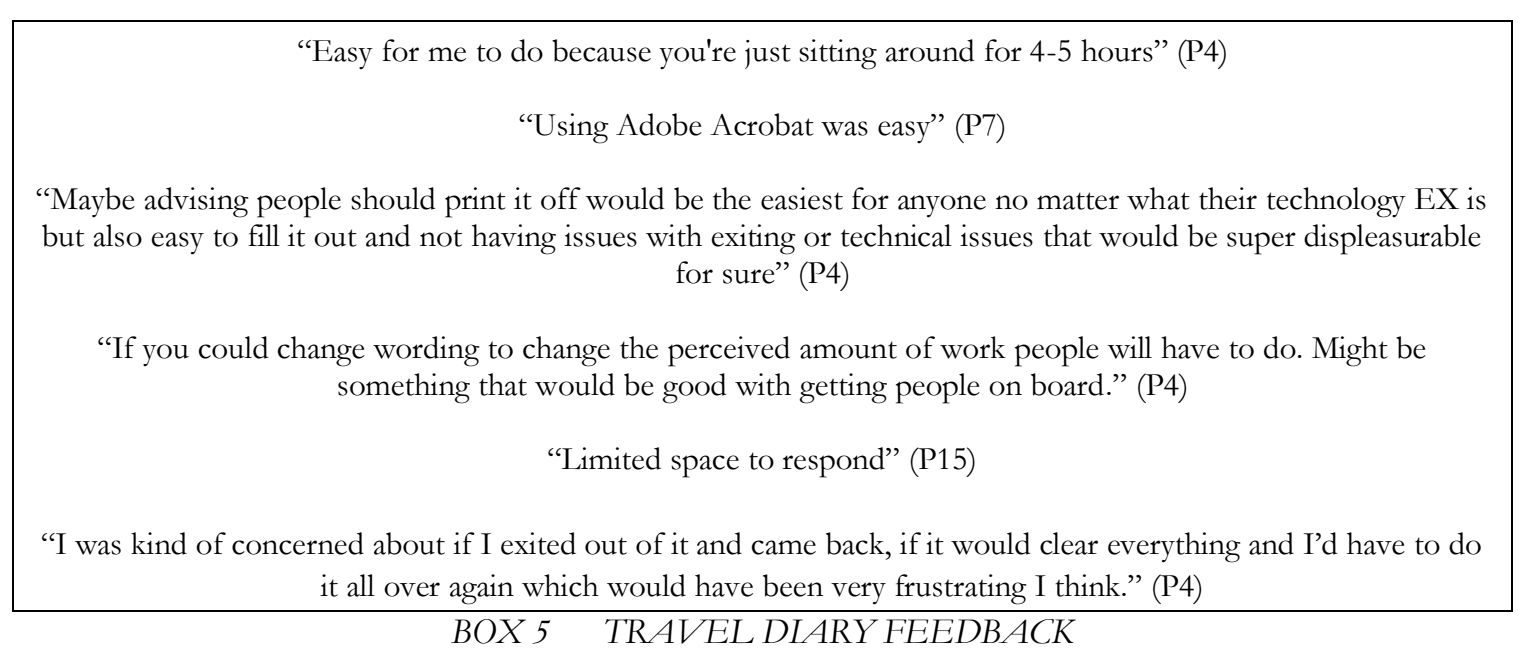

However, there were certain drawbacks in using the travel diaries, with one participant who could not complete the diary because of technical difficulties on their personal device. Going into testing, this was a concern, recognizing different levels of comfort in using technology or digital tools. While this participant did not complete the diary, they provided their reflections through the interview method instead which supported the importance of having alternative methods to capture passenger narratives. Another source of error was found 
in the way that the file for the travel diary opened on some of the participant's devices, which offered limited space to record their reflections. The diaries were offered in either digital or physical versions and although all participants willingly chose digital travel diaries, more methods of recording participant reflections could be explored to avoid some of these issues. The literature suggests that there is a shift towards using electronic, or digital, means of data collection for qualitative and real-time data collection (Janssens, Bos, Rosmalen, Wichers, \& Riese, 2018; Prelipcean et al., 2018). This was reflected in the participants' choice to use the digital version. The level of accessibility and ease of use of these methods was highly considered in their development, however there is room for improvement and adaptability to increase their ease of use for future studies.

\subsubsection{Review of Interview Method during Pandemic Conditions}

The recent flyer interviews provided an opportunity to connect with participants who were not local to Ottawa, while also offering more flexible scheduling compared to in-person interviewing. The virtual interviews allowed our participants to engage in an open-ended conversation describing their most recent travel experience. Much like other qualitative interview processes, this allowed for a person-centred process, focused on holistic approaches in gaining new knowledge of the passenger experience (Sandvik \& McCormack, 2018). The interviews offered an understanding of participant experiences of their actions, while exploring the meanings of their reflections to help frame the current context of air travel.

\subsubsection{Summary on Methods}

Overall, each method used produced relevant information from participants about their most recent travel experience(s), helping to frame the context of air travel within pandemic conditions. Each method was developed by building on the data collected from the previous 
method, serving as an example of how to collect real-time and reflective participant data within dynamic contexts. The feedback offered from participants about their use and involvement in these methods can be used to guide subsequent research in this field and similar industries. While the actual methods used in this study seemed to work well in gathering rich qualitative data, there is room for improvement to support work in sensitive contexts and the constraints that it may bring (e.g., travel restrictions, local requirements, costs of travel, etc.).

\subsection{Research Contribution}

This study focused on exploring how pandemic conditions shaped the context of air travel for a group of passengers and influenced their experience and perception of comfort. Our findings offer a glimpse into how systemic factors may affect passenger experience during such difficult circumstances. This research provides a baseline understanding of the current passengers' experience in air travel and has the potential to extend beyond the context of the COVID-19 pandemic into future pandemics, endemic conditions and travelling during seasonal peaks in respiratory viruses. The findings from this research and feedback about the methods developed and used can also be used among other fields of research to obtain real time participant data during remote research conditions. Real-time and recollective data from recent flyers provides an opportunity to explore different considerations in the air travel context that influence passengers and their comfort in flying now and in the future.

Our study also provides insight into methods used to document people's experiences while travelling during potentially stressful conditions and redundancy strategies to increase the pool of data collected within a dynamic context of research. Methods one (observational analysis) and two (travel diary) specifically, provided an opportunity to explore design research methods that were developed and adapted to the changing context of air travel as this study 
progressed, offering a baseline of understanding into how these methods may be used in other dynamic or potentially stressful conditions.

In comparing our findings with the literature review and environmental scan, we have revealed a number of factors that require more attention in travel research related to infection prevention and control. In our review of current design development, we did not find service models that map out IPAC in air travel experience as we attempted to do in this study - models that show the impact of processes and operations, information design, the design of airport and cabin environments, as well as personal and external contextual factors outside the control of service providers. Each of these service touchpoints should be considered in further research as a wholistic system to support passengers. These reflections can be used by many fields of research to develop solutions for air travel within a pandemic and for future dynamic and fragile situations that may arise. The findings and insights from this study outline the interdisciplinarity of design research, suggesting that the information gathered in this study can be used by other fields looking into the current and emerging context of air travel.

In a similar sense, this study combined multiple levels of interdisciplinarity research, grounded in the researcher experience(s) as well as training and expertise in industrial design, human factors/ergonomics, cognitive science, psychology, and social design. These layers of interdisciplinarity provided an opportunity for the research to be more wholistic in its approach to understanding the current passenger experience, participant comfort, and developing insights into the current travel experience through first-hand reflections. Moving forward, this research could lend itself into more fields of study to extend our understanding and evaluation of the current context of air travel and passenger experiences. 


\subsection{Study Limitations}

The COVID-19 pandemic introduced limitations to research in many different fields, around the world. In particular, the reliance on technology as a means of virtual research, testing, and collaboration were the major hindrances for this study. As such, it was important for the methods used to be designed in a way to promote participant engagement, while also gathering rich data about the current passenger experience. Finding participants who had travelled by plane under pandemic conditions was also a challenge for this study, as the changes made to quarantine requirements, border closures, and general uncertainty in flying impacted the number of participants available. Because of this, the small sample size ultimately affects the external validity of the findings from this study. Future work may focus on obtaining a larger sample size to determine if these findings could be generalized.

The novelty of the coronavirus too posed a challenge in the initial phases of this study, namely the limited literature and grey material available to provide context. A year later, there is now much more research available specific to COVID-19, however access to this kind of information was challenging and the available literature was sparse at the beginning stages of this study.

\subsection{Future Work Recommendations}

Our study accompanies other emerging research that is currently being published about air travel. According to Bielecki et al. (2021), hygiene measures, mask use, and distancing procedures have been most effective in reducing the risks of transmission in air travel, whereas temperature screening has been shown to be unreliable. This coincides with some of the points raised in the recent flyer interviews, where participants questioned the accuracy and use of temperature screening at different points in the airport experience. This presents an 
opportunity to explore more effective and reliable means of screening in pre-board areas to further reduce the risks of infection spreading in the airport and to establish evidenced-based practice to support the comfort of passengers.

Another finding that warrants more attention in the design of the physical environment is relative to passenger movement, proximity and behaviour. Our findings highlighted that a better use of empty spaces (e.g., unused gate/pre-board areas) in the airport could support better distancing, reduce crowding, and reduce stress for passengers that are not comfortable being near strangers. Design could also play a role in evaluating how to use the cabin space to promote separation or distancing between passengers, much like some of the proposed solutions that were discussed in the environmental scan (section 2.3.3 Expectations for Future Travel). Within the physical environment, our literature review demonstrated a cabin-centric focus in current research, but our findings suggest that the airport plays a major role in passenger experience. Because of participants' preoccupation with their airport experience, we feel it is necessary to review how the design of the physical and digital aspects of the airport may play a role in supporting a more positive passenger experience. We recommend looking into passenger experience as an entire system, beyond the cabin itself, to explore how different points in a passenger's travel experience may impact their perception of the process and their comfort in flying.

Another takeaway from this study relates to the implementation and execution of travel restrictions, recommendations, and policies within different airlines and airports. Participants voiced their concerns over uncertainty in the processes, operations, and safety measures in place at respective airports and within different airlines. Regulating how this information is provided clearly and consistently to passengers may help alleviate some of these 
concerns in future travel conditions. Meng et al. (2021) suggest that the effectiveness of control measures for COVID-19 in air travel industries is influenced by the strictness of the control policies and the duration for the policies to be in force. We recommend that COVID-19 information about restrictions, recommendations, and policies should be designed to be clear, consistent, and engaging so that passengers can be made readily aware of these changes, which could reduce passenger uncertainty. Our study also demonstrated that the means of communication and the dissemination of information to passengers needs to be re-evaluated as some passengers tend to 'tune out' of pop-up information or announcements in the booking, airport, and in-flight processes. Finding ways to design documentation that is engaging and will prompt passenger attention is something we suggest would be useful for future travel research. Coinciding with the increased use of digital and/or electronic mediums for participant data collection and other experiences, we also recommend the design and testing of how user interfaces and/or digital applications could be used to support passenger attention and retention of information throughout their travel experiences. Information from this research could support how digital mediums can be designed to support other aspects of user experiences in potentially stressful or changing contexts.

In addition, the travel measures in place (i.e., travel restrictions and quarantine) set out by IATA are used as public health tools to combat the international spread of the virus, with the implementation of 'said rules' being the responsibility of the airline (Bielecki et al., 2021; Worsnop, 2017). As seen in our study, the pre-flight and in-flight measures used varied across different airlines and airports. We recommend that consistency in these measures is needed across airlines and airports to ensure a more reliable and easily understandable process for future travellers and continuity of experience under what is already a precarious context. This 
would include providing clear information about policies, local requirements, and IPAC measures in place to individuals booking through to the disembark phases of travel.

Currently, new applications are being developed by aviation associations, such as IATA, to help support the future of air travel within the pandemic and to help prepare for future conditions that may impact passenger experience. An example of this is the IATA travel pass, a mobile application under development, which would allow travellers to store and manage their certifications for COVID-19 tests and/or vaccine history (International Air Travel Association, 2021). The app would also provide a global registry of health requirements, testing and vaccination centres, and ultimately serve as a digital passport for passengers to manage their documentation. Solutions like the travel passport would allow passengers to organize and prepare for their travel experience with ease, something that continually came up as a concern for participants in this study. Future work should be done to continue the development and design of similar tools to support the comfort and sense of preparedness for future travel conditions.

As Bieleki et al. (2021) stated, many of the responses to reducing the spread of COVID-19 in air travel have "failed to consider human behavior and airline procedures variations (p.1)" and so we call for further research to tie together aspects of user experience within the many layers of air travel design, to promote a better travel experience for the future. We also propose a larger scale survey, based on our findings and systems approach, to understand if these factors in passenger experience have been experienced by others, and to what extent they can be generalized. 


\section{Chapter 6: Conclusion}

This study explored the experiences of people flying during the COVID-19 pandemic and the role of passengers' interactions with others, processes and operations, the design of the built environment, and other factors related or outside the scope of travel service may have impacted their experience. A literature review and environmental scan were conducted to develop an understanding of prior and recent work in design for infection prevention and control in air travel, while also offering a glimpse into what current travellers have experienced within the COVID-19 pandemic. This study used a multi-method approach, including observation and reflective journaling, an in-situ travel diary, and interviews with recent travellers to gather real-time and recollective reflections from recent flyers to shape our understanding of their experience in air travel. Through a 'bottom-up' and 'top-down' thematic and content analysis, our findings reveal various factors and considerations that influenced the participants' comfort and experience in pandemic air travel. We found that passengers' concerns focused predominantly on passengers' preoccupation with safety, concerns with PPE compliance and consistency, comfort with capacity, awareness of COVID-19 operations, send of selfpreparedness and responsibility, lack of/desire to access information, experiences with change in service and COVID-19 specific practices, and reasons and barriers to future travel. These themes were then mapped to systemic layers of design consideration across air travel service to support future design teams strategize on potential areas of research. Our findings from the three methods, in addition to the development and evaluation of design methods used, provides an understanding of how this research may extend to other areas of research in aviation and design. Our findings from participant data also coincide with emerging research within air travel and passenger experience related to IPAC, which is why we are calling to develop this 
study at a broader scale so that our findings may be generalized for the future of air travel and passenger experience under similar conditions. We hope this study can support the work of other interdisciplinary research and design groups focused on air travel experience to mitigate the risks that have resulted from this unprecedented context. 


\section{References}

Ahmadpour, N., Lindgaard, G., Robert, J. M., \& Pownall, B. (2014). The thematic structure of passenger comfort experience and its relationship to the context features in the aircraft cabin [016]. Ergonomics, Vol. 57, pp. 801-815.

https://doi.org/10.1080/00140139.2014.899632

Ahmadpour, N., Robert, J.-M., \& Lindgaard, G. (2016). Aircraft Seat Comfort Experience. In Human Factors in Transportation (1st Edition, pp. 419-432). https://doi.org/10.1201/9781315370460-39

Air Canada. (2021). Health and Safety. Retrieved from Air Canada website: https://www.aircanada.com/ca/en/aco/home/book/travel-news-andupdates /2020/covid-19.html

Bielecki, M., Patel, D., Hinkelbein, J., Komorowski, M., Kester, J., Ebrahim, S., ... Schlagenhauf, P. (2021, January 1). Air travel and COVID-19 prevention in the pandemic and peri-pandemic period: A narrative review. Travel Medicine and Infectious Disease, Vol. 39. https://doi.org/10.1016/j.tmaid.2020.101915

Bowden, O. (2020, May 23). 'I dropped everything to say goodbye': Why some Canadians are still travelling . Global News. Retrieved from https://globalnews.ca/news/6974882/flying-during-coronavirus/

Brooklyn, C. (2020). What It's Like to Fly During COVID-19. Retrieved from World Nomad website: https://www.worldnomads.com/explore/north-america/unitedstates/what-its-like-to-fly-during-covid

Burge, H. A. (2005). Airplanes and Infectious Disease. https://doi.org/10.1007/b107241

Canada Border Services Agency. (2020). Stay connected - CanBorder app. Retrieved May 27, 
2021, from Canada Border Services Agency website: https://www.cbsa-asfc.gc.ca/newneuf/app-eng.html

CATSA. (2020). Measures taken in response to COVID-19. Retrieved May 27, 2021, from CATSA website: https://www.catsa-acsta.gc.ca/en/covid19-response

Chor, L. (2020, May 15). Flying long haul during Covid-19: air travel has never been stranger . The Guardian. Retrieved from https://www.theguardian.com/world/2020/may/15/flying-long-haul-during-covid-19air-travel-has-never-been-stranger

CIDRAP. (2021). COVID-19 Scan for Feb 04, 2021. Retrieved May 24, 2021, from CIDRAP website: https://www.cidrap.umn.edu/news-perspective/2021/02/covid-19scan-feb-04-2021

Clifford, N., Cope, M., Gillespie, T., \& French, S. (2016). Key Methods in Geography Google Books. In N. Clifford, M. Cope, T. Gillespie, \& S. French (Eds.), SAGE Publications Ltd (3rd ed.). Retrieved from https:/ /books.google.ca/books?hl=en\&lr=\&id=7hcFDAAAQBAJ\&oi=fnd\&pg=PA1 $43 \& \mathrm{dq}=$ semi + structured + interviews + AND + user + experience\&ots $=$ TDMJpq4Qdy\&si

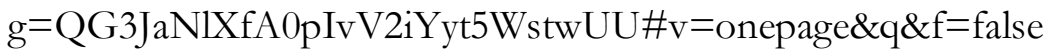

Detsky, A. S., \& Bogoch, I. I. (2020). COVID-19 in Canada: Experience and Response. JAMA, 324(8), 743-744. https://doi.org/10.1001/jama.2020.14033

Evans, P. (2020, April 23). No more middle seats? Airlines ponder new normal of flying in era of COVID-19 . Retrieved May 27, 2021, from CBC News website: https://www.cbc.ca/news/business/airlines-middle-seat-covid-19-1.5541305 Fazel, S. (2020). Flying safely during COVID-19: Tips from a public health researcher. 
National Post. Retrieved from https://nationalpost.com/opinion/flying-safely-duringcovid-19-tips-from-a-public-health-researcher

Fisher, M. (2020, April). COMMENTARY: Coronavirus will change the way Canadians travel. Global News. Retrieved from https://globalnews.ca/news/6854417/coronavirus-canada-travel-future/

Goldman, E. (2020, August 1). Exaggerated risk of transmission of COVID-19 by fomites. The Lancet Infectious Diseases, Vol. 20, pp. 892-893. https://doi.org/10.1016/S1473$3099(20) 30561-2$

Government of Alberta. (2021a). ABTraceTogether. Retrieved May 24, 2021, from Government of Alberta website: https://www.alberta.ca/ab-trace-together.aspx Government of Alberta. (2021b). COVID-19 travel requirements. Retrieved May 24, 2021, from Government of Alberta website: https://www.alberta.ca/covid-19-traveladvice.aspx\#jumplinks-1

Government of British Columbia. (2021). Travel and COVID-19. Retrieved May 24, 2021, from Government of British Columbia website: https://www2.gov.bc.ca/gov/content/covid-19/travel/current

Government of Canada. (2020a). Aviation measures in response to COVID-19. Retrieved May 26, 2021, from Government of Canada website: https://tc.canada.ca/en/initiatives/covid-19-measures-updates-guidance-issuedtransport-canada/aviation-measures-response-covid-19

Government of Canada. (2020b). COVID-19: Main modes of transmission. Retrieved May 24, 2021, from Government of Canada website: https://www.canada.ca/en/publichealth/services/diseases/2019-novel-coronavirus-infection/health-professionals/main- 
modes-transmission.html

Government of Canada. (2020c). COVID-19: Passenger transport where you may have been exposed. Retrieved May 26, 2021, from Government of Canada website: https://www.canada.ca/en/public-health/services/diseases/2019-novel-coronavirusinfection/latest-travel-health-advice/exposure-flights-cruise-ships-mass-gatherings.html Government of Canada. (2020d). Provincial and territorial restrictions - Travel restrictions in Canada - Travel.gc.ca. Retrieved May 26, 2021, from Government of Canada website: https://travel.gc.ca/travel-covid/travel-restrictions/provinces

Government of Canada. (2020e). Use ArriveCAN: Submit travel information to enter Canada. Retrieved May 27, 2021, from Government of Canada website: https://www.canada.ca/en/public-health/services/diseases/coronavirus-disease-covid19/arrivecan.html

Government of Canada. (2020f, October 23). COVID-19: How to quarantine (self-isolate) at home when you may have been exposed and have no symptoms . Retrieved May 26, 2021, from Government of Canada website: https://www.canada.ca/en/publichealth/services/publications/diseases-conditions /coronavirus-disease-covid-19-howto-self-isolate-home-exposed-no-symptoms.html

Government of Newfoundland \& Laborador. (2020). For Travellers - COVID-19. Retrieved May 24, 2021, from Government of Newfoundland \& Laborador website: https://www.gov.nl.ca/covid-19/individuals-and-households/travel-advice-2/ Hanington, B., \& Martin, B. (2012a). Universal Methods of Design : 100 Ways to Explore Complex Problems, Develop Innovative Strategies, and Deliver Effective Design So. Retrieved from http:/ / ebookcentral.proquest.com/lib/oculcarleton- 
ebooks / detail.action?docID=3399583

Hanington, B., \& Martin, B. (2012b). Universal Methods of Design. In Rockport Publishers.

Hertzberg, V. S., Weiss, H., Elon, L., Si, W., \& Norris, S. L. (2018). Behaviors, movements, and transmission of droplet-mediated respiratory diseases during transcontinental airline flights. Proceedings of the National Academy of Sciences of the United States of America, 115(14), 3623-3627. https://doi.org/10.1073/pnas.1711611115

International Air Transport Association. (2020a). Low Risk Transmission. Retrieved May 27, 2021, from International Air Transport Association website: https://www.iata.org/en/youandiata/travelers/health/low-risk-transmission/

International Air Transport Association. (2020b). On Arrival. Retrieved May 27, 2021, from International Air Transport Association website: https://www.iata.org/en/youandiata/travelers/health/on-arrival/

International Air Transport Association. (2021a). Cabin Air. Retrieved July 14, 2021, from International Air Transport Association website: https://www.iata.org/en/youandiata/travelers/health/cabin-air/ International Air Transport Association. (2021b, January 28). The impact of COVID-19 on aviation . Retrieved May 26, 2021, from International Air Transport Association website: https://airlines.iata.org/news/the-impact-of-covid-19-on-aviation International Air Travel Association. (2021). Travel Pass Initiative. Retrieved July 14, 2021, from International Air Travel Association website: https://www.iata.org/en/programs/passenger/travel-pass/

IPAC Canada. (n.d.). Guidance Documents (National and International) . Retrieved May 26, 2021, from IPAC Canada website: https://ipac-canada.org/guidance-documents- 
national-and-international.php

Jackson, H. (2020, April 22). Airline conducts rapid blood tests for COVID-19. Should this be the new normal? - National | Globalnews.ca. Global News. Retrieved from https://globalnews.ca/news/6851579/coronavirus-airline-blood-tests/

Janssens, K. A. M., Bos, E. H., Rosmalen, J. G. M., Wichers, M. C., \& Riese, H. (2018). A qualitative approach to guide choices for designing a diary study. BMC Medical Research Methodology, 18(1), 140. https://doi.org/10.1186/s12874-018-0579-6

Kraay, A. N. M., Hayashi, M. A. L., Berendes, D. M., Sobolik, J. S., Leon, J. S., \& Lopman, B. A. (2021). Risk for fomite-mediated transmission of SARS-CoV-2 in child daycares, schools, nursing homes, and offices. Emerging Infectious Diseases, 27(4), 1229-1231. https://doi.org/10.3201/eid2704.203631

Lei, H., Li, Y., Xiao, S., Lin, C. H., Norris, S. L., Wei, D., ... Ji, S. (2018). Routes of transmission of influenza A H1N1, SARS CoV, and norovirus in air cabin: Comparative analyses. Indoor Air, 28(3), 394-403. https://doi.org/10.1111/ina.12445

Levere, J. (2020). Airlines Say It's Safe to Travel. But Is It? . The New York Times. Retrieved from https://www.nytimes.com/2020/06/01/business/coronavirus-airportsairlines.html

Lewis, L., Patel, H., Cobb, S., D’Cruz, M., Bues, M., Stefani, O., \& Grobler, T. (2016). Distracting people from sources of discomfort in a simulated aircraft environment. Work (Reading, Mass.), 54(4), 963-979. https:/ / doi.org/10.3233/WOR-162356

Lewis, L., Patel, H., D’Cruz, M., \& Cobb, S. (2017). What makes a space invader? Passenger perceptions of personal space invasion in aircraft travel. Ergonomics, 60(11), 1461-1470. https://doi.org/10.1080/00140139.2017.1313456 
Luo, L., Liu, D., Liao, X., Wu, X., Jing, Q., Zheng, J., ... Mao, C. (2020). Modes of contact and risk of transmission in COVID-19 among close contacts. MedRxiv, 2020.03.24.20042606. https://doi.org/10.1101/2020.03.24.20042606

M.D. Pearl, R. (2021, March 15). Covid-19 Flight From Hell: My Run-In With An Infected Passenger. Forbes. Retrieved from https://www.forbes.com/sites/robertpearl/2021/03/15/covid-19-flight-from-hell-myrun-in-with-an-infected-passenger/?sh=da6e52e3b9e5

McGregor, G. (2020, May 9). What it's like to travel on a plane in the era of COVID-19. CTV News. Retrieved from https://www.ctvnews.ca/health/coronavirus/what-it-slike-to-travel-on-a-plane-in-the-era-of-covid-19-1.4932742

Menzies, D. (2005). Microbial Contamination in Airplane Cabins:Health Effects and Remediation (pp. 151-167). pp. 151-167. https://doi.org/10.1007/b107242

Noroozi, F., Kaminska, D., Corneanu, C., Sapinski, T., Escalera, S., \& Anbarjafari, G. (2019). Survey on Emotional Body Gesture Recognition. IEEE Transactions on Affective Computing, 1-1. https://doi.org/10.1109/TAFFC.2018.2874986

Onakpoya, I. J., Heneghan, C. J., Spencer, E. A., Brassey, J., Plüddemann, A., Evans, D. H., ... Jefferson, T. (2021). SARS-CoV-2 and the role of fomite transmission: a systematic review [version 1; peer review: 2 approved with reservations]. F1000 Research, 10, 233. https://doi.org/10.12688/f1000research.51590.1

Preece, J., Sharp, H., \& Rogers, Y. (2015). Interaction design: Beyond Human Computer Interaction (3rd Editio). https://doi.org/10.1049/cp:20060709

Prelipcean, A. C., Susilo, Y. O., \& Gidófalvi, G. (2018). Collecting travel diaries: Current state of the art, best practices, and future research directions. Transportation Research 
Procedia, 32, 155-166. https://doi.org/10.1016/j.trpro.2018.10.029

Proskow, J. (2020, May 18). Travel will never be the same, thanks to COVID-19 - National | Globalnews.ca. Global News. Retrieved from https://globalnews.ca/news/6939140/travel-will-never-be-the-same-thanks-to-covid$19 /$

Public Health Ontario. (2020). Coronavirus Disease 2019 (COVID-19) . Retrieved May 26, 2021, from Public Health Ontario website: https://www.publichealthontario.ca/en/diseases-and-conditions/infectiousdiseases/respiratory-diseases/novel-coronavirus

Quarantine Act. , (2005).

Ramsay, C. (2020, May 7). Passenger shocked by packed Air Canada flight: 'I was a little disappointed' | Globalnews.ca. Global News. Retrieved from https://globalnews.ca/news/6915723/edmonton-woman-packed-air-canada-flightcovid-19/

Saldaña, J. (2011). Fundamentals of qualitative research. Retrieved from https://ebookcentralproquest-com.proxy.library.carleton.ca/lib/oculcarletonebooks $/$ reader.action?docID $=665394 \& p p g=98 \#$

Sandvik, B. M., \& McCormack, B. (2018). Being person-centred in qualitative interviews: reflections on a process. International Practice Development Journal, 8(2), 1-8. https://doi.org/10.19043/ipdj.82.008

Sillers, P. (2020, May 22). Future of air travel: What could change because of Covid-19? . Retrieved May 26, 2021, from CNN Travel website: https://www.cnn.com/travel/article/air-travel-future-covid-19/index.html 
Slater, K. (1985). Human comfort. Springfield, Ill., U.S.A: C.C. Thomas.

Taylor, S. (2020, May 4). Air Transport 2035: Four Possible Post-COVID-19 Scenarios for Aviation . Retrieved May 26, 2021, from APEX website: https://apex.aero/articles/airtransport-2035-webinar-results/

The Canadian Press. (2020, April 22). WestJet announces 3,000 layoffs and domestic flight cancellations over COVID-19 . Retrieved May 27, 2021, from CTV News website: https://www.ctvnews.ca/business/westjet-announces-3-000-layoffs-and-domesticflight-cancellations-over-covid-19-1.4907864

Thompson, D. (2020). The Scourge of Hygiene Theater. The Atlantic. Retrieved from https://www.theatlantic.com/ideas/archive/2020/07/scourge-hygienetheater/614599/

Thompson, D. (2021). Hygiene Theater: Deep Cleaning Isn't a Victimless Crime . The Atlantic. Retrieved from https://www.theatlantic.com/ideas/archive/2021/04/endhygiene-theater/618576/

Toon, J. (2012). Study Will Provide Information on How Infectious Diseases May be Transmitted on Aircraft | Research Horizons . Retrieved May 27, 2021, from Georgia Tech website: https://rh.gatech.edu/news/134291/study-will-provide-informationhow-infectious-diseases-may-be-transmitted-aircraft

Toon, J. (2018, March 19). Researchers Determine Routes of Respiratory Infectious Disease Transmission on Aircraft | Research Horizons | Georgia Tech's Research News. Georgia Tech. Retrieved from https://rh.gatech.edu/news/603990/researchersdetermine-routes-respiratory-infectious-disease-transmission-aircraft Transport Canada. (2020). Canada's Flight Plan for Navigating COVID-19. Retrieved May 
26, 2021, from Government of Canada website:

https://tc.canada.ca/en/initiatives/covid-19-measures-updates-guidance-issuedtransport-canada/canada-s-flight-plan-navigating-covid-19

Transportation Research Board. (2010a). Practical Case-Response Approaches to Investigating the Spread of Disease in Airports and on Aircraft. Transportation Research Board.

Transportation Research Board. (2010b). Theoretical Modeling Approaches to Investigating the Spread of Disease in Airports and on Aircraft. Transportation Research Board.

Vink, P., Bazley, C., Kamp, I., \& Blok, M. (2012). Possibilities to improve the aircraft interior comfort experience. Applied Ergonomics, 43(2), 354-359.

https://doi.org/10.1016/j.apergo.2011.06.011

West Jet. (2021). Safety Above All. Retrieved May 27, 2021, from West Jet website: https://www.westjet.com/en-ca/prepare/safety

World Health Organization. (2020a). Coronavirus. Retrieved May 26, 2021, from World Health Organization website: https://www.who.int/healthtopics/coronavirus\#tab=tab_1

World Health Organization. (2020b, March). Timeline of WHO's response to COVID-19. Retrieved May 26, 2021, from World Health Organization website: https://www.who.int/emergencies/diseases/novel-coronavirus-2019/interactivetimeline?gclid=CjwKCAjw47eFBhA9EiwAy8kzNFXLfCRczO9kHhbEKmCrNyKmgn hWPov4ZDFL398yL51MoBv5QXXLSBoCkZwQAvD_BwE\#! 


\section{Appendices}

\section{Appendix A Keyword Search Comparing Access to Literature in}

\section{0 and 2021}

\begin{tabular}{|c|c|c|c|c|c|}
\hline Journal and/or Publication Source & $\begin{array}{l}\text { Key Word(s) } \\
\text { in Search }\end{array}$ & Date of search & $\begin{array}{l}\text { \#Relevant Sources as } \\
\text { of Date (2020) }\end{array}$ & Date of search & $\begin{array}{l}\text { \# Relevant Sources } \\
\text { of Date (2021) }\end{array}$ \\
\hline \multirow[t]{12}{*}{ Engineering Village. } & Airplane AND coronavirus & $2019 \cdot 2020$ & 10 & $2020 \cdot 2021$ & 14 \\
\hline & Airplane AND COVD-19 & 2019-2020 & 9 & $2020-2021$ & 17 \\
\hline & Air Travel AND coronavirus OR COVID-19 & 2019.2020 & 12,558 & 2020.2021 & 18,306 \\
\hline & Airport AND coronavirus OR COVID-19 & $2019 \cdot 2020$ & 12,559 & $2020-2021$ & 18,310 \\
\hline & Airplane AND health & 2019.2020 & 130 & $2020-2021$ & 68 \\
\hline & Air Travel AND health & 2019.2020 & 335 & 2020.2021 & 251 \\
\hline & User experience AND coronavirus OR COVD-19 & $2019-2020$ & 190 & $2020-2021$ & 242 \\
\hline & Passenger AND coronavirus OR COMD-19 & $2019 \cdot 2020$ & 97 & $2020 \cdot 2021$ & 158 \\
\hline & Flight AND coronavirus OR COVD-19 & $2019-2020$ & 79 & $2020-2021$ & 117 \\
\hline & Infection Prevention Control AND COVD-19 AND a & a 2019-2020 & 2 & $2020-2021$ & 10 \\
\hline & Coronavirus OR COVD-19 AND Infection Preventic & 2019-2020 & 349 & $2020 \cdot 2021$ & 510 \\
\hline & & & 26318 & & 38003 \\
\hline \multirow[t]{11}{*}{ PubMed } & Airplane AND coronavirus & 2020 & 83 & 2021 & 110 \\
\hline & Airplane AND COMD-19 & 2020 & 99 & 2021 & 58 \\
\hline & Air Travel AND coronavirus OR COVID-19 & 2020 & 91,342 & 2021 & 57,543 \\
\hline & Airport AND coron avirus OR COVID-19 & 2020 & 91,172 & 2021 & 57,543 \\
\hline & Covid AND airplane & 2020 & 99 & 2021 & 56 \\
\hline & COMD AND air travel & 2020 & 166 & 2021 & 82 \\
\hline & User experience AND coronavirus OR COVD-19 & 2020 & 56 & 2021 & 67 \\
\hline & Passenger AND coronavirus OR COMD-19 & 2020 & 147 & 2021 & 89 \\
\hline & Flight AND coronavirus OR COVD-19 & 2020 & 158 & 2021 & 97 \\
\hline & Infection Prevention Control AND COMD.19 & 2020 & 20,922 & 2021 & 10,248 \\
\hline & & & 204244 & & 115645 \\
\hline \multirow{11}{*}{ Taylor \& Francis } & Airplane AND coronavirus & 2020 & 84 & 2021 & 43 \\
\hline & Airplane AND COMD-19 & 2020 & 147 & 2021 & 74 \\
\hline & Air Travel AND coronavirus OR COVID.19 & 2020 & 2,848 & 2021 & 1,487 \\
\hline & Airport AND coronavirus OR COVID-19 & 2020 & 16,096 & 2021 & 8,596 \\
\hline & Covid AND airplane & 2020 & 147 & 2021 & 74 \\
\hline & COMD AND air travel & 2020 & 1,220 & 2021 & 629 \\
\hline & User experience AND coronavirus OR COVD-19 & 2020 & 15,414 & 2021 & 8,366 \\
\hline & Passenger AND coronavirus OR COMD-19 & 2020 & 16,089 & 2021 & 8,594 \\
\hline & Flight AND coronavirus OR COVD-19 & 2020 & 16,155 & 2021 & 8,524 \\
\hline & Infection Prevention Control AND COMD-19 & 2020 & 3.684 & 2021 & 1.967 \\
\hline & & & 71884 & & 38454 \\
\hline \multirow[t]{11}{*}{ Scopus } & Airplane AND coronavirus & 2020 & 89 & 2021 & 79 \\
\hline & Airplane AND COVD-19 & 2020 & 88 & 2021 & 95 \\
\hline & Air Travel AND coronavirus OR COVID-19 & 2020 & 9,072 & 2021 & 6.711 \\
\hline & Airport AND coronavirus OR COVID-19 & 2020 & 685 & 2021 & 590 \\
\hline & Covid AND airplane & 2020 & 88 & 2021 & 95 \\
\hline & COMD AND air travel & 2020 & 1,476 & 2021 & 1,350 \\
\hline & User experience AND coronavirus OR COVD-19 & 2020 & 2,325 & 2021 & 3.232 \\
\hline & Passenger AND coronavirus OR COMD-19 & 2020 & 923 & 2021 & 889 \\
\hline & Flight AND coronavirus OR COVD-19 & 2020 & 1,144 & 2021 & 1.116 \\
\hline & Infection Prevention Control AND COMD-19 & 2020 & 17,829 & 2021 & 11,440 \\
\hline & & & 33719 & & 25597 \\
\hline \multirow[t]{11}{*}{ Proquest } & Airplane AND coronavirus & 2020 & 0 & 2021 & 0 \\
\hline & Airplane AND COMD-19 & 2020 & 1 & 2021 & 0 \\
\hline & Air Travel AND coronavirus OR COVID-19 & 2020 & 355 & 2021 & 675 \\
\hline & Airport AND coronavirus OR COVID-19 & 2020 & 353 & 2021 & 675 \\
\hline & Covid AND airplane & 2020 & 0 & 2021 & 0 \\
\hline & COMD AND air travel & 2020 & 5 & 2021 & 2 \\
\hline & User experience AND coronavirus OR COVD-19 & 2020 & 1,312 & 2021 & 675 \\
\hline & Passenger AND coronavirus OR COMD-19 & 2020 & 1,312 & 2021 & 675 \\
\hline & Flight AND coronavirus OR COVD-19 & 2020 & 1,312 & 2021 & 675 \\
\hline & Infection Prevention Control AND COMD-19 & 2020 & 1 & 2021 & 5 \\
\hline & & & 4651 & & 3382 \\
\hline
\end{tabular}




\section{Appendix B Detailed Account of Two Passenger Narratives}

\section{(2020)}

Passenger experience \#1 - In this first case, a passenger flew from Ottawa to Calgary via Toronto prior to May 9, 2020 with WestJet (McGregor, 2020). In their retelling of their experience, they claimed to walk directly to security screening once arriving at the Ottawa airport. He noted that he only noticed a few of the other passengers were wearing masks. Upon boarding the flight to Toronto, a crew member asked him a list of questions: "Any symptoms, any international travel, any provincial quarantines?". Once cleared, he received a disinfectant wipe upon boarding the plane from a flight attendant who used a pair of tongs for the transfer. Once seated, this passenger reported that another flight attendant asked him to move to the back of the plane "to ensure proper weight distribution".

After arriving at the Pearson Airport in Toronto, he noted that the gate for his next flight was crowded, sharing that with middle seats not being sold at this time, that nearly every row of seating was occupied on the plane. In this second flight, he stated that all passengers wore masks, and the flight attendants wore masks and gloves as PPE, mandated by the federal government. In terms of on-board service, pretzels, cookies and water were provided to passengers, and lavatory use was challenging due to waiting in line in the aisles and trying to maintain appropriate physical distance from other passengers. Once landed, the passenger noted "usual chaos" when passengers retrieved their baggage, and a lack of distancing in the aisle upon disembarking. When reflecting on his flight, he noted irritation from wearing his face mask for an extended period of time, and uncertainty if he would by symptom free after his return flight, despite being asymptomatic after his flight to Calgary, although we cannot infer affect in his statements alone.

Passenger experience \#2 - This second case looked into a passenger's experience flying from Paris to Hong Kong via London with British Airways, prior to May 15, 2020 (Chor, 2020). Due to changes in flight availability, this passenger was forced to book a connecting flight through London to Hongkong. Upon arriving at the Heathrow airport, she described it as being "eerily quiet" and she felt she was alone in the airport until past security. Once in the waiting area, there were no retail or restaurant services open, there was no music and no announcements being played on the intercom. She felt that any other individual at the airport must have been on her same flight, noting that once boarded, the pilot announced that there were only 100 passengers on the flight and there would be a mandatory quarantine upon arrival at their destination. Once on the plane, flight attendants directed passengers to their seats, wearing a mask and gloves. She pointed a significant contrast in the PPE being worn, stating that the rest of the flight crew was not wearing any PPE whereas some of the passengers wore "full-body protective suits, plastic face shields, goggles, and gloves". Food and drink service were in place as usual, and a sense of calmness and patience from other passengers was mentioned regarding the remainder of the flight. 
Upon arriving in Hong Kong, passengers were "herded through station after station", where they were: asked to fill out health forms and orders; download a tracking app; provide their personal contact information; activate their tracking bracelets; read the quarantine order; and given a thermometer and instructions for self-testing. Following customs, passengers were sent to a testing facility where they were tested for COVID-19 and waived for clearance based on the results of their tests. This passenger said she waited 7 hours in this testing center, where she was cleared and ordered to conduct a second self-test within 12 days of her quarantine. From end to end, her travel to Hong Kong took a total of 19 hours with the new screening and testing protocols implemented. This contrasts with the average of 12-15 hours it would typically take flying from Paris to Hongkong.

Other sources and/or stories used to frame current passenger experience:

(Bowden, 2020; Brooklyn, 2020; Ramsay, 2020) 


\title{
Appendix C Ethics Protocol \#114849
}

\author{
Carleton \\ Canada's Capital University \\ Office of Research Ethics \\ 4500 ARISE Building | 1125 Colonel By Drive \\ Ottawa, Ontario K1S $5 B 6$ \\ 613-520-2600 Ext: 4085 \\ ethics@carleton.ca
}

\section{CERTIFICATION OF INSTITUTIONAL ETHICS CLEARANCE}

The following research has been granted clearance by the Carleton University Research Ethics Board-B (CUREB-B). CUREB-B is constituted and operates in compliance with the Tri-Council Policy Statement: Ethical Conduct for Research Involving Humans (TCPS2).

Ethics Clearance ID: Project \# 114849

Project Team Members: Ms. Kayla Daigle (Primary Investigator)

Chantal Trudel (Research Supervisor)

Shelley Kelsey (Research Supervisor)

Study Title: Improving Air Travel Comfort \& Experience: Designing for Infection Prevention and Control in Response to COVID-19

Funding Source: (If applicable):

Effective: December 17, 2020

Expires: December 31, 2021

This certification is subject to the following conditions:

1. Clearance is granted only for the research and purposes described in the application.

2. Any modification to the approved research must be submitted to CUREB-B via a Change to Protocol Form. All changes must be cleared prior to the continuance of the research.

3. An Annual Status Report for the renewal or closure of ethics clearance must be submitted and cleared by the renewal date listed above. Failure to submit the Annual Status Report will result in the closure of the file. If funding is associated, funds will be frozen.

4. During the course of the study, if you encounter an adverse event, material incidental finding, protocol deviation or other unanticipated problem, you must complete and submit a Report of Adverse Events and Unanticipated Problems Form.

5. It is the responsibility of the student to notify their supervisor of any adverse events, changes to their application, or requests to renew/close the protocol.

6. Failure to conduct the research in accordance with the principles of the Tri-Council Policy Statement: Ethical Conduct for Research Involving Humans 2nd edition and the Carleton 
University Policies and Procedures for the Ethical Conduct of Research may result in the suspension or termination of the research project.

IMPORTANT: Special requirements for COVID-19:

If this study involves in-person research interactions with human participants, whether on- or offcampus, the following rules apply:

1. Upon receiving clearance from CUREB, please seek the approval of the relevant Dean for your research. Provide a copy of your CUREB clearance to the Dean for their records. See Principles and Procedures for On-campus Research at Carleton University and note that this document applies both to on- and off-campus research that involves human participants. Please contact your Dean's Office for more information about obtaining their approval.

2. Provide a copy of the Dean's approval to the Office of Research Ethics prior to starting any inperson research activities.

3. If the Dean's approval requires any significant change(s) to any element of the study, you must notify the Office of Research Ethics of such change(s).

Upon reasonable request, it is the policy of CUREB, for cleared protocols, to release the name of the PI, the title of the project, and the date of clearance and any renewal(s).

Please email the Research Compliance Coordinators at ethics@carleton.ca if you have any questions.

CLEARED BY:

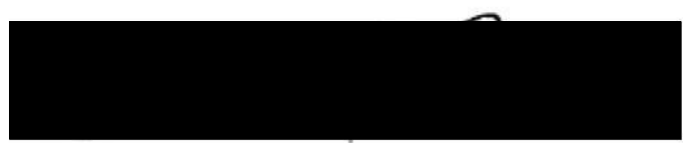

Bernadette Campbell, PhD, Chair, CUREB-B

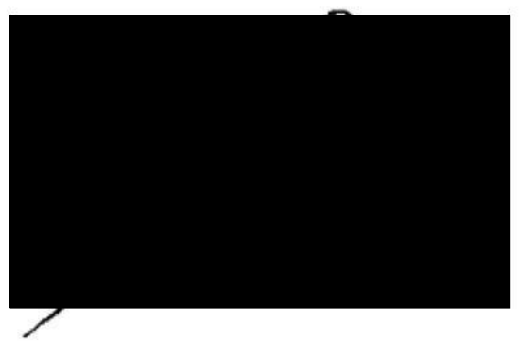

Natasha Artemeva, Co-Chair, PhD, Vice Chair, CUREB-B
Date: December 17, 2020 


\section{Appendix D Passenger Characteristics and Travel Information}

\section{(Methods 2 \& 3)}

\begin{tabular}{|c|c|c|c|c|c|}
\hline \multicolumn{6}{|c|}{ Passenger Travel Details } \\
\hline Participant & Age & Method & Date(s) of travel & Courier & Airports Visited \\
\hline 1 & $\begin{array}{l}20- \\
29\end{array}$ & Interview & December 10, 2020 & 2 & $\begin{array}{l}\text { Airport A, } \\
\text { Airport C }\end{array}$ \\
\hline 2 & $\begin{array}{l}30- \\
39\end{array}$ & Interview & September $11 \& 14,2020$ & 3 & \begin{tabular}{|l} 
Airport C, \\
Airport D
\end{tabular} \\
\hline 3 & $\begin{array}{l}60- \\
69\end{array}$ & Interview & $\begin{array}{l}\text { December 28, 2020, } \\
\text { January 2, 2021 }\end{array}$ & 2 & $\begin{array}{l}\text { Airport E, } \\
\text { Airport C }\end{array}$ \\
\hline 4 & $\begin{array}{l}20- \\
29\end{array}$ & $\begin{array}{l}\text { Travel Diary \& } \\
\text { Interview }\end{array}$ & $\begin{array}{l}\text { December 28, 2020, } \\
\text { January 2, } 2021\end{array}$ & 2 & $\begin{array}{l}\text { Airport E, } \\
\text { Airport C }\end{array}$ \\
\hline 5 & $\begin{array}{l}20- \\
29\end{array}$ & Interview & August 2020 & 4,1 & $\begin{array}{l}\text { Airport F, } \\
\text { Airport G, } \\
\text { Airport D, } \\
\text { Airport B }\end{array}$ \\
\hline 6 & $\begin{array}{l}20- \\
29\end{array}$ & Interview & July 2020 & $1,5,6$ & $\begin{array}{l}\text { Airport H, } \\
\text { Airport, I, } \\
\text { Airport, F, } \\
\text { Airport B, } \\
\text { Airport A }\end{array}$ \\
\hline 7 & $\begin{array}{l}20- \\
29\end{array}$ & $\begin{array}{l}\text { Travel Diary \& } \\
\text { Interview }\end{array}$ & January 20, 2021 & 1 & $\begin{array}{l}\text { Airport J, } \\
\text { Airport E, } \\
\text { Airport K }\end{array}$ \\
\hline 8 & $\begin{array}{l}20- \\
29\end{array}$ & $\begin{array}{l}\text { Travel Diary \& } \\
\text { Interview }\end{array}$ & $\begin{array}{l}\text { December 22, } 2020 \text { - January 2, } \\
2021\end{array}$ & 2 & $\begin{array}{l}\text { Airport L, } \\
\text { Airport D, Airport E }\end{array}$ \\
\hline 9 & $\begin{array}{l}30- \\
39\end{array}$ & Interview & November 14 - 21, 2020 & 1,4 & $\begin{array}{l}\text { Airport C, } \\
\text { Airport E, } \\
\text { Airport M, } \\
\text { Airport N }\end{array}$ \\
\hline 10 & $\begin{array}{l}60- \\
69\end{array}$ & Interview & January 21 - 25, 2021 & 2 & $\begin{array}{l}\text { Airport C, } \\
\text { Airport O }\end{array}$ \\
\hline 11 & $\begin{array}{l}20- \\
29\end{array}$ & Interview & $\begin{array}{l}\text { December 17, } 2020 \text { - January 9, } \\
2021\end{array}$ & 1 & $\begin{array}{l}\text { Airport P, } \\
\text { Airport D, } \\
\text { Airport C }\end{array}$ \\
\hline
\end{tabular}




\begin{tabular}{|c|c|c|c|c|c|}
\hline 12 & $\begin{array}{l}30- \\
39\end{array}$ & Interview & January 8 - Jan 30, 2021 & 2 & $\begin{array}{l}\text { Airport Q, } \\
\text { Airport C, } \\
\text { Airport R, } \\
\text { Airport E }\end{array}$ \\
\hline 13 & $\begin{array}{l}40- \\
49\end{array}$ & Interview & December 19 - 23, 2020 & 2 & $\begin{array}{l}\text { Airport C, } \\
\text { Airport S, } \\
\text { Airport D }\end{array}$ \\
\hline 14 & $\begin{array}{l}30- \\
39\end{array}$ & Interview & January 7, 2021 & 1 & $\begin{array}{l}\text { Airport T, } \\
\text { Airport E }\end{array}$ \\
\hline 15 & $\begin{array}{l}50- \\
59\end{array}$ & Travel Diary & $\begin{array}{l}\text { December 28, 2020, } \\
\text { January 2, } 2021\end{array}$ & 2 & $\begin{array}{l}\text { Airport E, } \\
\text { Airport C }\end{array}$ \\
\hline 16 & $\begin{array}{l}20- \\
29\end{array}$ & Travel Diary & $\begin{array}{l}\text { November 13, 2020, } \\
\text { January 6, } 2021\end{array}$ & 2 & $\begin{array}{l}\text { Airport A, } \\
\text { Airport C, } \\
\text { Airport U }\end{array}$ \\
\hline
\end{tabular}




\section{Appendix E Workbook Sheets from Method 1}
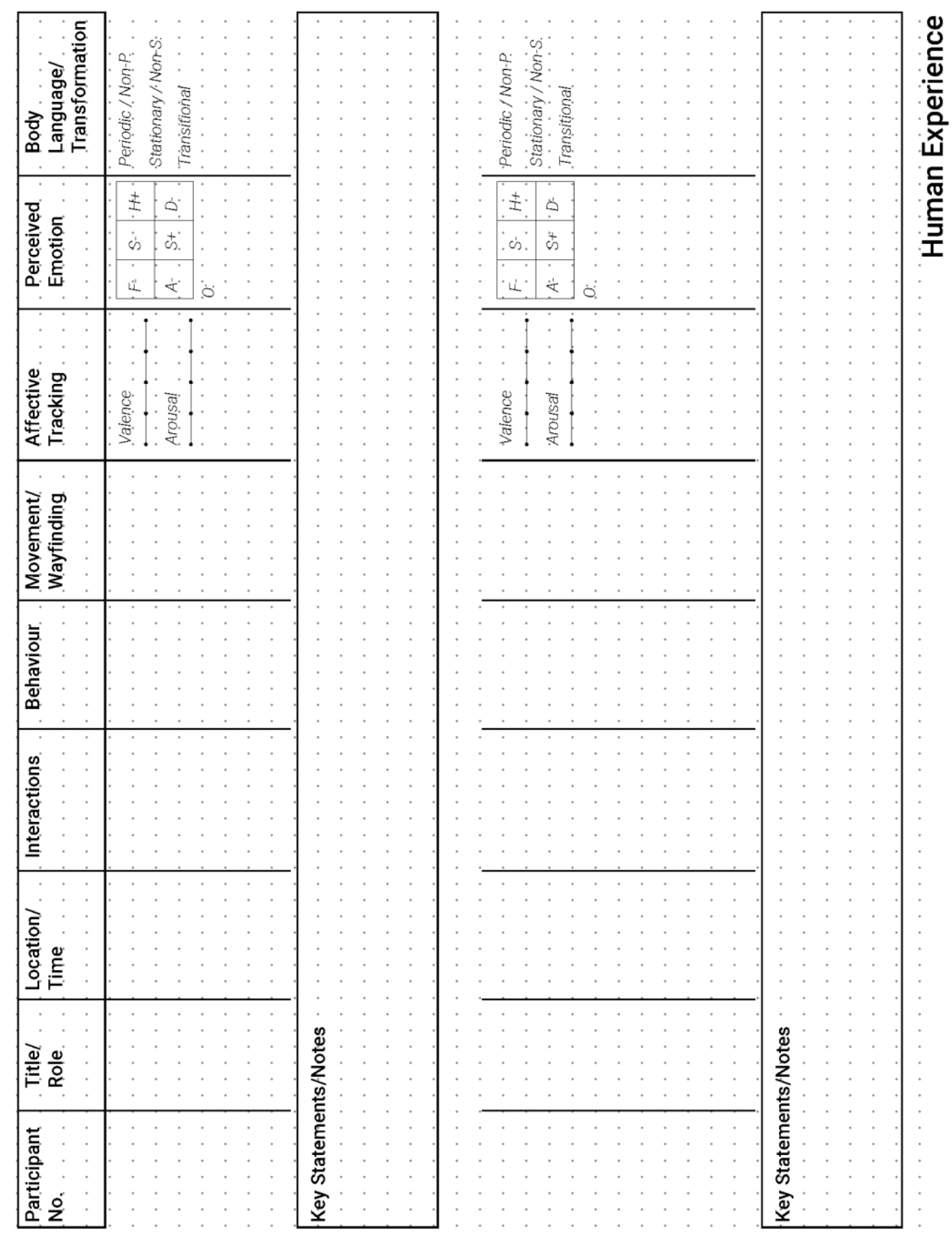


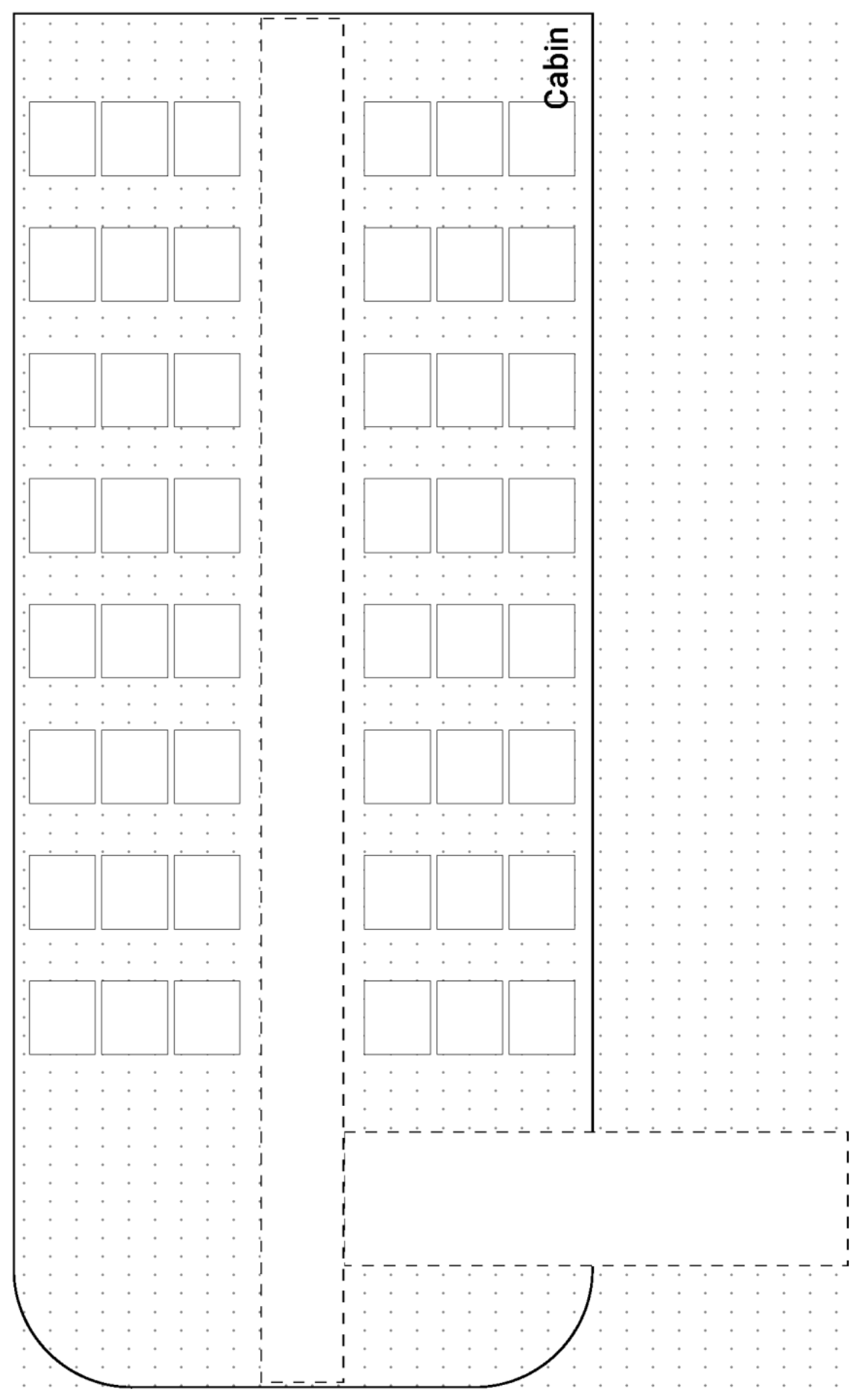




\section{Appendix F Interview Guide}

\section{Recent Air Traveler Interview Guide: Improving Air Travel Comfort \& Experience: Designing for Infection Prevention and Control in Response to COVID-19}

1. Could you please share your recent travel experience?

a. Walk through booking/planning, airport experience (check-in, security, pre-board), flight, disembark.

2. Could you describe any differences in the way you chose to plan and/or book your recent flight in response to COVID-19?

a. Were your booking preferences influenced by the outbreak numbers in certain destination/connecting cities?

b. What would improve your comfort in planning and booking travel in the future, while COVID-19 is still relevant?

c. What kind of information would improve your experience if available when planning and booking travel?

3. Can you describe how your air travel experience has changed since COVID-19 began?

4. How has your comfort been influenced while travelling throughout the pandemic?

a. In what way(s) could the physical environment be improved to provide better passenger experience?

b. In what way(s) could the service be improved to provide better passenger experience?

c. Could you describe if there are specific aspects of your travel journey that made it challenging, pleasant, or confusing?

5. In what ways did the addition of Personal Protective Equipment (PPE) influence your comfort in flying - positive or negative?

a. Did you notice any differences in what was worn by individuals working in the airport and aircraft?

6. If you were travelling as a care giver (i.e. with children, an older adult, someone who requires assistance, etc.), can you describe how your travel experience may have been impacted?

This research has been cleared by Carleton University Research Ethics Board-B (CUREB-B Clearance \#114849).

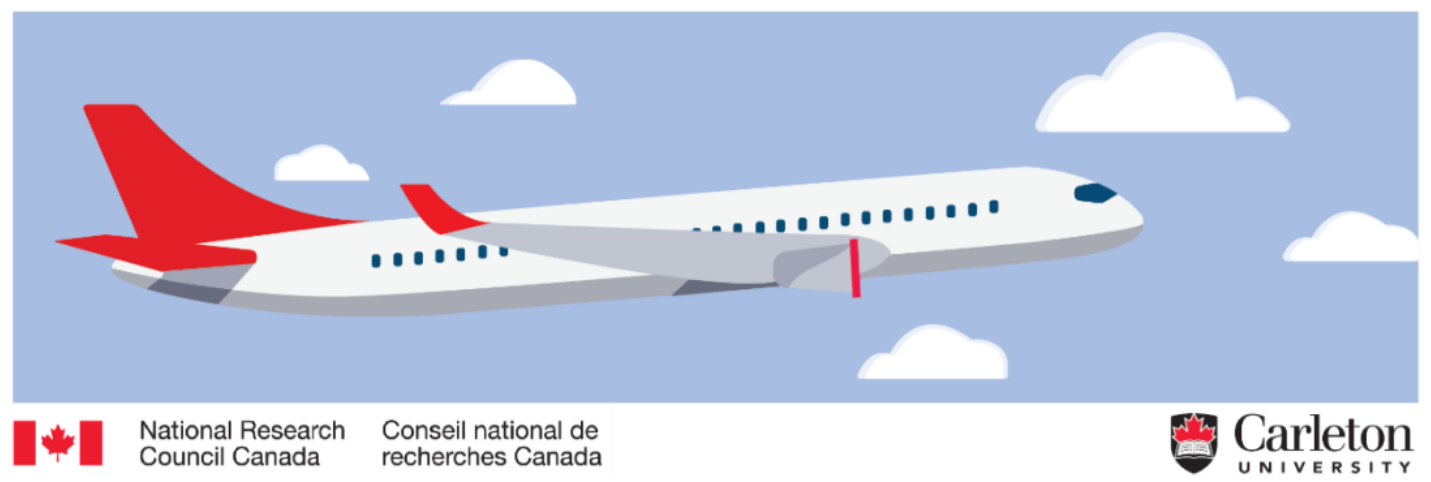




\section{Appendix G Comparison of Airports Visited (July and August}

\section{0)}

\begin{tabular}{|c|c|}
\hline \multicolumn{2}{|c|}{ Airport A(July 2020) } \\
\hline Airport Context & Cabin Context \\
\hline 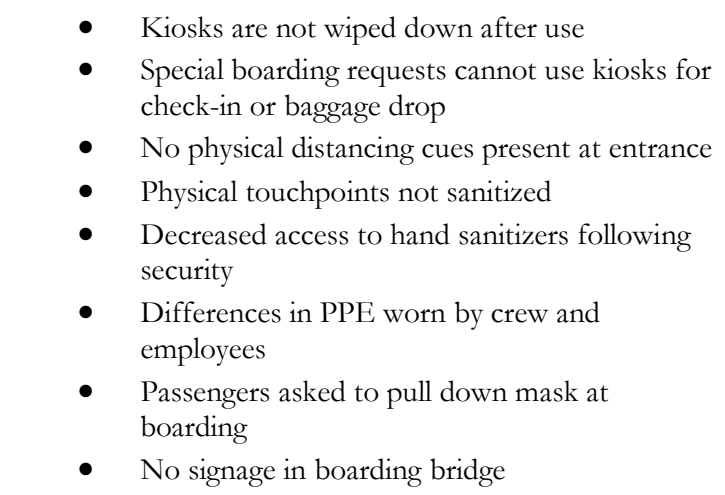 & $\begin{array}{l}\text { - } \\
\text { - } \quad \text { Nir Courier 1) CleanCare+ kit given upon } \\
\text { - } \quad \text { No business class seats are filled } \\
\text { - } \quad \text { No reminder for passengers to clean their } \\
\text { - } \quad \text { All personal space, no cues at seats } \\
\text { - } \quad \text { Potential understaffing } \\
\text { - } \quad \text { High touchpoint areas include seats, overhead } \\
\text { bins, lavatory door }\end{array}$ \\
\hline \multicolumn{2}{|c|}{ Airport B(July 2020) } \\
\hline Airport Context & Cabin Context \\
\hline $\begin{array}{l}\text { - } \quad \text { No information about COVID-19 or related } \\
\text { area and surrounding airport environment }\end{array}$ & $\begin{array}{l}\text { - (Air Courier 1) CleanCare+ kit given after } \\
\text { passengers seated right before takeoff } \\
\text { - No time or visual cues for passengers to clean } \\
\text { their space prior to takeoff } \\
\text { - } \quad \text { Differences in PPE worn by cabin crew } \\
\text { Difference in takeoff and landing } \\
\text { announcements, compared to previous flight }\end{array}$ \\
\hline \multicolumn{2}{|c|}{ Airport C(August 2020) } \\
\hline Airport Context & Cabin Context \\
\hline $\begin{array}{l}\text { - } \quad \text { COVID-19 signage seen at front entrances and } \\
\text { front areas of airport } \\
\text { - } \quad \text { Many kiosks at check-in and baggage drop } \\
\text { - } \quad \text { Nand sanitizer stations seen regularly at check- } \\
\text { near boarding area and surrounding airport } \\
\text { - } \quad \text { Distancing cues seen on gate seats and in line } \\
\text { - } \quad \text { Restaurants and shops are open } \\
\text { - } \quad \text { People seem to be following distancing cues }\end{array}$ & $\begin{array}{l}\text { - (Air Courier 1) CleanCare+ kit given upon } \\
\text { boarding air cabin } \\
\text { - No cues for passengers to clean space prior to } \\
\text { flight } \\
\text { - } \quad \text { Full capacity flight } \\
\text { - Differences in PPE worn by cabin crew } \\
\text { Different announcements given compared to } \\
\text { - earlier flights } \\
\text { Passengers given "travel health" link to review } \\
\text { when they land at destination }\end{array}$ \\
\hline
\end{tabular}




\section{Appendix $\mathrm{H}$ List of Findings and Takeaways from Method 1}

1. Does a lack of sanitizing wipes and/or cleaning measures around high touchpoint areas (i.e., kiosks and screens) cause concern for the spread of infection?

2. Why are there different levels of access to hand sanitizers at different points in the passengers experience (e.g., check-in vs. security vs. gate area)?

3. Is there a reason there are differences in the PPE worn by employees and cabin crew? Would regulating this impact a passengers experience or comfort?

4. There are no IPAC measures in the bridge area - distancing cues, sanitizers, etc.

5. Should visual cues be added in the cabin to remind passengers to distance or clean their area?

6. The cabin environment has a potential risk of infection with so many touchpoints as people move through aisles. Is there a way to reduce risk?

7. Why are the airline processes and announcements different on each flight, when flying with the same courier?

8. Announcements about local restrictions should be more clearly accessible and available upon arrival at destination? 


\title{
Appendix I List of Codes and Related Quotes From Method 2
}

\author{
CODE INSTANCE COUNT - TRAVEL DIARIES
}

IPAC (42)

"Each person got a sanitizing wipe to wipe down their seat and area before getting settled." (P8)

"There were signs at the entrance stating you had to wear a mask." (P16)

"[...] no signage in Calgary but much more HS stations." (P4)

\section{BEHAVIOUR (33)}

"Excited, as I do enjoy flying and travelling. A bit of apprehension, though, too, wondering if I should be flying or not and if it was the right choice to be making." (P8)

"No one is acting irrationally that I can tell, so not too scared. All are obeying regulations and being safe." (P8)

"Since it was later on in the pandemic I think people have gotten pretty used to the situation we are in and maybe a bit tired of it so they didn't seem very stressed or worried." (P16)

PPE (32)

"Masks were consistent because of regulations. I didn't really noticed any other PPE. Some might have been wearing goggles." (P16)

"Customers are all distancing and wearing masks. Staff are not really distancing, but are definitely wearing masks." (P8)

"[...] changed masks openly in line." (P4)

\section{TOUCHPOINT (25)}

"Handing passport over, checking tickets, same as usual." (P7)

"Hand over your passport and boarding pass, then stand back and remove your mask temporarily to show your face for your ID...putting bags in the overhead bins, grabbing tops of seats as they walk by to steady themselves." (P8)

"A lot of touching of security bins and I have to wonder how often they actually wash those." (P16)

\section{PROMPT (24)}

"Yes, the usual alerts were present, reminding people to avoid flying for non-essential reasons and to make sure you were adhering to COVID-19 regulations if you had to fly (i.e., mask at all times, separate where possible)." (P8)

"There were instructions but do not think people paid attention, I only heard half." (P4)

"The attendants would come around and ask those who took them off (or down) to put them back on." (P16)

\section{PERCEPTION OF SAFETY (19)}

"I felt safe in the knowledge everyone in the airport had to have a negative test result." (P7)

"Not very comfortable but comfortable enough to risk flying." (P16) 
"I was comfortable, just trying to keep my distance." (P16)

"People sitting too close." (P15)

\section{SERVICE (14)}

"Flight attendants are very good with COVID compliance orders, but are still going about their usual business." (P8)

"There are no dining services at this airport. There's literally only one gate, it's very small." (P8)

"They gave us little bags with water, a cookie, and hand sanitizer." (P7)

\section{BUILT ENVIRONMENT (13)}

(cabin and airport)

"People are mostly distancing, but kind of like getting on, they're a bit crowded in the aisles. Touch-based: grabbing bags from overhead bins, mostly.” (P8)

"[...] seat back tray but its probably one of the dirtiest surface on the plane with its rough surface." (P16)

\section{CAPACITY (13)}

“[...] surprised by emptiness, overall calm.” (P4)

"Limited services, no crowds." (P15)

\section{SECURITY (9)}

"Staff are all wearing their PPE and maintaining distance where possible (not between each other but with customers)." (P8)

\section{CLEAN (8)}

"I mean, airports are always known as germy places, so I think the main thing was just being EVEN MORE conscious

of washing my hands and wiping down hard bags and such." (P8)

"I used sanitized wipes to clean my seat." (P7)

\section{SCREENING (7)}

"I felt safe in the knowledge everyone in the airport had to have a negative test result." (P7)

BOOKING (6)

"Booked flight Oct. 22. I tried to strategically fly back earlier so I wouldn't be flying during the Christmas rush.” (P16)

\section{PROCESS (6)}

"West Jet was pretty good with their policies, not so much cancelling that I noticed, but seemed pretty easy to reschedule as needed. Didn't have to do either, though, so not 100\% sure." (P8) 


\section{ONLINE (5)}

"Online, always, even outside of COVID. It's so much quicker and easier and then you're all checked in when you get to the airport." (P8)

PRICE (5)

"Price for the flights were the same (thought they might be cheaper)." (P16)

"Price was slightly cheaper." (P7)

\section{SELF-PREPAREDNESS (5)}

"The only thing that was different was having to be aware of COVID regulations from one province to another. When Ontario went into lockdown on my return flight, I wasn't sure if they were going shut the provincial border to travellers as Doug Ford had mentioned he wanted to." (P16)

"I mean, airports are always known as germy places, so I think the main thing was just being EVEN MORE conscious of washing my hands and wiping down hard bags and such.” (P8)

\section{COMPARISON (4)}

"In general, the surprising willingness of people to travel during this time. I also found depending on the city people acted different with regulations. Seemed like the farther west I went the more lax people became." (P16)

"[...] more signs in Ontario." (P15)

\section{DISCOMFORT (4)}

"When I was sitting next to someone I wasn't as comfortable so I just tried to lean into the window/face that direction." (P16)

\section{CANCELLATION (3)}

“There was an option to cancel/change flight without penalty due to COVID.” (P16) 


\title{
Appendix J List of Codes and Related Quotes from Method 3
}

\author{
CODE INSTANCE COUNT - RECENT FLYER INTERVIEWS
}

PPE (124)

"I think a lot of people were waiting for their flights and it gave them a chance to take a break from wearing the mask in the terminal safely." (P2)

"People in front of me had their masks pulled under their nose and that was annoying. So when the flight attendants walked by they must have seen them as well and they made an announcement and the people put their masks back on" (P7)

"Had to keep mask on the whole time which was a pain in the butt. Was my second time flying during the pandemic so I knew not to wear a tight fitting mask, wore a looser one." (P10)

"it was pretty much standard the whole time and I'm pretty sure most of the flight attendants were wearing gloves when handing things out. I think some people working in security or around the airport in SF were also wearing face shields" (P5)

"while were were boarding was the airline itself did not like a few of our masks so we had to switch out our masks and we actually did that at the gate and it felt weird just because there wasn't an area to switch out the masks -- they pretty much told us to take them off in front of everyone and put on a different mask, which I thought was weird and felt like verification of our ID.. everyone had to take of their mask as well which I thought was interesting." (P4)

"In the US I noticed someone who was fully shielded up and masked and the person next to them had a mask. And that was the same too when I arrived in CAN. So I don't think the airports are enforcing some kind of uniform in terms of PPE” (P7)

"It's just weird how people whose masks were under their noses, attendants kept having to remind them to fix it, compliance out of Calgary was bad." (P9)

"the only time I felt uncomfortable was when people took off their masks to eat on the plane." (P11)

"Airplane environments are one of the better places to be because there are lots of masks worn, gloves worn are by the crew." (P12)

“They didn't have the hand sanitization stations, you had to look for them. A lot more Americans didn't wear their masks properly, they would be pulled down so their noses were exposed. To breathe easier which defeats the whole purpose. Every 7 or 8 th person wasn't wearing it property or had it pulled right down over their chins compared to Canadians, Calgarians. It was very noticeable and you see that guy and you moved away from them.” (P10)

"I did notice a decent amount of people had the same idea and some people were definitely slower eaters just because it gives you a chance to have your mask off for longer" (P2)

PERCEPTION OF SAFETY (76) 
"I feel comfortable in the way I'm approaching this scenario so it doesn't really matter to me what they're doing because I know I'm being as safe as I can" (P7)

"comfort-wise, the experience was fairly comfortable. Like I said there weren't many issues and people were pretty good about most things" (P8)

"The more empty, the more safe it was at this point" (P1)

"I was cognizant that we were all wearing masks and then we all get the food or beverage service and then everyone takes off their masks at the exact same time, which doesn't seem safe. I didn't feel too unsafe about it and because of how long it was I knew I had to eat or drink and use the bathroom and sleep on the plane, there's no avoiding it. If it was a shorter flight, you could avoid it but not on such a long flight" (P5)

"because we all had to take a test within $72 \mathrm{hr}$ it makes me feel more comfortable that this person has tested negative somewhat recently and the odds are better. It feels alot better." (P7)

"You just never know for your safety and the safety of others, it feels good knowing we're all being forced to take that step." (P8)

"We were very comfortable travelling with our personal protection equipment which was just a mask. We felt very comfortable wearing just a mask." (P12)

"I don't know if they can do much more than what they are doing.

All of the points they basically hit, all of the hard surfaces, cleaning of the plane, touch points, running down the aisle wearing masks, trying to minimize contact with service getting in and out of plane with as few interpersonal contacts that are unnecessary is just fine with me." (P13)

"I was very comfortable with it all because the fact that you weren't allowed into the airport without a negative test within the last 48 hours so immediately that told me that it was safer than most places and then I felt that everyone was all covered up" (P14)

"I think it was okay. I think because I wasn't sitting next to anyone" (P5)

\section{CAPACITY (67)}

"the most comforting part at the airport was empty, whip through 30 minutes super quick, not many lineups not many taking off masks at that point. I felt pretty safe" (P11)

"something that's unique about this travel...is the biggest thing that's unique is how few people were in the airport, how it's like a ghost town." (P3)

"flight was from NY to TO and that flight was pretty empty. So that one I felt the most comfortable with because there was no one in my section of seats and the closest person to me was maybe a couple rows in front of me" (P7)

"on the way there it was nice that it was so quiet, having a row to myself was a little more comfortable" (P14)

$\operatorname{IPAC}(63)$

"I did use HS alot. every time I touched something that someone else may have touched, I was very careful, especially when eating." (P5)

"basically, anywhere you have to touch something, I would love to see wipes and/or HS stations" (P1)

"It was nice seeing things like floor stickers and what were very clearly "temporary hand sanitizer stations"”(P1)

"There was definitely no wipes and even the HS you had to go look for it, it wasn't right there for you to use" (P6)

"something that was pretty consistent was the socially distancing signage. I think that was the most consistent and predominant throughout all of these airports, not so much about sanitizing or washing your hands" (P7)

"(Air Courier 1) had a care kit which was in a Ziplock bag and had a note from the medical officer and it had a glove, masks, water bottle, pretzels, HS and a wipe.” (P5)

"Entering aircraft they give you a sanitation little wipe to wipe down your seating area" (P12)

"I never saw someone come by and clean a gate after a flight departed and it didn't seem like anybody was washing down arm rests on any of the seating. That was different" (P9)

"I don't know how effective this is but it does make me feel better to wipe down the armrests and seat back" (P1)

"The other thing that should be communicated, or people should know, is the rules about strangers-- what's the distancing rules on strangers" (P3)

"at the time I didn't know what it was for and then I was thinking "no I don't want this, I was thinking it was for my hands" and then when I sat down.. maybe even on the way there I didn't understand them and I might have got rid of them or threw them out." (P3) 


\section{PROMPT (60)}

"if there's a different time they could let you know about different protocols to expect when you land would be" (P4)

"They were doing a good job in making sure everyone had their masks on." (P7)

"I've almost programmed myself to disregard popups, disregard-- when I'm on the internet you can throw anything you want at me and I won't see it, I only see what I'm looking for., it's a good thing about the internet because your pulling information that is being pushed on you so I'm very much... I disregard everything that pushed on me. So no, I only noticed the things I was looking for." (P3)

"One major change on disembarking, announced COVID guidelines, keep mask on, take your garbage with you, stuff like that. Want you get up as rows, not everyone standing up at the same time, stay away from each other, disembarked from front to back so no one is just standing face to face in the aisle." (P12)

"Announcements were played over the intercom in the airports telling you keep social distanced, wear masks, a lot of hand sanitizer stations were put in place where you could sanitize your hands." (P12)

"(Air Courier 1) and (Air Courier 2) have a particular website that says go check and see if your flight has been affected, and there wasn't any mention of that"(P1)

"a difference I did notice between (Airport E) and (Airport C) was how they did signage. So, (Airport E)was very signage-based and you could see a lot of spacing on the floor of where you should stand, they had stickers on every other seat that said "don't sit here", which people were abiding to, and then they had a lot of covid PSA type posters. But in (Airport C) I found that there was less signage, I didn't notice the signage as much but there were a lot of HS stations, like a ton of HS stations."(P4)

"we'd be reminded every few hours to try to keep it on but I wouldn't say a lot of people kept it [mask] on the entire flight."(P6)

"It could have been better if there was more information on the Travel Canada part. Once I filled it out wrong, they had a little table in the airport and they gave you a paper declaration no one controlled it, gave you a pen, everyone was touching it, not sure was cleaned." (P11)

"they were sending out emails the day before the flight offering people a free transfer to push it back to a later flight and I had the feeling they may have over booked maybe they were trying to keep some spaces free. The one coming back was pretty full" (P14)

\section{SCREENING (55)}

“"'you have to hit so many checkboxes of 'I'm not flying with flammables and stuff like that' and it's not like I'm going to be like 'well I was a little sniffly today" (P1)

"'more effective if it was at the airport door or at the very least before someone drops off their bag, Before you have to part with your belongings."(P1)

"Temperature was taken before you go in, right at the front of security and then they ask you the questions each time." (P8)

"I didn't pay attention to the screening they do for COVID -- the bottom line is that people can lie but they can't lie about temperature and they're doing that and I think that's a really good thing” (P3)

"I'm not Canadian and so for me they asked me a few more questions as to why I should even be here and I said for school" (P7)

"every time at boarding they took your temperature and did any announcement in gate area and then asked if you answered yes to any of the questions." (P9)

"took my temperature there and it was a stand not the hand held to your forehead, it was $8 \mathrm{ft}$ away infrared one. I don't think they asked me any questions other than are you feeling okay? They didn't ask if I had a fever, a cough, those 5 questions. Nobody asked me any of those questions" (P10) 
"trying to stay away from the mass of people." (P1)

"The other thing that should be communicated, or people should know, is the rules about strangers-- what's the distancing rules on strangers" (P3)

"I had three seats in the aisle or set of seats there was nobody there. So it was nice to have that space because it was such a long flight." (P5)

"the gate gets a little more complicated just because 10 minutes before your flight, you'll have all the people there so that's a lot of population control to do in a small space." (P7)

"one big line that wrapped back and forth you are within 5 feet of 5 or 6 people. Everyone masked up but part of this could have been done better." (P14)

"when they were lining up to board the plane to scan their passports, they were cognizant but once they got onto the plane no one really was $6 \mathrm{ft}$ apart it was bunched up and when getting off the plane, everyone was trying to get off' (P11)

LOCAL REQUIREMENTS (45)

'You can go home and quarantine for 14 days and if you don't have any symptoms, you are free. They handed us a piece of paper with all the rules and regulations. If you get the quick test, the good part is that you know you have been tested and you know you are good, then in 7 days you can get tested again then you can leave place of quarantine and get groceries, bank, doctor appointment but can't go to work. You leave address and phone number of where you are quarantining. You still can't go to work until the 14 days are done.” (P10)

“US doesn't have a 14-day quarantine rule. As opposed to Canada does. In Canada 14-day quarantine rule. In US pretty much fly from anywhere and next day go out." (P11)

"You know what the impediment is -- it's the rules when you come back. This whole idea of having to quarantine for a certain amount of days when you get back, that's a definite impediment and that's the reason. Not for the reason of risk, but for the consequences of when I come back that I become more isolated for 10 or 14 days or whatever it is supposed to be. That is a pain." (P3)

"as you took off and landed they would give the federal covid travel regulations that the government puts out each time, so they said that each time." (P8)

"Mexico it was just seemed like they took it really seriously so the tone was really different. If you don't do this, we'll just send you back. They had no time for people who didn't want to do the regulations. We have to do this, we have to have this" (P9)

"In America they didn't have as many precautions, a little bit more lax and the guys I travelled with thought so as well." (P10)

"When it comes to our decision to travel, we would like to and will but it will determine what restrictions that are" (P12)

"When we left it was going to be the 2-day isolation until results of quick test and when we were in the air our Premier Jason Kenney said it was a 14-day minimum and I got caught right in that vortex." (P10)

"There is more uncertainty where we don't know what provincial and also federal government will do to restrict travel. There wasn't a lot of heads up there was maybe a tweet by our Prime Minster about restrictions will change but no deadline or what will happen when big factor in decision as to when we should travel again" (P12)

\section{INTERACTION (44)}

"I remember when I first sat down you gave them a little nod or something and it's cool. And they were wearing their masks and wiping down their stuff and I appreciated that and felt I was lucky I could be sitting next to someone who cared." (P7)

"a good day I could interact with 10 people who take it seriously with full PPE or I could interact with someone who doesn't take it that seriously and is just wearing a mask. In that sense, it was kind of like playing the odds" (P7)

"it's one less person you're in contact with and one less line you have to stand in close to other people"(P1)

"the biggest thing that stood out to me was not my concern, but the other guy's concern when I was standing beside him when my bag was stuck. That was the biggest thing that resonated with me." (P3)

"I felt the one from (Airport B) to (Airport A) just because it was smaller and there were less people. The big flights had a lot of people and obviously we had to eat on those flights too and navigating from your seat to the washroom you have to pass through so many people just to get there." (P6) 


\section{BUILT ENVIRONMENT (43)}

(airport and cabin)

"I feel like even when you're two chairs away from someone you're still rather close -- so I'd rather have some sort of barrier but you have to keep in mind families wouldn't want to be scattered. So maybe having some with one person, some with two, some with four [seats together]" (P6)

"They'll cram as many seats on the plane and so that hallway --the aisle way you walk through between the seats is so narrow and so i've got my --it's too warm to wear the winter coat so I've got my winter coat over my arm, and I've got my knapsack I'm carrying and then I'm pulling the bag behind me, right? So try navigating in that condition and trying to walk down the aisle without bumping every seat and that really created anxiety with one particular person, I know because I got stuck and I'm pulling and I can see the guy in the aisle seat looking up at me and I wasn't uncomfortable but I know he was and so I kind of felt bad about that for his sake and yea so that aisle way is not easy." (P3)

"an area for opportunity there to use the other gates that were completely empty to do these activities...maybe we should make it so everyone has the opportunity if they need to take off their mask..to not have to do it where everyone is." (P4) "I would see all of these check-in lines and if you're not going to use them, get rid of them so people can stand socially distanced properly. I think the misusage of space, especially during security lines bothers me alot, no matter what." (P7) "people usually put their bags on the overhead things, people were not as good at distancing themselves at that point. And I know it's hard because people are in seats beside you but even while waiting in the aisles people would come and wait right beside you while you were putting your things up and I know we're all wearing a mask, but still" (P8)

"when they were lining up to board the plane to scan their passports, they were cognizant but once they got onto the plane no one really was $6 \mathrm{ft}$ apart it was bunched up and when getting off the plane, everyone was trying to get off' (P11)

"they put two flights, one to Montreal one to Toronto, two lines together, not exactly socially distanced at the airport, everyone was cramped together." (P14)

"I sat down at my gate and once we got closer to the time, around the gate got a bit crowded just because everyone's waiting to get on the plane." (P7)

\section{SECURITY (42)}

"before we went through security in the (Airport C)terminal, we did have a digital or thermometer scan or infrared scan. SO you just had to wait your turn before you get into the actual security line and you just stand in front of the camera and I'm assuming it does a scan and pops up a little green light and they tell you to go" (P2)

"That was the one interaction where I actually had to hand over my passport and stuff. That and security when you had to show your ticket and passport.” (P7)

"in Canada that as soon as you got through security they took a picture of you I don't remember that ever happening before. They put on sign and made you take your glasses off look at the camera. You stood with your hands at your sides...Maybe it was to check if you were the right person. When you boarded the plane they made you lower your mask to ensure it was you, also at security." (P11)

"Going through security was quicker than I'd noticed in the past" (P2)

"in security it would have been nice to know if they were sanitizing the bins, it would have felt safer and I might not have had to wipe stuff down." (P5)

" "I'm sure they're sanitizing the bags after they come out of those Xray machines" (P1)

"the security people seemed a little bit frustrated that people didn't know the 'new way to present your passport'." (P5)

"The security, I imagine if it was a busier time it would be difficult to keep it socially distanced because when I was there, there was the family in front of me and maybe 2-3 people behind me" (P7) 
“you've got your QR code on your phone you'll use and it's not like going to home depot where they have this thing that they'll point and click and boom it zaps.. But you've got to hold it under this thing and so for positioning it.. I had to position it and it wasn't taking it so I had to move it and I ended up touching the thing" (P3)

"I decided to hold my passport open to the page...one of the directions they had were remote scans that they were able to hold over and the other they just directed me to hold my phone under to scan my phone underneath. And then I had to show my passport [as my photo ID] so there were no touchpoints at that point" (P2)

"That was the one interaction where I actually had to hand over my passport and stuff. That and security when you had to show your ticket and passport. "(P7)

"it was pretty much the same thing. Still need to hand over your passport and boarding pass. I don't think they reduced it at all." (P11)

"basically anywhere you have to touch something, I would love to see wipes and/or HS stations" (P1)

"The customs, I think you still had to do the touch screen thing where you declare everything, they basically were more paying attention to the COVID stuff, making sure you had somewhere to go" (P5)

"Alot of it was done more on the kiosk by then. Unless you really needed someone they made everyone go to the kiosk, you couldn't walk up to the desk to check in or for bags. Everything was done through the kiosks.” (P6)

"increased automation of the airport experience... was something I found that I appreciated" (P1)

"very low points of contact and the tables were spread out in the restaurant," (P2)

"We got out of there, got our bags and show form, hold form up for them to see, usually give it over, then told to put into the box. They didn't even handle it." (P10)

"I was surprised there was no wipes at the kiosks, that's something I would like to see" (P1)

TRAVEL (37)

(reasons for, barriers to)

"willing to put up with not being super comfortable for the sake of being able to get home in four hours instead of three days." (P1)

"I'm still comfortable to travel -- I'm not currently just because it's not recommended and there's also not a lot of places to go but as soon as they lift some of the restrictions, I'm still comfortable to travel" (P2)

"I'm not worried too much about flying but I'll wait till I have a vaccine or if I was moving somewhere, that's a different situation than travelling for tourism. I'm going to try to avoid it for now until it's safe again." (P5)

"I would wait until numbers chill out a bit. I don't think I'd travel unless it was a necessity." (P6)

"I travelled from (Airport A)to (Airport J) 5 months ago and then I took this flight and then at the end of February I'll be flying from (Airport K) to (Airport A)so it's not that I'm comfortable with flying it's just a necessity” (P7)

"Beside the quarantine, it wouldn't stop me from flying again. I did cancel my February trip because of the 14-day minimum quarantine, not because of wearing the mask or all of security or inconveniences" (P10)

"My intent is to travel but it's hindered by measures such as quarantine I am comfortable returning and having to quarantine but now there is more measures put in place." (P12)

"Some of these factors that are outside your control are going to prevent you from travelling" (P3)

"when you fly your kind of excited to get where you're going, it's more of a [pleasurable or exciting] experience and its more mindless, but I'll say you could kind of feel everyone was a little more uncomfortable; it was more of a means to an end, people just needed to get where they were going and it wasn't much of an experience or good EX." (P4)

"I think there's a lot of people that judge and shun people who choose to travel and I think that is a major contributor to people our age especially," (P4)

"not necessarily the flight itself but the risk for yourself and to other people once you're at the final destination-- more about the final destination than the actual flight." (P5)

"physical comfort-wise I'd be comfortable to travel again if I had to but that mentality and social stuff.. I wouldn't do it unless it was less frowned upon." (P8)

SELF-PREPAREDNESS (36) 
"I brought my own of everything (HS and I knew I'd have to have it for the trip), and I had to buy masks because I haven't been wearing masks in Australia and the numbers were very low, but I did buy masks before I left and I bought the disposable ones, because I knew I'd have to change them and use multiple ones on the journey." (P5)

"I didn't even take it because I had my own water bottle with me and I didn't want to take off my mask during the flight." (P7)

"Did check a bag back to (Airport C), clean masked at check in. I sprayed all the bags with Lysol using gloves and let them sit then carried on when we arrived in (Airport O). I carried hand sanitizer on myself, which I never would have done before and two of the other guys I travelled with did as well. We wore masks throughout airport." (P10)

"we didn't want to eat on the plane so we ate beforehand. So in the airport the only time you could take your mask off was when you had something to eat so we kind of separated ourselves to eat and I noticed not everyone did that and I know that's something I spaced myself away from was when someone else was eating and they lowered their mask." (P4) "Now that you need to test on the way back, I think if they can really help layout the pre-testing on both ways of the trip. It would be great if it wasn't less on your own to figure it out. Especially for other country, where would you go? We would be scrambling to get it done." (P13)

\section{TECHNOLOGY (33)}

"When got back to (Airport C), had to get the two apps on phone Arrive Canada app and the Alberta app, don't know the name of that one, and had to show them you had the apps, basic questions on app answered. Contact address and phone number to contact you and gave you a code number and you had to have that when you got off the plane on your screen" (P10)

""I did have to help out [older lady] who couldn't figure out the computer with the bag check thing "(P1)

"we still had to do the screens with the declaration, the ArriveCAN app is just for COVID screening, and to make sure that you have somewhere to go, and that you don't have to go out, someone is able to bring you food, medication, etcetera." (P5)

"being clear about the ArriveCAN app and if you have to fill out the paper too. The app was fine but it was printed out badly and unclear where you needed to write things, the printing was grey and you couldn't read things clearly. I think it was unnecessary that they make you do both and then say you could have just used the app." (P5)

"I think using the ArriveCAN app throughout would just be even easier because then you don't even need to worry about that." (P7)

"people may not have had it on their phone, didn't know when they needed it, might have thought they needed it on a computer screen, whatever it was they just weren't ready. I think we needed to have it getting on the plane in Phoenix" (P10)

"Challenging thing was wearing the mask. More go get this test, get this paper, get this app. It's challenging for me because I'm an IT idiot and needed help getting it on my phone. I'm not the normal phone user. Some inconveniences but not I'm never going to fly again.” (P10)

\section{BOARDING (31)}

"I decided to hold my passport open to the page...one of the directions they had were remote scans that they were able to hold over and the other they just directed me to hold my phone under to scan my phone underneath. And then I had to show my passport [as my photo ID] so there were no touchpoints at that point" (P2)

"try to board people as fast as you can even if you have to board early. I'd rather sit in my chair on the plan than sit in the gate with another flight so close to me." (P7)

"always kind of unimpressed with how the airline handles loading and unloading the plane" (p1)

"if everybody went when they are supposed to they wouldn't have to do that but to be honest with you if you want to avoid that, you load the plan the opposite direction. You have the people on the back go on first and then fill it up going the other way." (P3)

“...what's the most effective but with covid I think they're trying to load from the back just so there's less people overlapping on the plane...then getting off the plane again just to prevent that from overlapping on the plane” (P2)

BOOKING (30) 
"I think a lot of people were waiting for their flights and it gave them a chance to take a break from wearing the mask in the terminal safely." (P2)

"I literally tried to sleep and not move or touch anything. Just sit there and wait it out." (P7)

"I was actually quite impressed by the lack of shenanigans amongst other passengers." (P1)

"on the way back there were a few passengers, and I know I've seen this a few times in the states as well, that just did not seem friendly at all. Definitely went into the whole EX with a bad attitude and I think that that was something a bit stressful because you're never really sure if those people end up saying "I don't want to wear a mask", you don't know how that's going to affect you or effect everyone else on board, or how that's going to be handled." (P4)

"in the airport, everyone was pretty good at staying at least $6 \mathrm{ft}$ apart, so I'd take off my mask to eat knowing we were spread out enough, and I saw other people doing the same and when they were done everyone was pretty good at putting it back on" (P8)

"I would have to say the most challenging part was getting the ticket, booking more than once, was a real hassle. Also figuring out what Canada was mandating at the time because they were changing two-week quarantine and fly directly to Calgary connecting flights and was kind of hard to figure out." (P11)

"one of the things when booking the flights, by that time it was July and (Air Courier 1)should have known if they weren't doing flights three times a day and then have none. I feel like they could have known that ahead of time. I don't know if it was part of their strategy, but it's hard when you have to change, and that's the situation everywhere where things are changing but I feel like they should have had a better grasp as to whether they were going to offer flights to and from certain destinations" (P5)

"there were no premium or business airfare, didn't want to travel in a row with 3 people. Ended up booking flights with (Air Courier 1) going from (Airport C) to (Airport D) to (Airport N) business class" (P9)

"you had to fill out (in advance for booking) like are you feeling sick, etc. and then as you check in digitally you had to fill out a covid questionnaire and you can only check in $24 \mathrm{hr}$ in advance, so it was obviously monitoring that too" (P8)

PROCESS (30)

"I'm assuming it's just too hard to keep under control...everyone is pretty antsy to get off the flight. I included" (P1) "If I had been breaking out into a fever and tried sneaking onto the plane, my bag has already been sent to the sorting area so that would be an extra hassle of needing my bag" (P1)

"We didn't know that there were protocols .. I know they've been doing different protocols but I didn't know what to expect from those protocols or if they'd be standardized." (P4)

"Preboarding and they made sure that people had their paperwork in the line. If people didn't have their paperwork, they were keeping them out of the line. Had to have been registered online with Hawaii before boarding" (P13)

"Then disembarking, just because there wasn't a bunch of people, it wasn't too much of a pain. People were okay.. I think you could tell a difference between how people normally were in terms of social distancing vs what they were doing on this flight disembarking." (P4)

SERVICE CHANGE (24)

"One of the greatest things was walking on the plane and getting the sanitizing wipe from the steward and wiping the seat down, seatbelt headrest, arm rests, tray, tv and all of that before I even sat in it. That was nice to get priority and get on and get that done before you were inundated with people" P9

"someone had not shown their passport properly, she wanted you to put your ticket and passport against the glass. But people were not used to whatever this new system was so they seemed a little more grumpy there" (P5)

"On the plane, there was a big difference. Limited service, water once per flight. Usually had more options, now very limited service" (P12)

"on the plane for the safety check they didn't demonstrate the seatbelt and stuff they played an audio. That something that was different." (P11)

"I noticed that a lot of the stores were closed" (P5)

"The flight attendants were on their game in terms of telling people [to wear masks] -- they were decked out in full suits and gloves and everything" (P7)

RESPONSIBILITY (22) 
"In the airport itself, it looked like it was up to each individual themselves that were wearing a mask. Smaller percentage wearing just shield some wearing mask and shield no so much gloves." (P12)

"I'm not denying people on getting on their flight, I don't get paid enough to do that"" (P1)

"I assume that it's not a requirement from the company so I appreciate it even more because they are doing it out of personal obligation. So in a way I feel more comfortable because again, if I see they are trying to be as safe as you can, I appreciate that and feel more comfortable" (P7)

"I was being very careful and I was okay with travelling but I didn't really have a choice either." (P5)

"I think in a lot of those tight-space scenarios I feel a lot more comfortable if I see the other person is being as cautious as I am and if they are being less cautious than me, it makes me more uncomfortable." (P7)

"You just never know for your safety and the safety of others, it feels good knowing we're all being forced to take that step." (P8)

"I think there is much more ask for personal control and restraint." (P9)

\section{CONTACT TRACING (18)}

"the most uncomfortable thing for me, I'm not sure about other provinces, but BC has a list of all their flights where covid cases have come up positive, so there was a lot apprehension and discomfort those few days, almost a week following my flight, waiting to see if anything came up with positive covid cases on those flights. that was the biggest discomfort." (P8)

"I felt like I wish someone had said that on the intercom just once to remind everyone that if you do get covid in the next 5 days you should let the airline know so they can let people know who was on the plane." (P7)

"The TransScan Canada I believe. For 14 days after I got back to Canada, I had to sign in every day and just check the boxes if I had any symptoms. Fortunately it was no I don't but I had to do that for my 14 day period quarantine.” (P14) "we still had to do the screens with the declaration, the ArriveCAN app is just for COVID screening, and to make sure that you have somewhere to go, and that you don't have to go out, someone is able to bring you food, medication, etcetera." (P5)

\section{UNCERTAINTY (18)}

"at the time I didn't know what it was for and then I was thinking "no I don't want this, I was thinking it was for my hands" and then when I sat down.. maybe even on the way there I didn't understand them and I might have got rid of them or threw them out." (P3)

"I'm not sure how everything works with the plane or how airflow works, I think that's what I'm most concerned about." (P4)

"it was not the ideal situation and it felt like a relief when I was able to get home. I wasn't sure if they would cancel the flights so I was glad I was able to come back, even though there wasn't alot of choice where I could go through.” (P5)

"I think it was a general fear of flying these days because it's such close-quarters and airports and airplanes are already super germy places and do I really want to add to that?” (P8)

"There is more uncertainty where we don't know what provincial and also federal government will do to restrict travel. There wasn't a lot of heads up there was no maybe a tweet by our Prime Minster about restrictions will change but no deadline or what will happen when big factor in decision as to when we should travel again" (P12)

"Now that you need to test on the way back, I think if they can really help layout the pre-testing on both ways of the trip. It would be great if it wasn't less on your own to figure it out. Especially for other country, where would you go? We would be scrambling to get it done." (P13)

"since it's a closed space and even having it so people can only take their masks off to eat or drink it's like "okay well, since we're in a closed space, I'm not really aware of how that affects me"." (P4) 
"I found the experience in (Airport C)stressful and weird. Especially in the US, if that would be a little more for sure to be more comfortable.." (P13)

"in the US if you don't have insurance, it costs a lot to get tested. And finding the time to get tested.. I had to take half of my day to wait in line to get tested and I had to get tested within 72 hours so it's a lot of planning on that side." (P7)

"Had to get the 3-day test, the nasal swab. Not easy to find a place to get the test. Cost \$185 US. There were more that were expensive. Not a pleasant experience, drive up. Short vacation and had to get it the first day of

vacation. Professionally done, COD. Results received day before flight out" (P10)

"A big thing was a lack of tests being done, not required to take one test on return, required to take test before boarding airplane and leaving Mexico, returning into Canada at Toronto, unable to take a free test since we're not living in Ontario" (P12)

"into Nova Scotia, they didn't require anyone to take a test. I would have preferred test and then again after a certain time" (P12)

"We came home in December and didn't need to be tested before coming home, Canada didn't put the rule in until the middle of January" (P13)

"because we all had to take a test within $72 \mathrm{hr}$ it makes me feel more comfortable that this person has tested negative somewhat recently and the odds are better. It feels alot better. "(P7)

"I was very comfortable with it all because the fact that you weren't allowed into the airport without a negative test within the last 48 hours so immediately that told me that it was safer than most places and then I felt that everyone was all covered up" (P14)

\section{SERVICE (15)}

"If you go there, chances are there's going to be a lot of picking up and setting down and more contact. So that could be a reason they're closed, but I'm not 100\% sure if that is the reason but it was something that crossed my mind when I heard people talking about everything being closed." (P2)

"It was my impression the turnaround crew takes the garbage and does a rough clean, I don't think that's the case any more for a full clean" (P12)

"thinking about it there were a few things and amenities like that that were closed ... and it wasn't like it was a temporary close for cleaning it was just blocked off. It seemed a little confusing “(P2)

\section{COMMUNICATION (14)}

"(Air Courier 1) and (Air Courier 2) have a particular website that says go check and see if your flight has been affected, and there wasn't any mention of that" (P1)

"I don't know if they are intentionally ambiguous about it or what -- so I ended up [doing what I rarely do] phoning the airlines because I always think I'll sit on hold if I do that and I ended up talking to someone at WJ about it and I could have gotten a flight a little bit cheaper from (Air Courier 1) "(P3)

"I think just knowing what to expect at different points of the process and knowing that they are doing something is a good first step for sure. "(P4)

"It was tough to hear the ladies talk on the flight through the masks, it's loud and everyone's voices were muffled with the masks. You really had to pay attention when they were asking you what you wanted to drink.” (P13)

PREVIOUS TRAVEL (14)

"I've taken flights before so that aspect was fine, and usually I find it much more enjoyable but it's a little bit more stressful. It's just the alertness of being careful all the time, it just doesn't feel as comfortable." (P5)

"I flew out to BC in June right at the beginning of everything, so seeing the contrast from June to December was the biggest for me" (P8)

"Pleasant, flying today isn't pleasant like it used to be." (P10)

"pretty much on the same day last year flying internationally, it was so busy. So just seeing the difference was pretty insane" (P4) 
RESEARCH (13)

"if there's any marketing they could do to try stopping any misinformation or different expectations people have for the EX.” (P4)

"The media and government has everyone so scared. His buddy did some research and found only $1.5 \%$ of the people carry it travelling on a plane" (P10)

"I was also hearing that it hasn't been a major contributor to covid spread. So anyway because of that I probably went on the airplane with a lot less concern than most people would. "(P3)

"Before we flew we read up on the statistics of how many cases are transmitted on planes and while travelling. I don't think this information is relayed enough and there is a bit of fear mongering travel causes certainly there are people coming back with COVID but not so much while being in the airplane or airport environment. "(P12)

"I think those two things to communicate before anybody travels would really put a lot of people at ease and it would also grow the scale of travel." (P3)

BUSINESS CLASS (!0)

“there were no premium or business airfare, didn't want to travel in a row with 3 people. Ended up booking flights with (Air Courier 1 (going from (Airport C) to (Airport D) to (Airport N) business class" (P9)

"being in business class we didn't have that much of reduction in the service that we had. Aside from the lounge access not being open. We got a great meal. It was cold but great meal, like a charchutiere. I don't know if a hot meal would have been that different. They still served us alcoholic beverages." (P9)

"Letting people know if you buy the special ticket you don't get the exclusive things that you got before "(P11)

\section{CHANGE (10)}

"I guess I was surprised to see how much was done. I am more comfortable flying now than I probably ever was." (P9) "Due to COVID there are much less flights available per day so that made a big impact on our ability to leaving on a certain day or travelling through certain airports." (P12)

"I feel that there is so much that has come from COVID that shouldn't go away. I'm fine with the testing. Test me at every airport. I will do all of that, when there is a vaccine, I will immediately get it. No problem. "(P9)

"When we were flying from (Airport F) to (Airport V), because it's an international flight you generally have to be there 1-2 hours before but they told us to be there 4 hours before our flight, so that was interesting. "(P6)

""had me worrying if something had changed drastically between when I took-off and landed"(P1)

MEDIA (8)

"if there's any marketing they could do to try stopping any misinformation or different expectations people have for the EX.” (P4)

"seeing the news from the States, seeing how their flights have been and some of the bad things that have been happening on some of the flights in the states and how they are handling things, isn't necessarily what I'm comfortable with and I wasn't sure how different things would be" (P4)

"There was none of the stuff you see -- like viral videos of someone demanding their rights for being infringed because they had to wear a mask -- there was no drama in that regard, so that was positive" (P2)

"The media shows a full clean after each flight, I don't think that's the case. The disinfecting is left to you with the sanitation wipe" (P12)

\section{ATTENTION (6)}


"I honestly don't usually listen to the entire safety instructions anymore so I was already out of focus. So I didn't pay attention to the full audio but I do remember at the beginning hearing them say a few things about keeping masks on ...the whole flight crew kept their masks on for the entire flight." (P2)

"by the time they start calling to start boarding the plane, I'm usually half-way into flight mode.. I don't really want to deal with anybody anymore"(P1)

"They probably had due to COVID blah blah blah but I wasn't listening. I was worried about getting my tablet, my book, my pillow. I wasn't even listening to the seatbelt thing. If they did, I didn't hear it." (P10)

\section{COMPARISON (6)}

“it's funny how people's perceptions can be "I'm comfortable pumping gas even though when I grab that nozzle the thing hasn't been cleaned ever" (P3)

"my experience was probably not much more risky than going to the grocery store -- probably the biggest reason was that there was hardly anybody there." (P3)

"at the airport it's the same as everyone going to the grocery store -- as long as you're wearing a cloth mask you should be okay." (P1)

\section{RESTRICTIONS (6)}

"had to fly to (Airport C) since there weren't that many flights available then direct to (Airport R)." (P12)

"I'm still comfortable to travel -- I'm not currently just because it's not recommended and there's also not a lot of places to go but as soon as they lift some of the restrictions, I'm still comfortable to travel" (P2)

"I like to travel in the afternoon flights and usually (Airport O)has 2-3 flights a day, well the afternoon ones were cancelled so they were down to one morning flight a day. Huge restriction so had to change a couple of times and then had going through Los Angeles but had them change to a direct flight." (P10)

\section{DURATION (5)}

"getting to the airport a bit early because we weren't sure how long it was going to take" (P2)

"because we had to get to the airport so much earlier than before [covid] a lot of the times we'd get there and the gates wouldn't be open or the gates would change because we would be there for an extended amount of time" (P6)

"This time we had to change gates because we were at the airport so long waiting and they'd change back and forth. "(P6)

\section{CLEAN (4)}

"I could sanitize my hands as much as I wanted to"” (P1)

"some of the stuff on the airplane where they're talking about how they sanitize everything between flights and clean everything, some people have been joking like "wait you haven't been doing that before"” (P2)

\section{FINANCE/FINANCIAL (3)}

"All the pricing seemed to be up, like they knew that you were a captive audience and couldn't go anywhere else for food or whatever, not many places open.” (P9)

"now when we return hotel for very large amount of money for the 3 nights stay per person \$2000" (P12) 


\section{SUGGESTION (3)}

"I think they should have people, and that's specifically their job, and maybe they are hired by the airline industry and then the airlines have to pay to use their services to go sanitize their plane" (P3)

"if I got my test and I could put a picture of that on the app so they have it on file, instead of me having to carry my test results around with me. So then it's one less thing I have to hand over. So they could just full swing into the ArriveCAN app and make it for domestic and international flights, for everything you just have to fill this out. I think that would be a good way of keeping track of people as well.” (P7)

"I think making spaces between seats bigger would improve it, you feel pretty squashed. You can spread out all over the place in the airport and getting in and out of the plane. "(P13)

\section{SERVICE COMPARISON (3)}

"thinking about it there were a few things and amenities like that that were closed .. and it wasn't like it was a temporary close for cleaning it was just blocked off. It seemed a little confusing "(P7)

"It was even a step up from where the US was in terms of sanitizers were everywhere." (P9)

\section{ACCESSIBILITY (1)}

"I don't know if it's just the sound on the plane, which is loud, it was hard to hear. Communication difficult for everyone with the mask. I can't imagine if I was hard of hearing or a lot older, it would just be impossible and how difficult it would be" (P13)

\section{PRIVACY (1)}

"Exactly the ones that we are used to hearing in almost any indoor setting at this point. I find it weird that you are asked if you have been in contact with anyone who has been diagnosed since we are so ingrained with privacy." (P9)

\section{SAFETY (1)}

"along with the transparency side of things is knowing that they are still checking up on their planes and safety and everything and that they're not making any cuts that would make it unsafe." (P4) 


\section{Appendix K Keyword Instance Count from Method 3}

\begin{tabular}{|c|c|c|c|c|c|}
\hline Key Word(s) & $\begin{array}{l}\text { Instance } \\
\text { Count }\end{array}$ & Key Word(s) & $\begin{array}{l}\text { Instance } \\
\text { Count }\end{array}$ & Key Word(s) & $\begin{array}{l}\text { Instance } \\
\text { Count }\end{array}$ \\
\hline Flight & 145 & Booking & 29 & $\begin{array}{l}\text { Washroom Or } \\
\text { Lavatory Or Bathroom }\end{array}$ & 8 \\
\hline $\begin{array}{l}\text { Mask Or Face } \\
\text { Covering }\end{array}$ & 144 & Clean & 25 & Cost Or Price & 7 \\
\hline Food Or Eat & 114 & Touch & 25 & Grocery Store & 6 \\
\hline Airport & 86 & $\begin{array}{l}\text { Quarantine Or } \\
\text { Isolation }\end{array}$ & 24 & News Or Media & 6 \\
\hline $\begin{array}{l}\text { Crew Or Employee Or } \\
\text { Flight Attendant }\end{array}$ & 70 & $\begin{array}{l}\text { Distance Or } \\
\text { Distancing }\end{array}$ & 23 & Stress Or Stressful & 5 \\
\hline Seating Or Seat & 62 & $\begin{array}{l}\text { Signs Or Sign Or } \\
\text { Poster }\end{array}$ & 21 & $\begin{array}{l}\text { Vaccine Or } \\
\text { Vaccination }\end{array}$ & 5 \\
\hline App & 56 & Kiosk Or Screen & 19 & Necessity Or Necessary & 5 \\
\hline Security & 56 & Information & 18 & Online & 4 \\
\hline $\begin{array}{l}\text { Comfort Or } \\
\text { Comfortable }\end{array}$ & 54 & $\begin{array}{l}\text { Check-in Or } \\
\text { Checking In }\end{array}$ & 18 & Perception & 4 \\
\hline Space Or Area & 46 & Social & 17 & Standby & 3 \\
\hline Luggage Or Baggage & 43 & Service & 17 & Stranger & 3 \\
\hline Full Or Crowded & 41 & Next To & 16 & Relief & 2 \\
\hline Hand Sanitizer & 35 & Efficient Or Quick & 15 & Ghost Town & 2 \\
\hline Safe & 34 & Announcement & 13 & Responsibility & 2 \\
\hline Drink Or Water & 34 & Aircraft Or Cabin & 13 & Overhead Bin & 2 \\
\hline Quiet Or Empty & 31 & Aisle & 13 & Stigma & 2 \\
\hline Wash Or Clean & 31 & $\begin{array}{l}\text { Cancel Or } \\
\text { Cancellation }\end{array}$ & 11 & Privacy & 1 \\
\hline Gate & 31 & & & & \\
\hline
\end{tabular}

